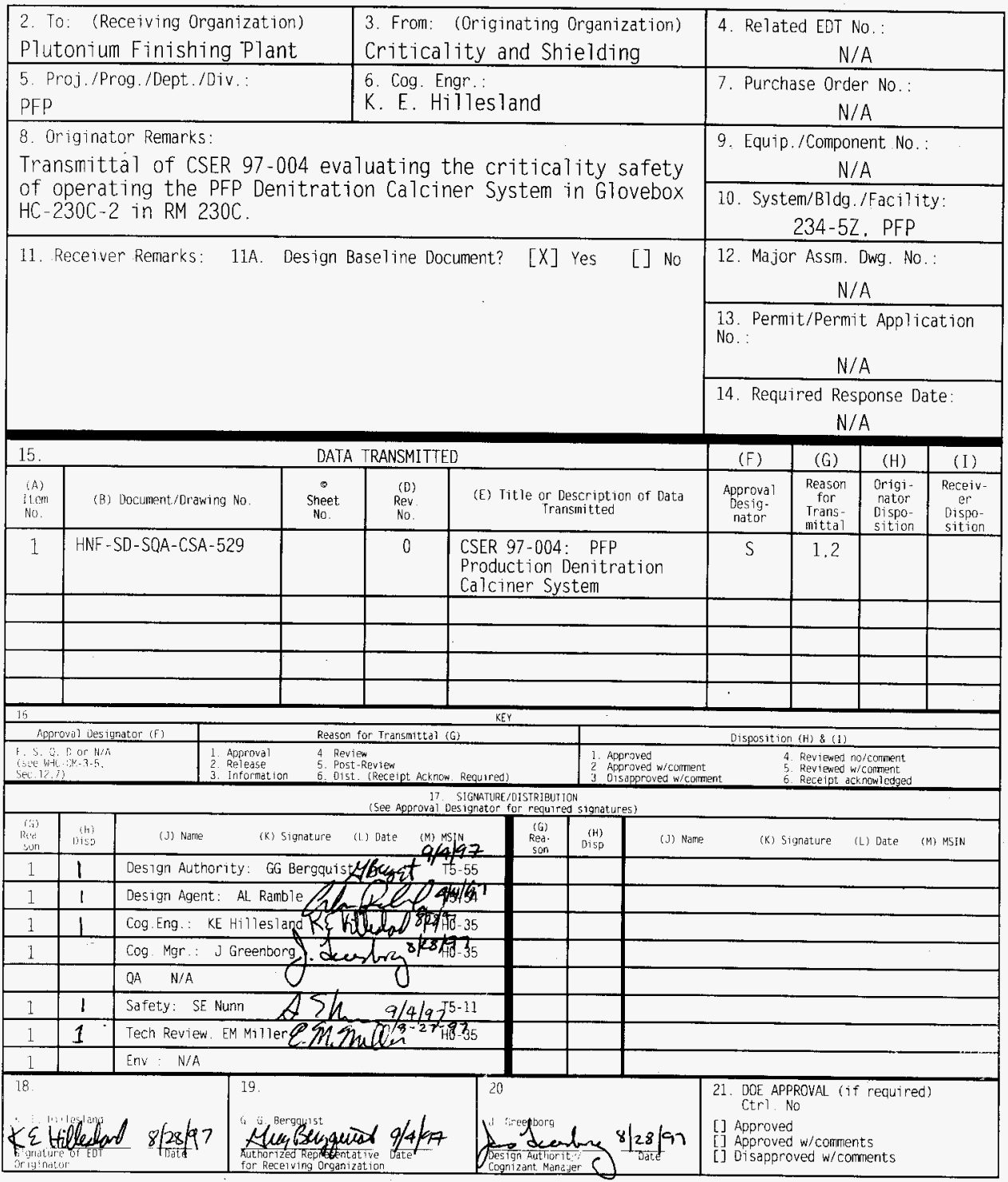




\title{
CSER 97-004: PFP Production Denitration Calciner System
}

\section{Karl E. Hillesland}

Fluor Daniel Northwest, Inc., Richland, WA 99352

U.S. Department of Energy Contract DE-AC06-96RL13200

\author{
EDT/ECN: 6202921299 UC: 507 \\ Org Code: $403 \quad$ Charge Code: E56009 \\ B\&R Code: EW7040000 Total Pages: 100
}

Key Words: Criticality, Calciner, Plutonium

Abstract: The plutonium stabilization program at the Plutonium Finishing Plant (PFP) includes conversion of acidic plutonium nitrate solution into plutonium oxide. Conversion is facilitated through use of a vertical calciner installed in Glovebox HC-230C-2, which is located in RM 230C of this facility. This evaluation supports the Criticality Prevention Specification for the calcining process inside this glovebox. As the product of the calciner is a high density plutonium oxide, a number of limits are required to insure criticality safety. The containers allowed are product receiver vessels and $0.5 \ell$ slip lid cans and polyjars. The limits allow for two "unit masses" of $2 \ell$ total volume each, separated by a distance of at least $25.4 \mathrm{~cm}(10 \mathrm{in}$.). This evaluation allows for operation of the calciner for product densities not in excess of $5.5 \mathrm{~g} \mathrm{Pu} / \mathrm{cm}^{3}$.

TRADEMARK DISCLAIMER. Reference herein to any specific comnercial product, process, or service by trade name, trademark. manufacturer. or otherwise. does not necessarily constitute or imply its endorsement, recommendation. or favoring by the United States Government or any agency thereof or its contractors or subcontractors.

Printed in the United States of America. To obtain copies of this document. contact: Document Control Services. P. 0. Box 950. Mai 7stop H6-08. Richland WA 99352. Phone (509) 372-2420; Fax (509) 376-4989.

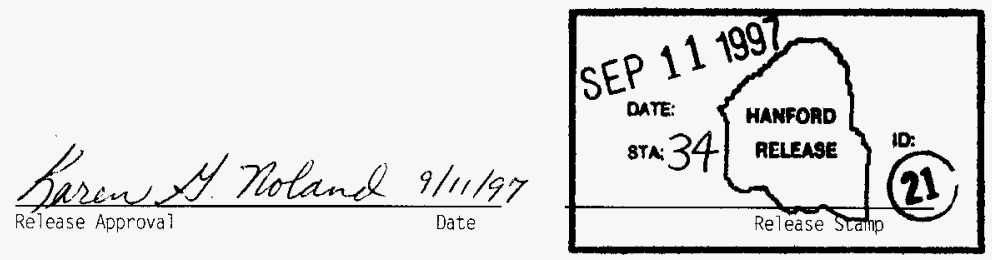

\section{Approved for Public Release}


HNF-SD-SQA-CSA-529, Rev. 0

CONTENTS

1.0 INTRODUCTION AND SUMMARY $\ldots \ldots \ldots \ldots \ldots \ldots \ldots \ldots \ldots \ldots \ldots \ldots \ldots$

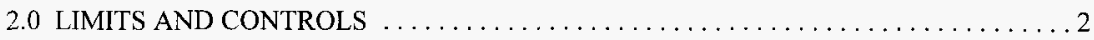

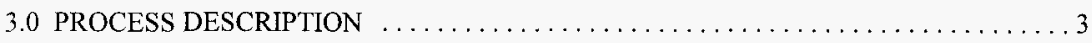

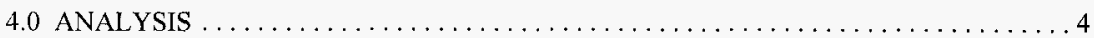

4.1 CONCENTRATION AND COMPOSITION OF THE FISSILE MATERIAL $\ldots \ldots 4$

4.1.1 Feed Solution .............................. 4

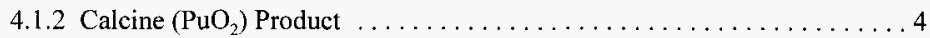

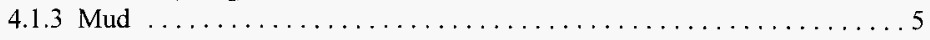

4.1.4 Precipitated Pu Solids in Tanks . . . . . . . . . . . . . . . . . 6

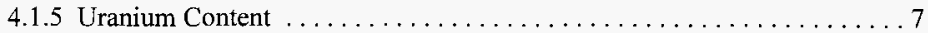

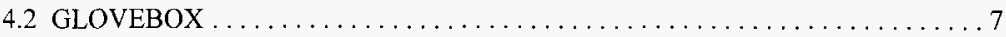

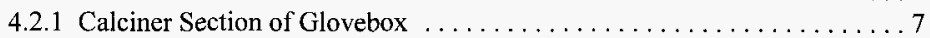

4.2 .2 Waste Section of Glovebox $\ldots \ldots \ldots \ldots \ldots \ldots \ldots \ldots \ldots \ldots$

4.2.3 Connecting Section of Glovebox $\ldots \ldots \ldots \ldots \ldots \ldots \ldots \ldots \ldots$

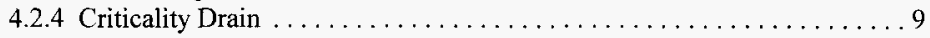

4.2.5 Accumulation of Fissile Material on Glovebox Floor $\ldots \ldots \ldots \ldots \ldots 10$

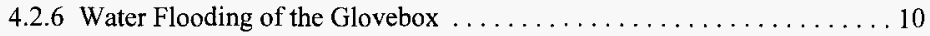

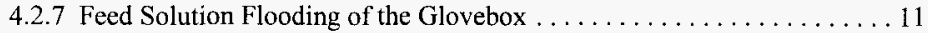

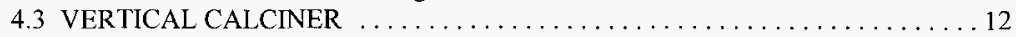

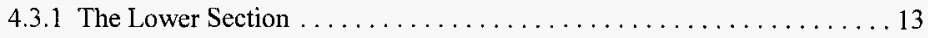

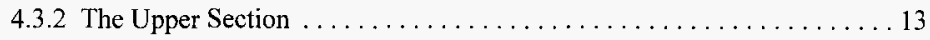

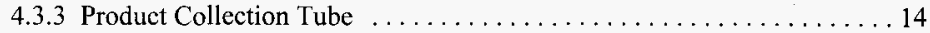

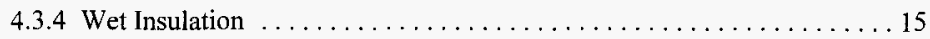

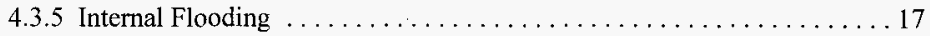

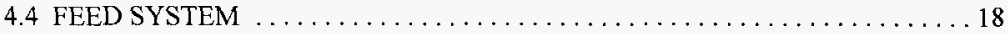

4.4.1 Feed Tanks ................................... 18

4.4.2 Other Feed System Volumes ......................... 19

4.4.3 Plutonium Concentration in Feed Solution .................. 19

4.4.4 Double Batch of Plutonium Precipitates $\ldots \ldots \ldots \ldots \ldots \ldots \ldots \ldots \ldots$

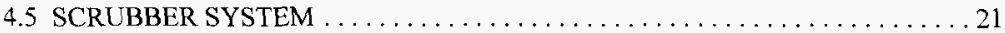

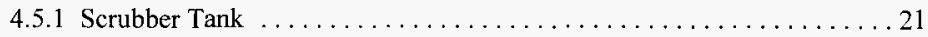

4.5.2 Spent Scrubber Receipt Tanks ....................... 21

4.5.3 Phase Separator Tank ............................. 22

4.5.4 Other Scrubber System Volumes ....................... 23

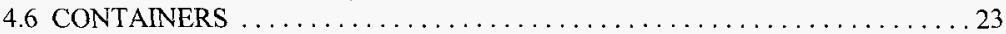

4.6.1 Worst Case Unit Mass ............................... 23

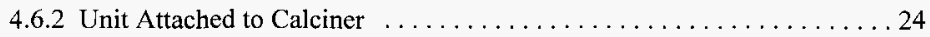

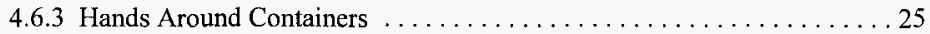

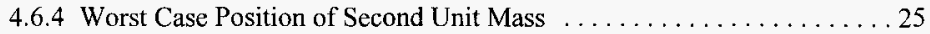

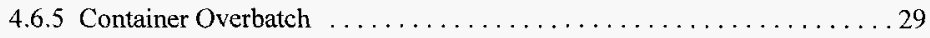


HNF-SD-SQA-CSA-529, Rev. 0

4.6.6 Stacking of Containers . . . . . . . . . . . . . . . . . 30

4.6.7 Placing a Container on the Lower Insulation . . . . . . . . . . . . 30

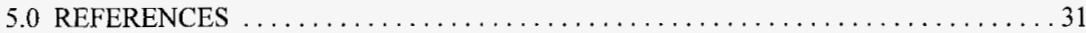

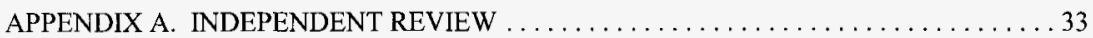

APPENDIX B. MONK VALIDATION $\ldots \ldots \ldots \ldots \ldots \ldots \ldots \ldots \ldots \ldots \ldots \ldots \ldots \ldots$

APPENDIX C. WORKBOOK FOR CALCULATION OF MATERIAL COMPOSITIONS . . 40

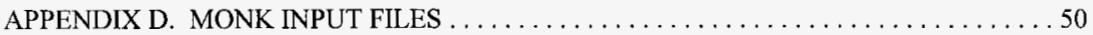

ATTACHMENT 1. CORRESPONDENCE CONCERNING FEED SOLUTION

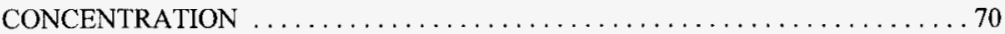

ATTACHMENT 2. CORRESPONDENCE CONCERNING PRODUCT DENSITY

PRODUCED BY THE LAB CALCINER $\ldots \ldots \ldots \ldots \ldots \ldots \ldots \ldots \ldots \ldots \ldots \ldots$

ATTACHMENT 3. PR CANS CONTAINING URANIUM TO BE CALCINED . . . . . . 76

ATTACHMENT 4. PRELIMINARY DRAWINGS $\ldots \ldots \ldots \ldots \ldots \ldots \ldots \ldots \ldots$

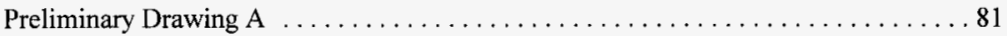

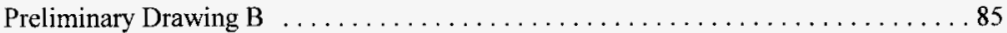

ATTACHMENT 5. HAND MEASUREMENTS TAKEN BY K.E. HILLESLAND AND

RECEIVED FROM J.F. DURNIL BY PHONE, $3 / 12 / 97 \ldots \ldots \ldots \ldots \ldots \ldots \ldots$

ATTACHMENT 6. CORRESPONDENCE CONCERNING MAXIMUM CREDIBLE FEED

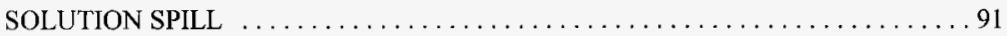

ATTACHMENT 7. HAND SKETCH OF LOWER INSULATION ON CALCINER . . . . 94

ATTACHMENT 8. DIMENSIONS OF FILTERS AS MEASURED BY J.F. DURNIL . . . 96 
HNF-SD-SQA-CSA-529, Rev. 0

\section{CSER 97-004: PFP Production Denitration Calciner System}

Prepared by: $\frac{X \sum \text { Helleslan }}{\begin{array}{l}\text { K. E. Hillesland } \\ \text { Criticality and Shielding }\end{array}}$ Date: $8 / 28 / 97$

Reviewed by:Elwaced MA Mullen Date:8-28-77

E. M. Miller

Criticality and Shielding

Approved by:

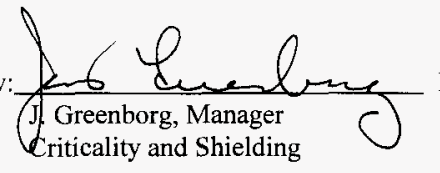

Date: $8 / 29 / 97$

\subsection{INTRODUCTION AND SUMMARY}

The plutonium stabilization program at the Plutonium Finishing Plant (PFP) includes conversion of acidic plutonium nitrate solution into plutonium oxide. Conversion is facilitated through use of a vertical calciner installed in Glovebox HC-230C-2, which is to be installed in RM $230 \mathrm{C}$ of this facility. This evaluation supports the Criticality Prevention Specification for the calcining process inside this glovebox.

Two unit masses of $2 \mathrm{l}$ volume each are allowed in the glovebox at a time with $25.4 \mathrm{~cm}(10$ in.) spacing between unit masses. Allowable containers include 1 pound slip lid cans, polyjars, 30 $\mathrm{m} \ell$ sample jars, and product receiver vessels. Accumulations of fissile material on the glovebox floor shall not exceed a depth of $0.95 \mathrm{~cm}(3 / 8 \mathrm{in}$.). The basic safety controls are based on a maximum tap density of calcine product not in excess of $5.5 \mathrm{~g} \mathrm{Pu} / \mathrm{cm}^{3}$. This report does not cover disassembly of the calciner. 


\section{HNF-SD-SQA-CSA-529, Rev. 0}

\subsection{LIMITS AND CONTROLS}

1) The calciner may be operated without a mass limit if the tap density of the calcine product does not exceed $5.5 \mathrm{~g} \mathrm{Pu} / \mathrm{cm}^{3}$. This density requirement may be met by frequent measurements of product tap density combined with immediate cessation of feed addition if a measurement indicates that the product tap density has exceeded $5.5 \mathrm{~g} \mathrm{Pu} / \mathrm{cm}^{3}$.

2) The fissile concentration of feed solution shall be limited to no more than $450 \mathrm{~g} / \mathrm{l}$ of ${ }^{239} \mathrm{Pu}$ plus ${ }^{235} \mathrm{U} .{ }^{235} \mathrm{U}$ content is included in this determination when uranium enrichment is above $1.0 \%{ }^{235} \mathrm{U}$. Uranium concentration is limited to a maximum of $50 \mathrm{~g}{ }^{235} \mathrm{U} / \ell$ of solution.

3) All plutonium in the glovebox shall have a minimum ${ }^{240} \mathrm{Pu}$ content of $5 \%$ by weight of plutonium, and a maximum ${ }^{241} \mathrm{Pu}$ content of $2 \%$ by weight of plutonium.

4) Accumulations of fissile material on the glovebox floor shall be limited to a depth of no more than $0.95 \mathrm{~cm}(3 / 8 \mathrm{in}$.). If accumulations of fissile material on the glovebox floor exceed $0.95 \mathrm{~cm}(3 / 8 \mathrm{in}$.) or there is a spill anywhere besides the floor of the glovebox, immediately discontinue adding feed to the calciner and/or glovebox until the limit for the depth on the glovebox floor has been reestablished and/or the spill has been cleaned up.

5) The lower insulation of the calciner shall be maintained free of absorbed fissile solution; if fissile solution is spilled on the insulation, feed to the calciner shall be discontinued and the insulation replaced before processing is resumed. A metal shell on the insulation is required to reduce exposure of the lower insulation to spills and leaks. Water absorbent insulation is not allowed on the upper portion of the calciner.

6) The depth of solids and precipitates with density greater than $450 \mathrm{~g} \mathrm{Pu} / \mathrm{l}$ is limited to a total height of $25.4 \mathrm{~cm}(10 \mathrm{in}$.) in all tanks in the glovebox. Any solids accumulation in excess of $25.4 \mathrm{~cm}$ shall be investigated immediately for plutonium content. If the solids are found to exceed the concentration limit, they shall be removed from the tank in accordance with the approved written plan prior to continuing operations.

7) Containers allowed in the glovebox are $0.5 \ell$ nominal volume containers, product receiver vessels, and $30 \mathrm{~m} \ell$ sample jars. Limits for containers are specified in terms of $2 \ell$ unit masses. For the purpose of this limit, a product receiver shall be considered $1 \ell$.

a) Container unit masses are to be spaced $25.4 \mathrm{~cm}$ (10 in.) apart edge to edge.

b) There shall be a $25.4 \mathrm{~cm}$ ( $10 \mathrm{in}$.) spacing between any unit mass and the calciner vessel, excepting a single allowable unit mass beneath the bottom plate of the calciner.

c) There shall be no more than two unit masses allowed in the glovebox at any time. 
d) Stacking of containers is not allowed.

e) Containers may be placed on the glovebox floor, and not on any other horizontal surface.

f) $0.5 \mathrm{l}$ nominal volume containers shall have maximum dimensions no greater than 1 pound slip lid cans (part number 42-1500-300) and polyjars (part number 57-6359-160).

8) There shall be no more than ten clean-up rags $\left(1 \mathrm{ft}^{2}\right.$ area each) in the glovebox at a time. Only one is allowed adjacent to a given piece of equipment or a given container with fissile material at a time.

9) The valve on the product drop tube shall be opened only when a product receiver vessel is in place, or the calciner has been disassembled to insure no significant quantity of product remains in the calciner.

10) A sheared impeller shaft shall not be withdrawn from the assembled calciner.

11) The criticality drain in the glovebox shall be maintained in a freely-flowable condition.

12) The glovebox HC-230C-2 shall be seismically qualified.

13) Firefighting designation for the glovebox is Firefighting Category $\mathrm{C}$.

14) Feed solution with plutonium concentration above $50 \mathrm{~g} / \ell$ and a temperature below 65 degrees $\mathrm{C}$ shall have an acid concentration of at least $0.5 \mathrm{M}$.

\subsection{PROCESS DESCRIPTION}

Plutonium nitrate suitable for calcination in the vertical calciner is transferred from the HC-227S glovebox through double encased transfer line to a feed receipt tank located in HC$230 \mathrm{C}-2, \mathrm{RM} 230 \mathrm{C}$. A controlled volume is then gravity fed into the feed pump tank. Once the feed pump tank contains the appropriate amount of solution, the valve from the feed receipt tank is closed, and the solution in the feed pump tank is mixed with atomizing air flow into a preheated bed of $\mathrm{PuO}_{2}$ powder in the vertical calciner. The vertical calciner agitates the injected mixture between external and internal heaters to $1000^{\circ} \mathrm{C}$ to form plutonium oxide $\left(\mathrm{PuO}_{2}\right)$.

Off-gases from this process are removed through the top of the calciner by vacuum. Sintered ceramic filter elements are used to remove any entrained plutonium dioxide powder. The off-gases are then circulated through a scrubber before leaving the glovebox. Spent scrubber solution is staged within the glovebox for sampling before removal from the glovebox. 


\section{HNF-SD-SQA-CSA-529, Rev. 0}

\subsection{ANALYSIS}

The sources for all spatial dimensions were in English units. Therefore, the English units are given as they appear in the respective sources, and the equivalent metric units are given, rounded to four significant digits. The calculational input files also use English units for specification of spatial dimensions. All other dimensions are specified in SI units, and were entered as such in the calculational input files.

Appendix B provides a summary for the documentation (Maklin 1992, Miller 1994a) of the validation carried out for the MONK6B (UKAEA, 1992) Monte Carlo code and its predecessor versions as applicable to plutonium materials encountered at PFP. With the crosssection library supplied, the MONK6A/6B validation calculations indicate an allowed maximum $k$-effective $\left(\mathrm{k}_{\text {eff }}\right)$ value of 0.935 for new system calculations to assure subcriticality with an acceptable margin, including the uncertainties in the analytical methods and benchmark experimental data. The estimated standard deviation for all calculations in this analysis was less than 0.003 .

\subsection{CONCENTRATION AND COMPOSITION OF THE FISSILE MATERIAL}

Mass fractions for many of the following were calculated on an Excel ${ }^{101} 5.0$ workbook. The workbook is attached in Appendix C. ${ }^{240} \mathrm{Pu}$ is less reactive than ${ }^{239} \mathrm{Pu}$, where as ${ }^{241} \mathrm{Pu}$ is more reactive. In this analysis, all plutonium is considered to contain $5 \%{ }^{240} \mathrm{Pu}$ and $2 \%{ }^{241} \mathrm{Pu}$ by weight of plutonium. Therefore, a minimum ${ }^{240} \mathrm{Pu}$ content of $5 \mathrm{wt} \%$, and a maximum ${ }^{241} \mathrm{Pu}$ content of $2 \mathrm{wt} \%$ is specified as a limit on feed to the calciner.

\subsubsection{Feed Solution}

Feed solution at PFP may vary in plutonium concentration up to the allowable fissile concentration of $450 \mathrm{~g} \mathrm{Pu} / \mathrm{l}$ in PFP and PUREX solution processes (Attachment 1). At $450 \mathrm{~g}$ $\mathrm{Pu} / \mathrm{\ell}$, the density of plutonium nitrate solution is $1.75 \mathrm{~g} / \mathrm{cm}^{3}$, based on a theoretical density of $5.629 \mathrm{~g} / \mathrm{cm}^{3}$ for plutonium nitrate. This is the maximum plutonium concentration considered in this analysis.

\subsubsection{Calcine $\left(\mathrm{PuO}_{2}\right)$ Product}

The maximum expected tap density of the calcine product is $5.0 \mathrm{~g} \mathrm{Pu} / \mathrm{cm}^{3}$, or $5.67 \mathrm{~g} / \mathrm{cm}^{3}$ for the oxide under normal operating conditions. This is based on experience with the PFP laboratory calciner, where normal product tap density was found to be 4.0 to $4.3 \mathrm{~g} \mathrm{Pu} / \mathrm{cm}^{3}$. A

${ }^{1}$ Excel 5.0 is copyrighted by Microsoft Corporation. Microsoft is a registered trademark of Microsoft Corporation. 
product density of $4.75 \mathrm{~g} \mathrm{Pu} / \mathrm{cm}^{3}$ was reached when it was continuously heated and stirred without addition of fresh feed solution (Attachment 2).

Calcine product densities of $5.5,6.0$, and $6.5 \mathrm{~g} \mathrm{Pu} / \mathrm{cm}^{3}$ were used for conservative evaluation of the calciner. However, operation of the calciner above $5.5 \mathrm{~g} \mathrm{Pu} / \mathrm{cm}^{3}\left(6.24 \mathrm{~g} / \mathrm{cm}^{3}\right.$ oxide) is not justified by this CSER.

\subsubsection{Mud}

Water flooding can be caused by earthquake and fire scenarios. Loss of feed solution containment may be caused by leaks in the feed solution system, including the possibility of a leak in the line bringing feed solution into the glovebox. In the event that the temperature interlock on the feed to the calciner fails, feed solution could be injected into a cold calciner. Each of these events allows for the formation of "mud" by mixing the liquid with the $\mathrm{PuO}_{2}$ product. In this section, it will be shown that complete saturation of maximum density plutonium oxide with maximum concentration feed solution yields the most reactive mud composition.

The theoretical density of plutonium oxide is $11.46 \mathrm{~g} / \mathrm{cm}^{3}$ (Carter, 1968). Given an assumed product density, one may calculate the interstitial volume available for liquid saturation. For example, an assumed product density of $6.0 \mathrm{~g} \mathrm{Pu} / \mathrm{cm}^{3}$ corresponds to a total $\mathrm{PuO}_{2}$ product density of $6.80 \mathrm{~g} / \mathrm{cm}^{3}$. Comparison of this density to the theoretical density for $\mathrm{PuO}_{2}$ indicates a void fraction of 0.406 in the product. Filling this void space with liquid would be considered full saturation.

The cases listed in Table 1 were modelled with the calciner full of mud, the calciner filters filled with $450 \mathrm{~g} \mathrm{Pu} / \ell$ feed solution, and the calciner lower insulation saturated with water. The floor is covered with $0.9525 \mathrm{~cm} \mathrm{(3/8} \mathrm{in.)} \mathrm{of} \mathrm{the} \mathrm{same} \mathrm{mud} \mathrm{as} \mathrm{in} \mathrm{the} \mathrm{calciner,} \mathrm{and} \mathrm{above} \mathrm{it,}$ $4.445 \mathrm{~cm}(13 / 4 \mathrm{in}$.) of $450 \mathrm{~g} \mathrm{Pu} / \mathrm{l}$ feed solution which reaches to the top of the criticality drain. The scrubber tank and two feed tanks are filled with $140 \mathrm{~g} \mathrm{Pu} / \mathrm{l}$ feed solution above the $25.4 \mathrm{~cm}$ (10 in.) particulates. Two product receiver vessels filled with the same mud as in the calciner are under the calciner and two $25.4 \mathrm{~cm}(10 \mathrm{in}$.) away towards the scrubber tank. The calciner mud was made of various density calcine, $450 \mathrm{~g} \mathrm{Pu} / \ell$ feed solution or water, and at different saturations to vary the $\mathrm{H} / \mathrm{Pu}$ to find the most reactive mud. For the dry case, the calciner and product receiver containers hold dry product and the filters are full, but the tanks are as described for the other cases, and the mud on the floor is saturated with $450 \mathrm{~g} \mathrm{Pu} / \mathrm{l}$ solution. As internal flooding of the calciner is considered an independent event from flooding external to the calciner, these cases represent two contingencies, resulting in $k_{e f f} s$ above the allowable in some cases. To form some of the higher $\mathrm{H} / \mathrm{Pu}$ ratios, it is necessary to reduce the plutonium oxide density.

Most cases were run for plutonium solution (plutonium and water only), excluding the nitrate in feed solution. This is conservative in comparison to an equivalent case using plutonium nitrate, and allows for easier comparison to the cases involving water saturation. Case 
HNF-SD-SQA-CSA-529, Rev. 0

sol55n shows that the reactivity drops over 0.020 in $\mathrm{k}_{\text {eff }}$ when nitrate is included at a total plutonium density of $5.71 \mathrm{~g} \mathrm{Pu} / \mathrm{cm}^{3}$.

Table 1 indicates that for product densities up to $6.0 \mathrm{~g} \mathrm{Pu} / \mathrm{cm}^{3}$, the most reactive mud is formed from $6.0 \mathrm{~g} \mathrm{Pu} / \mathrm{cm}^{3} \mathrm{PuO}_{2}$ fully saturated with $450 \mathrm{~g} \mathrm{Pu} / \ell$ solution, forming the material with the highest plutonium density.

Table 1. Reactivity for Various Forms of "Mud"

\begin{tabular}{|l|l|l|l|l|l|l|l||}
\hline \hline Case & $\begin{array}{l}\text { Product } \\
\text { Density } \\
\left(\mathrm{g} \mathrm{Pu} / \mathrm{cm}^{3}\right)\end{array}$ & $\begin{array}{l}\text { Total Pu } \\
\text { Density } \\
\left(\mathrm{\rho} \mathrm{Pu} / \mathrm{cm}^{3}\right)\end{array}$ & Liquid & $\begin{array}{l}\text { Percent } \\
\text { Saturation }\end{array}$ & $\mathrm{H} / \mathrm{Pu}$ & $\mathrm{k}_{\text {eff }}$ & $\begin{array}{l}\text { Std. } \\
\text { Dev. }\end{array}$ \\
\hline \hline solsp50 & 5.00 & 5.23 & Pu solution & $100 \%$ & 2.51 & 0.9438 & 0.0029 \\
\hline sol55n & 5.50 & 5.71 & Pu nitrate & $100 \%$ & 1.78 & 0.9443 & 0.0029 \\
\hline solsp55 & 5.50 & 5.71 & Pu solution & $100 \%$ & 2.07 & 0.9650 & 0.0029 \\
\hline solsp & 6.00 & 6.18 & Pu solution & $100 \%$ & 1.71 & 0.9807 & 0.0029 \\
\hline HPu50s & 6.00 & 6.09 & Pu solution & $44 \%$ & 0.85 & 0.9354 & 0.0029 \\
\hline HPu25s & 6.00 & 6.05 & Pu solution & $22 \%$ & 0.43 & 0.9243 & 0.0029 \\
\hline HPu0 & 6.00 & 6.00 & (none) & $0 \%$ & 0.00 & 0.8997 & 0.0029 \\
\hline HPu50w & 6.00 & 6.00 & Water & $49 \%$ & 0.88 & 0.9254 & 0.0029 \\
\hline HPu100w & 6.00 & 6.00 & Water & $100 \%$ & 1.80 & 0.9673 & 0.0029 \\
\hline HPu450w & 4.00 & 4.00 & Water & $100 \%$ & 4.01 & 0.9027 & 0.0029 \\
\hline HPu1200w & 2.00 & 2.00 & Water & $100 \%$ & 10.6 & 0.8486 & 0.0029 \\
\hline \hline
\end{tabular}

\subsubsection{Precipitated Pu Solids in Tanks}

Precipitation of plutonium solids from nitrate solution is modeled as plutonium nitrate at $2 \mathrm{~g} \mathrm{Pu} / \mathrm{cm}^{3}$ mixed with water. This gives a total density of $4.35 \mathrm{~g} / \mathrm{cm}^{3}$ based on a theoretical density of $5.629 \mathrm{~g} / \mathrm{cm}^{3}$ for plutonium nitrate, filling the remaining interstitial volume with water. The $2 \mathrm{~g} \mathrm{Pu} / \mathrm{cm}^{3}$ is considered a reasonable value. In general, the densest precipitate is plutonium oxide (Miller, 1997a). Plutonium oxide formed from plutonium nitrate at temperatures below $400^{\circ} \mathrm{C}$ has a bulk density of no more than $2 \mathrm{~g} \mathrm{PuO}_{2} / \mathrm{cm}^{3}$ according to Page III.C.2-2 of ARH-600 (Carter, 1968).

At $450 \mathrm{~g} \mathrm{Pu} / \mathrm{\ell}$ of solution in the feed tanks, the $10 \mathrm{\ell}$ nominal volume can hold $4.5 \mathrm{~kg}$ of plutonium. The plutonium mass for $2 \mathrm{~g} \mathrm{Pu} / \mathrm{cm}^{3}$ at the allowable $25.4 \mathrm{~cm}$ (10 in.) layer of 
precipitate amounts to a total mass of $9.8 \mathrm{~kg}$ in each tank. Therefore, the density for the precipitate together with the allowable height is considered conservative.

\subsubsection{Uranium Content}

Some of the samples to be calcined contain ${ }^{235} \mathrm{U}$. The Nuclear Criticality Safety Manual HNF-CM-4-29 Section 5.2.1.4 states that $1 \mathrm{~g}$ of ${ }^{235} \mathrm{U}$ may be considered equivalent to $\mathrm{l} \mathrm{g}$ of ${ }^{239} \mathrm{Pu}$. In Section 5.2 .1 .3 of the same chapter, solutions with enrichments of less than $1.0 \%$ are considered exempt from criticality safety control. Therefore, for solutions of enrichment above $1.0 \%, 1 \mathrm{~g}$ of ${ }^{235} \mathrm{U}$ will be considered $1 \mathrm{~g}$ of ${ }^{239} \mathrm{Pu}$ for purposes of concentration $(450 \mathrm{~g} / \mathrm{l})$, density and mass limits. As the equivalence is valid for "small quantities ... associated with plutonium processing", the equivalence will be considered valid for solutions with ${ }^{235} \mathrm{U}$ content of up to $50 \mathrm{~g}$ ${ }^{235} \mathrm{U} / \mathrm{l}$. Attachment 3 indicates that no enriched uranium concentrations above this level are expected. For solutions of greater than $1.0 \%{ }^{235} \mathrm{U}$ enrichment and greater than $50 \mathrm{~g}{ }^{235} \mathrm{U} / \mathrm{l}$, additional analysis will be necessary.

\subsection{GLOVEBOX}

Most of glovebox HC-230C-2 was originally constructed for the Fuels and Materials Examination Facility (FMEF). One portion of the glovebox (hereafter referred to as the "calciner section") is primarily used for the actual calcination process. Another section (hereafter referred to as the "waste section") is used to process waste scrubber solution. The third section (hereafter referred to as the "connecting section") connects the $\mathrm{HC}-230 \mathrm{C}-2$ glovebox to the HC-3 conveyer for further processing.

\subsubsection{Calciner Section of Glovebox}

The derived inner dimensions of the calciner section are $105 \mathrm{~cm}(411 / 4 \mathrm{in}$.) $\times 264 \mathrm{~cm}$ (104 1/4 in.) in the two horizontal directions. These values are based on scaling from a preliminary drawing (Attachment 4, Drawing A) and hand measurement (Attachment 5). The height scaled from the preliminary drawing is $180 \mathrm{~cm}(707 / 8 \mathrm{in}$.). The basic model for the calciner section contains the following fissile quantities:

- The calciner is filled with $6.0 \mathrm{~g} \mathrm{Pu} / \mathrm{cm}^{3}$ dry $\mathrm{PuO}_{2}$ product up to the bottom of the dome, amounting to a total volume of approximately $1.6 \ell$. This section of the calciner is surrounded by $30.48 \mathrm{~cm}$ (12 in.) thick insulation saturated with water.

- Three product receiver vessels are beneath the calciner, and three more are beneath the feed pump tank, which amounts to two overbatches. Each container is filled with $6.0 \mathrm{~g} \mathrm{Pu} / \mathrm{cm}^{3}$, dry product, and surrounded by a $2.54 \mathrm{~cm}$ thick annulus of water representing hands. 
- There is a $0.9525 \mathrm{~cm}\left(3 / 8 \mathrm{in}\right.$.) thick layer of $6.0 \mathrm{~g} \mathrm{Pu} / \mathrm{cm}^{3}$, dry product covering the entire glovebox floor.

- Both feed tanks and the scrubber tank are completely filled with $140 \mathrm{~g} \mathrm{Pu} / \mathrm{l}$ feed solution, excepting a $25.4 \mathrm{~cm}$ layer of $2 \mathrm{~g} \mathrm{Pu} / \mathrm{cm}^{3}$ precipitate on the bottom of each. Section 4.4 .3 shows that $140 \mathrm{~g} \mathrm{Pu} / \mathrm{l}$ feed solution is more reactive than $450 \mathrm{~g}$ Pu/ $/$ feed solution. Filling the $20 \mathrm{\ell}$ scrubber tank with feed solution, which normally would have none, conservatively compensates for pumps and piping not included in the models.

The walls of the glovebox $(0.9525 \mathrm{~cm}$ or $3 / 8$ in. thick $)$ are made from lead $(0.4763 \mathrm{~cm}$ or $3 / 16$ in.) sealed between two layers of steel (Miller, $1997 \mathrm{~b}$ ). The model uses a $30.48 \mathrm{~cm}(1 \mathrm{ft}$.) layer of water on all four sides of this section to represent the bodies of workers. A $30.48 \mathrm{~cm}$ (1 ft.) layer of water is placed on the top and bottom of the glovebox as well to bound reflection from the floor and ceiling. Since steel is an absorber, and the $30.48 \mathrm{~cm}$ of water will provide full reflection, the steel and lead materials of the glovebox itself are excluded from the model. This model is also conservative in that it includes the water reflector at the side of the calciner section that would in actuality be shared with the connecting section. The keff $\pm 1 \sigma$ for this system (case undert3) is $0.8929 \pm 0.0029$. This basic model is modified to construct each specific contingency case.

Because the calciner section contains the bulk of the fissile material and is modelled with $30.48 \mathrm{~cm}(1 \mathrm{ft}$.) thick water reflector on all four sides, top and bottom, analyses of the calciner section of the glovebox are considered bounding for analysis of the entire glovebox.

\subsubsection{Waste Section of Glovebox}

The waste section of the glovebox contains solution used for scrubbing of the off-gasses that come from the calciner. The width of the glovebox (minimum horizontal dimension) is indicated as $107 \mathrm{~cm}$ (42 in.) based on a preliminary drawing with dimensions (Attachment 4, Drawing B), and scaling from a second preliminary drawing (Attachment 4, Drawing A).

Although it is suspected that the width should be equal to that of the calciner section, the value of $107 \mathrm{~cm}$ is considered adequately accurate for this analysis. The height was taken to be the same as the calciner portion $(180 \mathrm{~cm}$ or $707 / 8 \mathrm{in}$.). The model for the waste section includes two tanks (four cylinders) for storage of spent scrubber solution. These tanks are referred to as spent scrubber receipt tanks (SSRTs).

The walls of the glovebox are made from lead sealed between two layers of steel. This is

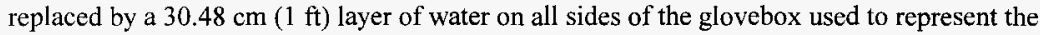
bodies of workers as is done for the connecting section (Section 4.2.1). There is also a $30.48 \mathrm{~cm}$ ( $1 \mathrm{ft}$ ) layer of water on the top and bottom to bound reflection from the floor and ceiling. The water reflector is also present at the side of the calciner section that would in actuality be shared with the connecting section. The total length of the waste section is modelled as being only $124.5 \mathrm{~cm}(49 \mathrm{in}$.). This is conservative in that it brings the water reflector closer to the SSRTs. As the SSRTs are much larger in volume than the single vent catch tank, and filling the single 
vent catch tank is considered an independent contingency (see Sections 4.4.2 and 4.5.4), analysis for filled SSRTs is considered bounding for this analysis. Section 4.5.2 discusses the contingency of abnormally high fissile material content in the SSRTs.

\subsubsection{Connecting Section of Glovebox}

The connecting section of the glovebox will provide access to one end of the $\mathrm{HC}-3$ conveyer glovebox. Operators will need to move $0.5 \ell$ slip-lid cans $1.8 \mathrm{~m}(6 \mathrm{ft})$ by hand from the connecting section of the glovebox to the end of the conveyor to be transported to glovebox HC-21 A for storage in the Hanford Convenience Can (HCC). The phase separation tank is on the border of this section and the calciner section. It is considered in the calculations of Section 4.5.3 as an extension to the model for the calciner section. The only other potential for the presence of fissile material is accumulation on the floor and the presence of unit masses. Therefore, no independent calculations were made for the connecting section. Analysis for the calciner section of the glovebox should be bounding for the connecting section.

\subsubsection{Criticality Drain}

There is a vertical, bottom criticality drain located in the floor of the calciner section of the glovebox to limit the level of liquid accumulation in the entire glovebox. The criticality drain was measured in the fabrication shop as having a height of approximately $3.65 \mathrm{~cm}$ (1 7/16") above the glovebox floor, not including the height of the gasket. This value is based on measurements of two parts of the criticality drain, a portion that was installed at the time, and a second portion that was measured outside of the box. Consequently, the total height used in this analysis will be $4.1275 \mathrm{~cm}(15 / 8$ ") to account for any inaccuracies in measurement. The inside diameter of the drain was measured in the fabrication shop as being a little under $7.62 \mathrm{~cm}(3 \mathrm{in}$.).

Although there are a number of weirs on the floor of the glovebox, none are as tall as the top of the criticality drain. Therefore, the criticality drain will limit the level of liquid in all portions of the glovebox.

The "Criticality Drain Performance Study" (Lehmkuhl, 1974) shows that for a flow rate of 14 gallons per minute, there is a head of less than $1.27 \mathrm{~cm}(1 / 2 \mathrm{in}$.) for a $7.62 \mathrm{~cm}(3 \mathrm{in}$.) criticality drain. Since the highest flow rate into a glovebox reported in the "Z-Plant Sprinkler System Criticality Safety Analysis Report" (Hammelman, 1974) is 6.0 gallons per minute, the $1.27 \mathrm{~cm}(1 / 2 \mathrm{in}$.) head is considered bounding for this analysis. Therefore, the maximum height of liquid accumulation on the bottom of the glovebox is taken as $5.3975 \mathrm{~cm}(21 / 8 \mathrm{in}$.). For the calciner section of the glovebox, this would correspond to a total volume of $149 \ell$. 


\section{HNF-SD-SQA-CSA-529, Rev. 0}

\subsubsection{Accumulation of Fissile Material on Glovebox Floor}

Accumulations of fissile material on the glovebox floor is administratively limited to a depth of no more than $0.95 \mathrm{~cm}(3 / 8 \mathrm{in}$.). Consequently, all calculations include a $0.9525 \mathrm{~cm}(3 / 8$ in.) layer of $\mathrm{PuO}_{2}$ on the glovebox floor unless specified otherwise. Table 2 shows the effect of doubling this thickness to $1.905 \mathrm{~cm}\left(3 / 4 \mathrm{in}\right.$.) at a product density of $6.0 \mathrm{~g} \mathrm{Pu} / \mathrm{cm}^{3}$. As can be seen, this contingency results in only a small change in reactivity. Case undert 3 is the base case for the calciner portion of the glovebox as described in Section 4.2.1. Case buildup is the same case, but with the double batch of material on the glovebox floor. A doubling of accumulation on the floor results in a small change in $\mathrm{k}_{\mathrm{eff}}$ because the reactivity of the glovebox is primarily due to the product receiver vessels in this model. This is demonstrated by case $b f$. Case $b f$ differs from case buildup, only in that the calciner has been completely filled with product, and the off-gas filters in the calciner filled with feed solution. The calculated $\mathrm{k}_{\mathrm{eff}}$ for case $b f$ is actually lower than case buildup, but within two sigma.

Table 2. Buildup of Material on Glovebox Floor

\begin{tabular}{||l|l|l|l|l||}
\hline \hline Case & Product on Floor & $\begin{array}{l}\text { Product } \\
\text { in Cacliner }\end{array}$ & $\mathrm{k}_{\mathrm{efr}}$ & Std. Dev. \\
\hline \hline undert3 & $0.9525(3 / 8 \mathrm{in})$. & $1.6 \mathrm{~L}$ & 0.8929 & 0.0029 \\
\hline buildup & $1.905(3 / 4 \mathrm{in})$. & $1.6 \mathrm{~L}$ & 0.9081 & 0.0029 \\
\hline bf & $1.905(3 / 4 \mathrm{in})$. & full & 0.9039 & 0.0029 \\
\hline
\end{tabular}

\subsubsection{Water Flooding of the Glovebox}

Water flooding can be caused by earthquake and fire scenarios. This contingency considers a worst case flood of the glovebox. This model represents a modification of the model for the calciner portion of the glovebox as described in Section 4.2.1. In the model for this contingency, the allowable $0.9525 \mathrm{~cm}(3 / 8 \mathrm{in}$.) layer of product on the glovebox floor is saturated with $450 \mathrm{~g} \mathrm{Pu} / \ell$ feed solution without the nitrate. Solution saturation represents an additional conservatism over water saturation.

All containers on the floor are assumed to be full of $\mathrm{PuO}_{2}$ product saturated with $450 \mathrm{~g}$ $\mathrm{Pu} / \ell$ feed solution without nitrate as well. The containers consist of two product receivers beneath the feed pump tank and two beneath the calciner. There are no water hands around these containers, as there should be no one operating the calciner during flooding conditions. The internal space of the calciner section is filled with "mist" and the insulation left dry. The effect of wet insulation is discussed in Section 4.3.4 and shown in Table 7. The calciner is completely filled with dry product. All product has a plutonium density of $5.5 \mathrm{~g} \mathrm{Pu} / \mathrm{cm}^{3}$. Results for the various mist conditions are shown in Table 3. 
The $k_{\text {eff }}$ is below the 0.935 allowable for mist densities up to $0.2 \mathrm{~g} / \mathrm{cm}^{3}$. Even at 0.5 $\mathrm{g} / \mathrm{cm}^{3}$, the $\mathrm{k}_{\text {eff }}$ is 0.9379 , which is only slightly over the allowable of 0.935 . In either case, the density is far greater than any expected mist density due to sprinklers or other fire fighting activities. The system is considered sufficiently subcritical under this contingency.

Table 3. Calculations for Water Flooding of the Glovebox

\begin{tabular}{||l|l|l|l|l||}
\hline Case & Mist Material & Mist Density $\left(\mathrm{g} / \mathrm{cm}^{3}\right)$ & $\mathrm{k}_{\text {eff }}$ & Std. Dev. \\
\hline \hline nomist & (none) & (none) & 0.7378 & 0.0029 \\
\hline wmp001 & water & 0.001 & 0.7358 & 0.0029 \\
\hline$w m p 002$ & water & 0.002 & 0.7350 & 0.0029 \\
\hline$w m p 005$ & water & 0.005 & 0.7439 & 0.0029 \\
\hline$w m p 01$ & water & 0.01 & 0.7385 & 0.0029 \\
\hline$w m p 02$ & water & 0.02 & 0.7404 & 0.0028 \\
\hline$w m p 05$ & water & 0.05 & 0.7730 & 0.0029 \\
\hline$w m p 1$ & water & 0.1 & 0.8112 & 0.0029 \\
\hline$w m p 2$ & water & 0.2 & 0.8522 & 0.0029 \\
\hline$w m p 5$ & water & 0.5 & 0.9379 & 0.0029 \\
\hline$w m 1$ & water & 1.0 & 0.9912 & 0.0029 \\
\hline
\end{tabular}

\subsubsection{Feed Solution Flooding of the Glovebox}

Loss of feed solution containment may be caused by leaks in the feed solution system, including the possibility of a leak in the line bringing feed solution into the glovebox. This model represents a modification of the model used in the previous section for a water flood contingency (Section 4.2.6). In addition to the allowable $0.9525 \mathrm{~cm}$ (3/8 in.) layer of product on the glovebox floor saturated with feed solution, there is also a layer of feed solution up to the maximum liquid level allowed by the criticality drain $(5.3975 \mathrm{~cm}$ or $21 / 8 \mathrm{in}$.). Therefore, the buildup of material on the glovebox floor for flooding is as follows:

Top

$4.4450 \mathrm{~cm}(13 / 4 \mathrm{in}$.) feed solution

$0.9525 \mathrm{~cm}(3 / 8 \mathrm{in}$.) feed solution mud

Bottom 


\section{HNF-SD-SQA-CSA-529, Rev. 0}

The layer of solution on the floor amounts to a total volume of $123 \ell$ in the calciner section as modeled. This volume does not include that of the other two sections of the glovebox. As the total volume of the two feed tanks is nominally $20 \ell$ and the total volume of solution in the feed line coming into the box under extreme circumstances is $54 \ell$ (Attachment 6), the assumed layer of feed solution represents an incredible amount of solution for a feed spill.

Again, nitrate is neglected, adding an additional level of conservatism. The containers consist of two product receivers beneath the feed pump tank and two beneath the calciner. All containers are assumed to be full of $\mathrm{PuO}_{2}$ product saturated with feed solution. The feed solution on the floor and saturating the product to form mud is modeled as $450 \mathrm{~g} \mathrm{Pu} / \ell$ plutonium solution, thus conservatively neglecting the nitrate. All product has a plutonium density of $5.5 \mathrm{~g} \mathrm{Pu} / \mathrm{cm}^{3}$.

Because the calciner is hot, there is some chance that feed solution could be flashed to steam, driving droplets of feed solution into the air. Some droplets may arise from a feed leak, even for a low pressure pump. Three cases were run in which there is a mist of feed solution (modeled as plutonium solution, neglecting nitrate) at densities of $0.001 \mathrm{~g} / \mathrm{cm}^{3}$ to $0.1 \mathrm{~g} / \mathrm{cm}^{3}$. However, a mist density of $0.001 \mathrm{~g} / \mathrm{cm}^{3}$ is two orders of magnitude greater than flog, clouds, or rain. Even at this density, the $\mathrm{k}_{\mathrm{eff}}$ for the glovebox is below 0.9 . Raising the mist density to the extremely conservative density of $0.01 \mathrm{~g} / \mathrm{cm}^{3}$, the $\mathrm{k}_{\mathrm{eff}}$ is still less than the allowable of 0.935 . This shows that as a mist of feed solution increases, $\mathbf{k}_{\mathrm{eff}}$ increases slowly at possible mist densities. The highest mist concentration considered is $0.1 \mathrm{~g} / \mathrm{cm}^{3}$, for which the $\mathrm{k}_{\mathrm{eff}}$ is over 1.00 . However, this represents an incredible amount of feed solution $(\sim 500 \mathrm{~kg})$ in the glovebox.

Table 4. Calculations for Feed Solution Flooding of the Glovebox

\begin{tabular}{||l|l|l|l|}
\hline \hline Case & Mist Density $\left(\mathrm{g} / \mathrm{cm}^{3}\right)$ & $\mathbf{k}_{\text {eff }}$ & Std. Dev, \\
\hline \hline smp001 & 0.001 & 0.8928 & 0.0029 \\
\hline smp01 & 0.01 & 0.9119 & 0.0029 \\
\hline$s m p l$ & 0.1 & 1.0484 & 0.0029 \\
\hline
\end{tabular}

\subsection{VERTICAL CALCINER}

The production vertical calciner is virtually identical to the prototype currently in the 188-1 glovebox at PFP. Drawing number H-2-95609 (BWHC, 1997) shows dimensions for this new production calciner. The outer vessel of the calciner consists of two sections of 310 stainless steel, 6 inch schedule 10 pipe. The dimensions for this pipe as modeled are $16.15 \mathrm{~cm}$ (6.357 in.) ID, $16.83 \mathrm{~cm}$ (6.625 in.) OD. Details specific to each section of pipe are given below. 
HNF-SD-SQA-CSA-529, Rev. 0

\subsubsection{The Lower Section}

The heating and agitation of the product take place in the lower portion of the calciner. There is a dome made from 4 inch pipe and pipe cap in the center, which is modelled as extending up $17.95 \mathrm{~cm}(7.066 \mathrm{in}$.) into the internal volume of the calciner from the bottom. No credit is taken for the volume occupied by the agitator, except that the rod is modeled as having its lower end $2.54 \mathrm{~cm}$ ( $1 \mathrm{in}$.) above the top of the dome. Although the product collection tube will often be filled with product during normal operating conditions, it is considered of negligible importance for criticality safety due to its small radius $(2.54 \mathrm{~cm})$ and because it only extends up into the annular region of the calciner where reactivity is lowest. The product collection tube is not included in the model, except as discussed in Section 4.3.3.

This section is wrapped in a highly water absorbent insulation with approximate dimensions as given in Attachment 7. Although the thickest portion of the insulation is $15.24 \mathrm{~cm}$ ( $6 \mathrm{in}$.), the insulation is modelled as a close-fitting annulus just over $30.48 \mathrm{~cm}$ (12 in.) thick along its entire axial length. This is conservative because the insulation is $10.16 \mathrm{~cm}(4 \mathrm{in}$.) thick and its inner surface is $9.366 \mathrm{~cm}$ (3.688 in.) from the outside surface of the calciner vessel along most of the middle portion of the insulation's axial length.

Visible inspection for dryness is not possible because the insulation is covered by a metal cover to prevent liquid contacting the insulation. All calculations will consider water saturation of the insulation as part of the normal condition as a conservatism (see Section 4.3.4.1 below) to represent spills of non-fissile solutions and condensation buildup when the calciner is cooled down. As feed solution is contained within a closed system in the glovebox, a feed solution spill is considered a contingency. If fissile material is spilled on the insulation, feed to the calciner shall be discontinued and the insulation replaced before processing is resumed. This contingency is addressed in Section 4.3.4.2.

\subsubsection{The Upper Section}

The upper calcining section contains filter elements for filtering particulates from the offgasses produced in the calcining process. The filters were modeled based on dimensions from the model used in CSER 95-005 for the calciner in glovebox 188-1 (Geiger, 1995a and 1995b) and a third party reference to personal correspondence with L.H. Rodgers, as there were no drawings made available for these dimensions. These dimensions were used in the base case model for the calciner section of the glovebox as described in Section 4.2.1. Later hand measurements of the production calciner filters by J.F. Durnil yielded different internal dimensions (Attachment 8). A list of dimensions for both filter models is given in Table 5 below. Using the shorter length is conservative since a shorter filter leaves more room for product in the calciner. The inside dimensions are important only for the case of feed solution filling the calciner as discussed in Section 4.3.5. 
HNF-SD-SQA-CSA-529, Rev. 0

Table 5. Off-Gas Filter Dimensions

\begin{tabular}{|c|c|c|}
\hline Dimension & $\begin{array}{l}\text { From CSER 95-005 } \\
\text { (Geiger, 1995a) }\end{array}$ & $\begin{array}{l}\text { Measurement by J.F. Durnil } \\
\text { (Attachment } 8 \text { ) }\end{array}$ \\
\hline Total Length & $30.48 \mathrm{~cm}$ (12 in.) & $\begin{array}{l}30.80 \mathrm{~cm}(12 \mathrm{l} / 8 \mathrm{in} .) \\
\quad \text { - modeled as } 30.48 \mathrm{~cm}(12 \mathrm{in} .)\end{array}$ \\
\hline Outside Diameter & $5.080 \mathrm{~cm}(2 \mathrm{in})$. & $5.080 \mathrm{~cm}(2 \mathrm{in})$. \\
\hline Inside Diameter & $2.870 \mathrm{~cm}(1.13 \mathrm{in})$. & $3.651 \mathrm{~cm}(17 / 16 \mathrm{in})$. \\
\hline Bottom Thickness & $3.810 \mathrm{~cm}(1.5 \mathrm{in})$. & $2.858 \mathrm{~cm}(11 / 8 \mathrm{in})$. \\
\hline
\end{tabular}

This section is wrapped in metal reflective insulation that does not absorb liquids (see Appendix B of Geiger, 1995b). The manufacturer supplied drawings show an outside diameter of $40 \mathrm{~cm}(15.75 \mathrm{in}$.) and a height of $36.83 \mathrm{~cm}$ (14.5 in) for the prototype calciner. These are the dimensions used for the production calciner, as there was no information available on these dimensions at the time of the analysis. The insulation was conservatively modeled as being $10 \%$ density 304L steel to accommodate the concentric sheets and narrow strips of sheet metal used to create many spaces of dead air within the insulation. Later correspondence revealed that the insulation on the upper insulation contains less mass than modeled. In any case, the amount of steel modeled is quite small, and would have little effect on reactivity.

\subsubsection{Product Collection Tube}

A product collection tube is used to feed the final product from the calciner into product receiver vessels. The outside pipe of the tube is $1 \mathrm{in}$. sched $10 \mathrm{~s}$ pipe. The top of the tube is inside the center dome of the calciner. There is a $11.43 \mathrm{~cm}(4.5 \mathrm{in}$.) tall slot in the side of the dome, and a slot cut into the side of the tube to allow product to flow from the calciner down the tube into an attached product receiver vessel. The height of the product inside the calciner is controlied by a weir inside the tube. The flow of product is controlled by a valve attached to the product collection tube. The tube was found to adjust such that the bottom may range between $12.7 \mathrm{~cm}$ ( $5 \mathrm{in}$.) to $30.48 \mathrm{~cm}$ (12 in.) from the glovebox floor based on hand measurement in the fabrication shop (Attachment 5).

If the valve is left open while there is no product receiver in place, material from the calciner may spill on the glovebox floor. Cases hand and undert3, in Tables 15 and 9 respectively, include an overbatch of containers beneath the calciner amounting to nearly $3 \ell$, each container being surrounded by a one inch water annulus. This should constitute a bounding evaluation for a spill of material on the floor due to opening the valve on the product collection tube when no product receiver vessel is in place. Neither case exceeds a $k_{\text {eff }}$ of 0.91 . 


\subsubsection{Wet Insulation}

In this scenario, the insulation on the bottom portion of the calciner is saturated with water. As given in Appendix E of CSER 95-005 (Geiger, 1995a) the insulation has $90 \%$ void space by volume.

Appendix B of the addendum to CSER 95-005 (Geiger, 1995b) contains a test that shows that the "mirror" insulation used in the upper section of the calciner drains at a rate of 25 e/minute, indicating that a fill rate of at least $25 \mathrm{\ell} /$ minute would be required to cause accumulation of liquid in the insulation. Consequently, to fill the insulation on the upper section with water is considered incredible. However, additional water at $0.1 \mathrm{~g} / \mathrm{cm}^{3}$ is added to this volume to bound the amount of water that may cling to the inner and outer surfaces of this insulation when soaked insulation is considered.

\subsubsection{Water Soaked Insulation}

Two cases were run to show the effect of water completely saturating the lower insulation under otherwise normal operating conditions. This model represents a modification of the model for the calciner portion of the glovebox as described in Section 4.2.1. In each case, the product is dry and has a plutonium density of $6.5 \mathrm{~g} \mathrm{Pu} / \mathrm{cm}^{3}$. The second unit mass is $25.4 \mathrm{~cm}(10 \mathrm{in}$.) from the first unit mass in the direction of the scrubber tank in Section 4.6.4. The model does not include water annuli to represent hands. The results given in Table 6 indicate little effect on reactivity due to water saturating the insulation. This rather unexpected result is attributed to the fact that the fissile material in the calciner is only within a thin annulus. The reactivity level is primarily due to the interaction of the more solid volumes of plutonium in the tanks and containers.

Table 6. Water Saturating Insulation

\begin{tabular}{||l|l|l|l||}
\hline \hline Case & Lower Insulation Status & $k_{\text {. }}$ & Std. Dev. \\
\hline down & dry & 0.7606 & 0.0029 \\
\hline wet & wet & 0.7686 & 0.0029 \\
\hline
\end{tabular}

An additional case was run to show the effect of saturating the insulation of the calciner with feed solution under flooding conditions as described in Section 4.2.6. Table 7 shows a comparison between the worst case credible flooding condition with dry and wet insulation $(0.2$ $\mathrm{g} / \mathrm{cm}^{3}$ ). As the results are within one sigma of each other, this indicates that adding wet insulation does not change reactivity appreciably when mist is already present. 
HNF-SD-SQA-CSA-529, Rev. 0

Table 7. Water Saturation of Insulation Under Flood Conditions

\begin{tabular}{|l|l|l|l|}
\hline Case & Insulation Status & $\mathrm{k}_{\text {of }}$ & Std. Dev. \\
\hline \hline wmp2 & dry & 0.8522 & 0.0029 \\
\hline wetp2 & wet & 0.8501 & 0.0029 \\
\hline
\end{tabular}

\subsubsection{Feed Solution Soaked Insulation}

The lower insulation on the calciner has a 90 percent void space and absorbs water rapidly (see Appendix E of Geiger, 1995a). The dimensions of the insulation make it an unfavorable "container" if saturated with feed solution.

Feed solution is contained within a closed system in the glovebox. Feed solution can only saturate the lower calciner insulation if a pressurized feed line has a guillotine break. The break would have to go unnoticed for a sufficient amount of time to allow for significant buildup of solution in the insulation. Secondly, a required metal casing around the lower insulation will deflect a stream of feed solution from a pipe break from reaching the insulation.

The feed line entering the glovebox to the first (feed receipt) tank is pressurized. In addition to the conditions mentioned above, there would have to be a stream of solution directed at the calciner for a break in this line to cause saturation of the insulation. The pressure would also need to be sufficient to reach the insulation. That the insulation would actually become completely saturated with feed solution is considered incredible from a break of this nature.

The only other feed line under pressure is between the feed pump and the calciner. This line enters the calciner from below after passing through the hole in the center of a metal plate approximately $71 \mathrm{~cm}$ ( 28 inches) in diameter. This plate provides a second barrier for breaks in the feed line beneath it.

The pump used for feeding solution into the calciner is an LMI Metering Pump Model E70, with a maximum output of $4.9 \mathrm{lph}$ (LMI, 1996). To saturate the lower insulation of the calciner with $3 \ell$ of solution would require that a leak go unnoticed by the operator for 37 minutes, assuming that all the feed solution being pumped at the maximum pump capacity is absorbed by the insulation. The loss of head because of the elevation change from the pump to the insulation and the loss of solution to other flow paths would reduce that absorbed by the insulation below this amount. Furthermore, solution buildup in the insulation at the bottom of the calciner is not as much a problem from a criticality standpoint as solution buildup near the top of the lower insulation, where there is a larger cross-section of product. This larger crosssection of product would only be the result of an abnormal accumulation above the outlet tube.

It is considered incredible that the insulation would be completely saturated with feed solution. An evaluation is made for saturation of the insulation with a smaller, more credible amount of feed solution. Cases involving $3 \ell$ solution spills from Addendum 1 of CSER 95-005 (Geiger, 1995b) are considered bounding for any credible feed solution leak. In the analysis of 
this addendum, there were four configurations considered. Descriptions and calculated $\mathrm{k}_{\mathrm{eff}} \mathrm{s}$ for these configurations are given below. The values given are for $6.5 \mathrm{~g} \mathrm{Pu} / \mathrm{cm}^{3}$ in the $\mathrm{PuO}_{2}$ product.

1) The $k_{\text {eff }} \pm 1 \sigma$ for plutonium nitrate solution saturating an annular shell against the inner surface of the insulation, with water saturating the remainder of the insulation was calculated to be $0.8562 \pm 0.0040$.

2) The $k_{\text {eff }} \pm 1 \sigma$ for plutonium nitrate solution saturating a slab against the top surface of the insulation, with water saturating the remainder of the insulation was calculated to be $0.8496 \pm 0.0040$.

3) The $k_{\text {eff }} \pm 1 \sigma$ for plutonium nitrate solution saturating the outer "half" of a torus (vertical cross section a semicircle) with the inner cylindrical surface coinciding with the inner surface of the insulation at the top, and with water saturating the remaining insulation was calculated to be $0.8595 \pm 0.0043$.

4) The $k_{\text {eff }} \pm 1 \sigma$ for a homogeneous mixture of water and the spilled plutonium nitrate solution saturating the entire volume of the insulation was calculated to be $0.9328 \pm 0.0042$.

In all four of these configurations the calculated keff was below 0.935. For a Pu density in the calcine of $7.0 \mathrm{~g} / \mathrm{cm}^{3}$, an incredible density for the calciner and a violation of the density limit, case 4 exceeds the allowable.

\subsubsection{Internal Flooding}

The calcine inside the calciner may be turned into "mud" as described in Section 4.1.3 in the event that the temperature interlock on the vertical calciner fails, allowing the feed pump to continue to provide fresh solution into the cold calciner. This contingency is considered in Table 8 . The interior of the calciner is completely filled with the most reactive plutonium solution mud found in Section 4.1.3 surrounded by wet insulation. The model also assumes that the internal volume of all three filter elements are filled with $450 \mathrm{~g} \mathrm{Pu} / \mathrm{cm}^{3}$ solution. This model represents a modification of the model for the calciner portion of the glovebox as described in Section 4.2.1.

The calciner model for calculations in this section does not include the $1.27 \mathrm{~cm}(1 / 2 \mathrm{in}$.) steel plate at the bottom of the dome of the calciner, thus maximizing interaction between the product in the calciner and the product receiver vessels on the floor by neglecting the shielding mass of the heating element and the feed injection system that is between the calciner and the product receiver vessels. These cases also include revised internal dimensions for the off-gas filters as discussed in Section 4.3.2. By expanding the internal dimensions of the filters, the volume of feed solution inside the filters is increased. 
Two product receivers are located under the calciner, and two under the feed pump tank, all with water hands surrounding them. All containers are filled with dry calcine, with the exception of one product receiver vessel considered to have been attached to the bottom of the calciner at the time of the failure. This product receiver vessel is filled with the same mud as in the calciner, which has an $\mathrm{H} / \mathrm{Pu}$ ratio above 2.073 . The operator will notice abnormal wetness at this level, and should stop work until a written recovery plan is in place.

Case int $55 d v 5$ includes both containers on the floor of the glovebox, with the mud filled container attached to the product drop tube. In case int $55 u v 5$, the containers are up against the bottom of the calciner baseplate, even though the presence of hardware such as the feed solution injection system would disallow this. Also, it is not expected that the operator would detach the identifiably mud filled jar and move it together with the jar of dry calcine up above the bottom of the product collection tube as is modeled in case int $55 u v 5$. The $\mathrm{k}_{\mathrm{cff}} \mathrm{s}$ for both cases are below the allowable.

Table 8. Internal Flooding for Cases Including the Product Collection Tube

\begin{tabular}{||l|l|l|l|l||}
\hline Case & $\begin{array}{l}\text { Mud Filled } \\
\text { Container Position }\end{array}$ & $\begin{array}{l}\text { Dry Product } \\
\text { Filled Container }\end{array}$ & $\mathrm{k}_{\mathrm{eff}}$ & Std. Dev. \\
\hline \hline int55dv5 & floor & floor & 0.9298 & 0.0029 \\
\hline int5 $\mathrm{uv5}$ & up & up & 0.9296 & 0.0029 \\
\hline
\end{tabular}

\subsection{FEED SYSTEM}

The feed system for the calciner is mainly located within the calciner portion of the glovebox. The calciner portion of the glovebox includes two feed tanks, a flush tank, feed lines, valves, air supply, and a pump for the feed system. The vent catch tank in the waste section of the glovebox is used to catch overflow from the feed tanks and the flush tank.

\subsubsection{Feed Tanks}

Both feed tanks are made from 6 inch Pyrex ${ }^{122}$ pipe. Vendor data (Wittekind, 1997) indicates an inside diameter of $15.71 \mathrm{~cm}$ (6.186 in.) including tolerances. The height of both tanks is nominally $60.96 \mathrm{~cm}$ (24 in.), yielding a total volume capacity of $11.8 \mathrm{l}(721 \mathrm{cu}$. in.). The pipe wall is not included in the model. The bottom and top of each tank is a $28.575 \mathrm{~cm}(11.25$ in.) diameter, $1.27 \mathrm{~cm}$ (1/2 in.) thick steel flange as measured in the fabrication shop (Attachment

5). There is a second flange on both the top and bottom used to hold the pipe in place, which is not included in the model.

\footnotetext{
${ }^{2}$ Pyrex is a registered trademark of Corning Glass Works
} 


\section{HNF-SD-SQA-CSA-529, Rev. 0}

The feed tanks are positioned such that the vertical center line is $20 \mathrm{~cm}(8 \mathrm{in}$.) from the east wall. This is about $1.27 \mathrm{~cm}(1 / 2 \mathrm{in}$.) further from the wall than hand measurement indicates, but brings the tanks slightly closer to the calciner. The feed pump tank is modeled as being 109.5 $\mathrm{cm}$ (43 1/8 in.) from the south wall, and the feed receipt tank is modeled as being $40.01 \mathrm{~cm}$ (15 $3 / 4 \mathrm{in}$.) from the south wall, as determined by scaling from a preliminary drawing (Attachment 4, Drawing A) and confirmation by hand measurement (Attachment 5). The bottom of the feed pump tank internal volume is $16.51 \mathrm{~cm}(61 / 2 \mathrm{in}$.) from the floor as determined by hand measurement, and the bottom of the internal volume for the feed receipt tank is $83.32 \mathrm{~cm}$ ( 33 in.) from the floor as determined by scaling from a preliminary drawing and confirmed by hand measurement.

Calculational models will include a $25.4 \mathrm{~cm}$ ( $10 \mathrm{in}$.) layer of plutonium precipitate on the bottom of each tank of fissile material as a normal condition, as this will be the administratively controlled limit. As the assumed density for this precipitate is $2 \mathrm{~g} \mathrm{Pu} / \mathrm{cm}^{3}$, this represents a total of $9.8 \mathrm{~kg}$ of plutonium. A feed tank has a nominal capacity of $10 \mathrm{l}$, which means that a feed tank completely filled with $450 \mathrm{~g} \mathrm{Pu} / \mathrm{cm}^{3}$ feed solution holds a total of $4.5 \mathrm{~kg}$. Furthermore, any significant buildup of solids on the bottom of the feed tanks will create problems in terms of clogging the system, requiring shutdown of the calciner operation until the solids are cleared.

\subsubsection{Other Feed System Volumes}

The waste section of the glovebox contains a vent catch tank, which collects liquid overflow from the feed system. Since the spent scrubber receipt tanks are modeled as being filled with feed solution in the calculation for Section 4.5.2, this is considered to bound the independent contingency of an overflow of a feed tank into the vent catch tank. A contingency concerning vacuum trap overflow into the vent tank is discussed further in the section on the scrubber system (Section 4.5.4). analysis.

All pumps in the glovebox have negligible holdup volume for the purpose of this

There is a flush tank connected to the feed pump that is used to facilitate restart after unplanned shutdown, and an air supply tank used to atomize feed solution for injection into the calciner. The flush tank has a nominal capacity of only $4 \ell$, the air supply has even less, and neither will contain fissile material under normal conditions. The off-normal condition of the scrubber tank filled with feed solution as described in Section 4.5.1, which represents an independent contingency, will bound any credible buildup of fissile material in these two tanks. Therefore, neither tank is included in the model.

\subsubsection{Plutonium Concentration in Feed Solution}

The maximum concentration administratively allowed in plutonium nitrate solutions is $450 \mathrm{~g} \mathrm{Pu} / \mathrm{\ell}$. Table III.A.4(95)-1 of ARH-600 (Carter, 1968) indicates that the concentration of 
minimum critical diameter for a fully reflected infinite cylinder is about $140 \mathrm{~g} \mathrm{Pu} / \ell$. This corresponds to a plutonium nitrate density of $1.24 \mathrm{~g} / \mathrm{cm}^{3}$. Calculations as given in Table 9 show that the $140 \mathrm{~g} \mathrm{Pu} / \ell$ concentration is more reactive. This model represents a modification of the model for the calciner portion of the glovebox as described in Section 4.2.1.

Table 9. Variation in Reactivity as a Function of Feed Solution Concentration

\begin{tabular}{||l|l|l|l||}
\hline \hline Case & $\begin{array}{l}\text { Feed Solution } \\
\text { Concentration }\end{array}$ & $\mathrm{k}_{\text {eff }}$ & Std. Dev. \\
\hline \hline undert3 & $140 \mathrm{~g} \mathrm{Pu} / \ell$ & 0.8929 & 0.0029 \\
\hline c450 & $450 \mathrm{~g} \mathrm{Pu} / \ell$ & 0.8841 & 0.0029 \\
\hline
\end{tabular}

The feed tanks as modeled do not have full reflection. For an unreflected infinite cylinder, Table III.A.4(95)-1 of ARH-600 (Carter, 1968) indicates a minimum critical diameter at about $130 \mathrm{~g} \mathrm{Pu} / \ell$. However, as Table 9 of this section indicates, there would be little effect on reactivity for variations in concentration of this magnitude.

\subsubsection{Double Batch of Plutonium Precipitates}

The level of precipitates in the feed solution will effectively be zero under normal conditions, as the feed solution is mixed to avoid the formation of precipitation, and because the feed system within the glovebox will not operate due to plugging of the feed system to the calciner with any significant buildup of solids. As the allowed level of plutonium precipitate in each tank is $25.4 \mathrm{~cm}$ ( $10 \mathrm{in}$.), a double batch contingency would be to have a $50.8 \mathrm{~cm}$ (20 in.) layer of precipitate in both the feed pump and feed receipt tanks. The solids level in the scrubber tank is likewise increased to $50.8 \mathrm{~cm}$ (10 in.). As the density for precipitates as modeled is $2 \mathrm{~g}$ $\mathrm{Pu} / \mathrm{cm}^{3}$, the total plutonium mass for this level of solids is $19.6 \mathrm{~kg}$ for each tank, which is extremely conservative. To show that reactivity does not increase with a reduction in the level of plutonium precipitates in the tanks, a case is run with no precipitates. This model represents a modification of the model for the calciner portion of the glovebox as described in Section 4.2.1.

A doubling of solids in the tanks results in a small change in $\mathrm{k}_{\text {eff }}$ because the reactivity of the glovebox is primarily due to the product receiver vessels. This is demonstrated by case $d f$. Case $d f$ differs from case double, only in that the calciner has been completely filled with product, and the off-gas filters in the calciner filled with feed solution. The calculated $k_{\text {eff }}$ for case $d f$ is actually lower than case double, but within two sigma. 
HNF-SD-SQA-CSA-529, Rev. 0

Table 10. Variation of Plutonium Precipitate Level

\begin{tabular}{|l|l|l|l|l||}
\hline Case & Precipitate level & Product in Calciner & $\mathrm{k}_{\mathrm{cff}}$ & Std. Dev. \\
\hline \hline zero & 0 & $1.6 \mathrm{~L}$ & 0.8871 & 0.0029 \\
\hline undert 3 & $25.4 \mathrm{~cm}(10 \mathrm{in})$. & $1.6 \mathrm{~L}$ & 0.8929 & 0.0029 \\
\hline double & $50.8 \mathrm{~cm}(20 \mathrm{in})$. & $1.6 \mathrm{~L}$ & 0.8942 & 0.0029 \\
\hline df & $50.8 \mathrm{~cm}(20 \mathrm{in})$. & full & 0.8900 & 0.0029 \\
\hline
\end{tabular}

\subsection{SCRUBBER SYSTEM}

The scrubber system is not expected to contain more than a token amount of fissile material (less than $0.01 \mathrm{~g} \mathrm{Pu} / \mathrm{cm}^{3}$ of solution) under normal operating conditions. However, it is possible under abnormal conditions for this fissile concentration to be exceeded, although not to concentrations exceeding that of feed solution.

The bulk of the scrubber solution is contained within the scrubber tank in the calciner portion of the glovebox, and a set of tanks in the waste portion of the glovebox for storage of spent scrubber solution until the spent solution is sampled and removed from the glovebox. All tanks are made from the same 6 inch Pyrex ${ }^{18}$ pipe used for construction of the feed tanks as described in Section 4.4.1.

\subsubsection{Scrubber Tank}

The scrubber tank is nominally $122 \mathrm{~cm}$ (48 in.) tall. The bottom of the scrubber tank internal volume is modeled as being $35.56 \mathrm{~cm}$ (14 in.) from the glovebox floor. Hand measurement indicates this distance is $34.29 \mathrm{~cm}$ (13 1/2 in.) (Attachment 5). However, the 1.27 $\mathrm{cm}(1 / 2 \mathrm{in}$.) difference will have little effect on reactivity.

In the case that the off-gas filters break, fissile concentration of the scrubber solution may increase, but not beyond the feed solution concentration of $450 \mathrm{~g} \mathrm{Pu} / \ell$. To bound all accident conditions for a buildup of fissile concentration in the scrubber system, all cases were run with the scrubber full of feed solution, and a $25.4 \mathrm{~cm}(10 \mathrm{in}$.) layer of plutonium precipitate. Table 9 of Section 4.4.3 shows the results for both $140 \mathrm{~g} \mathrm{Pu} / \mathrm{cm}^{3}$ and $450 \mathrm{~g} \mathrm{Pu} / \mathrm{cm}^{3}$ solution.

\subsubsection{Spent Scrubber Receipt Tanks}

In the event that an abnormal amount of fissile material makes its way into the scrubber system, it would not necessarily be detected until it reaches the spent scrubber receipt tanks (SSRTs), where the solution is tested before removal from the glovebox. Calculations were 
made for the case that all the SSRTs used to contain spent scrubber solution are instead filled with feed solution and $25.4 \mathrm{~cm}$ (10 in.) of Pu solids as described in Section 4.1.4. Since only half of the tanks are used to receive spent scrubber solution at a time, to fill all tanks with abnormally high concentrations is considered conservatively bounding. Two container unit masses are assumed to be in this portion of the glovebox, with one unit mass under each of two cylinders for the SSRTs. These two unit masses each include an overbatch of one product receiver, for a total unit mass of $3 \ell$ each. Results are given in Table 11 below. The product in the containers is 6.0 $\mathrm{g} \mathrm{Pu} / \mathrm{cm}^{3}$, which is in excess of the density limit. This bounding case is within allowables.

Table 11. Feed Solution in Spent Scrubber Receipt Tanks

\begin{tabular}{|l|l|l|l||}
\hline Case & $\begin{array}{l}\text { Feed Solution } \\
\text { Concentration }\end{array}$ & $\mathrm{k}_{\text {eff }}$ & Std. Dev. \\
\hline \hline waste & $140 \mathrm{~g} \mathrm{Pu} / \ell$ & 0.9009 & 0.0029 \\
\hline$w 450$ & $450 \mathrm{~g} \mathrm{Pu} / \ell$ & 0.8910 & 0.0029 \\
\hline
\end{tabular}

\subsubsection{Phase Separator Tank}

The phase separator tank will contain some scrubber solution under normal operating conditions. The contingency of the phase separator tank filling with scrubber solution with abnormally high fissile content is considered.

PFD-Z-300-1 (Stubbs, 1997) lists the size of the phase separator tank as being $91.44 \mathrm{~cm}$ ( 36 in.) tall. It is positioned on the opposite side of the calciner from the scrubber and feed tanks. Although closer to the calciner than the scrubber tank, it has a smaller volume. One calculation was made to show that the contingency of a phase separator tank fully loaded with $140 \mathrm{~g} \mathrm{Pu} / \ell$ feed solution has little effect on reactivity. Table 12 shows a comparison between this case (phase) and the model it was derived from (case down in Section 4.3.4.1). The calciner insulation is dry in these cases in order to maximize interaction between the calciner and the phase separator tank in case phase. Case $p f$ differs from case phase only in that the calciner is filled with product.

The phase separator was placed in the model of the calciner section of the glovebox with the vertical centerline $7.62 \mathrm{~cm}(3 \mathrm{in}$.) beyond the edge of this section. The artificial end of the calciner section model was moved back $30.48 \mathrm{~cm}$ (12 in.) to give room for the phase separator tank. The tank was also placed $20.32 \mathrm{~cm}$ ( $8 \mathrm{in}$.) from the west wall, as was done for the other tanks in the calciner section. Although preliminary drawings indicate that the bottom of the internal volume of the phase tank would be $70.49 \mathrm{~cm}(273 / 4 \mathrm{in}$.) from the glovebox floor, these same drawings indicate a $60.96 \mathrm{~cm}$ (48 in.) tall tank. Therefore, the bottom of the internal volume was moved down an additional $30.48 \mathrm{~cm}$ (12 in.) to be $40.01 \mathrm{~cm} \mathrm{(15} \mathrm{3/4} \mathrm{in.)} \mathrm{from} \mathrm{the}$ floor to accommodate the longer length given in PFD-Z-300-001. 
HNF-SD-SQA-CSA-529, Rev. 0

Table 12. Contribution of Phase Separator Tank to Reactivity

\begin{tabular}{|l|l|l|l|l||}
\hline Case & $\begin{array}{l}\text { Phase Separator } \\
\text { with Feed Solution }\end{array}$ & $\begin{array}{l}\text { Product } \\
\text { in Calciner }\end{array}$ & $\mathrm{k}_{\text {eff }}$ & Std. Dev. \\
\hline \hline down & no & $1.6 \mathrm{~L}$ & 0.7606 & 0.0029 \\
\hline phase & yes & $1.6 \mathrm{~L}$ & 0.7731 & 0.0029 \\
\hline$p f$ & yes & full & 0.7885 & 0.0029 \\
\hline
\end{tabular}

\subsubsection{Other Scrubber System Volumes}

With respect to the scrubber system, two contingencies would be required to fill the vacuum trap or vent catch tank with liquids with greater than a token amount of fissile material. The first would be the existence of scrubber solution with more than a token amount of fissile material concentration. The second would be the overflow of the phase separator tank. The vacuum trap and vent catch tanks are of much smaller volume than the scrubber tank and the spent scrubber receipt tanks, which are shown to be critically safe in Section 4.5.2, even when full of feed solution. analysis.

All pumps in the glovebox have negligible holdup volume for the purpose of this

\subsection{CONTAINERS}

There are three types of containers that will be allowed in the glovebox: product receiver vessels, $0.5 \ell$ containers ( 1 pound slip lid cans and polyjars), and $30 \mathrm{~m} \ell$ sample jars. A limit requires that no more than two unit masses of $2 \ell$ each be in the glovebox at one time. For the purpose of this limit, a product receiver vessel is considered $1 \ell$. The worst case position of the first unit is assumed to be under the calciner. The worst case position of the second unit mass is determined in Section 4.6.4. The models presented in this section represent modifications of the model for the calciner portion of the glovebox as described in Section 4.2.1.

\subsubsection{Worst Case Unit Mass}

The $0.5 \ell$ (nominal) containers proposed for use in the HC-230C-2 glovebox are the 1 pound slip lid can (part number 42-1500-300) with the dimensions of $8.89 \mathrm{~cm}$ (3.5 in.) OD x $8.89 \mathrm{~cm}$ ( $3.5 \mathrm{in}$.) height, and the polyjar (part number 57-6359-160) with the dimensions of 8.255 $\mathrm{cm}(3.25 \mathrm{in}$.) OD $\times 10.16 \mathrm{~cm}$ (4 in.) height. The total internal volume for the 1 pound slip lid can is $552 \mathrm{ml}$, and for the polyjar it is $543 \mathrm{~m} \ell$. 


\section{HNF-SD-SQA-CSA-529, Rev. 0}

The internal dimensions for the product receiver vessel, which are taken from CSER 95005 (Geiger, 1995a), are $4.445 \mathrm{~cm}$ ( $13 / 4 \mathrm{in}$.) radius $\times 15.24 \mathrm{~cm}$ (6 in.) height. The total internal volume for the product receiver vessel is $946 \mathrm{~m}$. This model for the product receiver vessel uses a flat bottom rather than a rounded bottom, which results in a larger modeled volume than the actual volume.

Note that the diameter of the product receiver vessel bounds the diameters of both the 1 pound slip lid can and the polyjar. For this reason, a unit mass was modeled as being two product receiver vessels, thus bounding any normal condition configuration for a unit mass. Although the contents of two 1 pound slip cans is $15 \%$ greater than that of a single product receiver vessel, two product receiver vessels side-by-side are assumed to be more reactive than four slip lid cans or a single product receiver vessel adjacent to two slip lid cans. Stacking of containers is not allowed, and is discussed as a contingency in Section 4.6.6.

\subsubsection{Unit Attached to Calciner}

It is assumed that the worst case position for one of the unit masses will be right beneath the calciner. One product receiver vessel may be attached to the bottom of the calciner at any time. This product receiver vessel is considered part of a unit mass beneath the calciner.

Table 13 shows that leaving the product receiver vessel with the unit mass on the floor is more reactive than leaving it attached to the calciner product drop tube in the two cases that were run. The first case (down) positions the product receiver vessel on the floor with the rest of the unit mass. In the case of $u p$, the containers are up against the bottom of the calciner baseplate, even though the presence of hardware such as the feed solution injection system would disallow this. Neither case has water reflectors around the product receivers to represent hands of workers, and the insulation on the calciner is dry.

The unit mass considered consists of three product receiver vessels, constituting an overbatch contingency. The second unit mass is $25.4 \mathrm{~cm}$ (10 in.) away from the first in the direction of the scrubber tank. This model represents a modification of the model for the calciner portion of the glovebox as described in Section 4.2.1, excepting that the insulation on the calciner is dry, workers' hands are not included, and the product has a plutonium density of $6.5 \mathrm{~g}$ $\mathrm{Pu} / \mathrm{cm}^{3}$, which is substantially more conservative than the $5.5 \mathrm{~g} \mathrm{Pu} / \mathrm{cm}^{3}$ limit for the calciner.

Table 13. Position of Product Receiver Vessel on Calciner Product Collection Tube

\begin{tabular}{||l|l|l|l|l||}
\hline \hline Case & Product & Position of Containers Under Calciner & $\mathrm{k}_{\mathrm{N}}$ & Std.Dev. \\
\hline \hline down & $6.5 \mathrm{~g} \mathrm{Pu} / \mathrm{cm}^{3}$, dry & Both on floor & 0.7606 & 0.0029 \\
\hline up & $6.5 \mathrm{~g} \mathrm{Pu} / \mathrm{cm}^{3}$. dry & One against bottom of calciner base plate & 0.7453 & 0.0029 \\
\hline
\end{tabular}




\subsubsection{Hands Around Containers}

To study the effects of hands in the glovebox, case wet of Section 4.3.4.1 was modified to form a case hand by placing a $2.54 \mathrm{~cm}$ ( 1 in.) thick, close fitting annulus of water around every container. The containers each hold dry $6.5 \mathrm{~g} \mathrm{Pu} / \mathrm{cm}^{3}$ product, which is substantially more conservative than the allowed density limit of $5.5 \mathrm{~g} \mathrm{Pu} / \mathrm{cm}^{3}$ for the calciner. Table 14 shows how the presence of hands around containers can increase reactivity substantially. However, the hands as modelled are quite conservative by virtue of their size and number (one for each can). There are three product receivers in each unit mass, representing an overbatch contingency for each. The second unit mass was placed $25.4 \mathrm{~cm}(10 \mathrm{in}$.) away from the first unit mass towards the direction of the scrubber tank. The scrubber tank was modeled as being filled with feed solution as described in Section 4.5.1 above, and the calciner insulation is saturated with water.

Table 14. Effect of Hands Around Containers

\begin{tabular}{|l|l|l|l|}
\hline Case & Hands Present & $\mathrm{k}_{\text {St. Dev }}$ & Std \\
\hline \hline wet & no & 0.7686 & 0.0029 \\
\hline hand & yes & 0.9035 & 0.0029 \\
\hline
\end{tabular}

\subsubsection{Worst Case Position of Second Unit Mass}

To find the worst case position of the second unit on the glovebox floor, two cases were run. The first case ( $h a n d$ ) considered the second unit $25.4 \mathrm{~cm}$ (10 in.) away from the first unit, which is under the calciner, in the direction of the scrubber tank filled with feed solution. The scrubber tank could have the largest volume of feed solution of any other tank in the calciner portion of the glovebox under an accident condition that allows feed solution to flow through the off-gas filters on the calciner (see Section 4.5.1 above). Other aspects of case hand are discussed in Section 4.6 .3 above.

Case undert is the same as case hand, but the second unit is beneath the feed pump tank. The bottom of the feed pump tank sits only $63 / 8 \mathrm{in}$. from the floor, thus bringing the second unit as close as possible to a tank with feed solution while being on the glovebox floor. Table 15 shows how reactivity increases by positioning the second unit mass under the Feed Pump Tank. Both cases are for extra dense calcine $\left(6.5 \mathrm{~g} \mathrm{Pu} / \mathrm{cm}^{3}\right)$ and an extra product receiver in every unit mass, representing multiple contingencies. That one case is just over the allowable shows the system to have a considerable margin of safety. The results in Table 16 show that the $k_{\text {eff }}$ drops below 0.935 as the number of contingencies is reduced. 
HNF-SD-SQA-CSA-529, Rev. 0

Table 15. Position of Second Unit mass

(Includes Overbatching and $6.5 \mathrm{~g} \mathrm{Pu} / \mathrm{cm}^{3}$ Product Density)

\begin{tabular}{|l|l|l|l||}
\hline Case & Second Unit Position & $\mathrm{k}_{1}$ & Std. Dev \\
\hline \hline hand & Near scrubber & 0.9035 & 0.0029 \\
\hline undert & Under feed pump tank & 0.9354 & 0.0029 \\
\hline
\end{tabular}

Table 16. Second Unit mass Under Feed Pump Tank

\begin{tabular}{|l|l|l|l|l|}
\hline Case & $\begin{array}{l}\text { Product Density } \\
\left(\mathrm{g} P \text { u } / \mathrm{cm}^{3}\right)\end{array}$ & $\begin{array}{l}\text { Product Receiver Vessels } \\
\text { Under Feed Tank }\end{array}$ & $\mathrm{k}_{\mathrm{eff}}$ & Std. Dev. \\
\hline \hline undert3 & 6.0 & 3 & 0.8929 & 0.0029 \\
\hline undert4 & 6.5 & 2 & 0.8808 & 0.0029 \\
\hline
\end{tabular}

Containers can be moved about freely in the glovebox as long as the maximum volume requirement and the appropriate spacing requirements between unit masses and the calciner are met. Additional cases were run to show the effect on reactivity when product receipt vessels are positioned adjacent to the $25.4 \mathrm{~cm}$ ( $10 \mathrm{in}$.) layer of plutonium precipitate in the feed pump tank.

The base case, undert 3 , considers three containers underneath the feed pump tank, representing an overbatch contingency. In case next, one product receiver vessel is moved up next to the layer of precipitates. In case next2, all three product receiver vessels are grouped around the Feed Pump tank as shown in Figure 1. In case next3, the three product receiver vessels are moved up such that two out of three of the product receiver vessels are next to the feed pump tank, and the third is placed adjacent to both of the first two units as shown in Figure 2. There are hands around all three containers in all the calculations. The results show that placing the unit mass beneath the feed pump tank, which also places it on top of the assumed layer of product on the bottom of the glovebox, is the worst case position for this second unit. This position for the second unit is used in the base model described in Section 4.1.3. 
HNF-SD-SQA-CSA-529, Rev. 0

Table 17. Container Next to $25.4 \mathrm{~cm}$ (10 in.) Solids Layer in Feed Pump Tank

\begin{tabular}{||l|l|l|l||}
\hline Case & Container Position & $k_{-}$ & Std.Dev \\
\hline \hline undert3 & Three containers beneath tank & 0.8929 & 0.0029 \\
\hline next & One moved next to tank & 0.8283 & 0.0029 \\
\hline next2 & Second unit wrapped around tank (Figure 1) & 0.8415 & 0.0029 \\
\hline next3 & Second unit clustered next to tank (Figure 2) & 0.8424 & 0.0029 \\
\hline
\end{tabular}


HNF-SD-SQA-CSA-529, Rev. 0

\section{Figure 1. Product Receiver Vessels Next to Solids in Feed Pump Tank (case next2)}

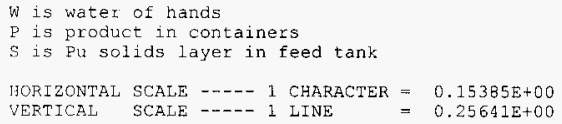

WWWWWWWWWWWW

WพWWWWWWNWWWWWWWWWW

WWWWWWWWWWWWWWWWWWWW

WWWWWWWWWWWWWWWWWWWWWWWWWW

WWWWWWWWWWPPPPPPPP P PWWWWWWWWW

WWWWWWWWP PPPPP PPPPEPPPPPWWWWWWW

WWWWWWWPP PPPPP PPPPPPPPPPPWWWWWWWW

WWWWWWWPPP P PPPPPPPPPPPPPPP

WWWWWWPPPPPPPPPPPPPPPPPPPPPPWWWWWWW

WWWWWWWPPPPPPPPPPPPPPPPPPPPPPWWWWWWW

WWWWWWWPPPPPPPPEPPPPPPPPPPPPPWWWWWWW

WWWWTWWPPPPPPPPPPPPPPPPPPPPPPWWWWWWW SSS5SSSS

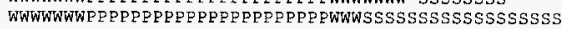

WWWWWWWPPPPPPPP PPPPPPPPPPPWWSSSSSSSSSSSSSSSS5SSSSSS

WWWWWWWWWPPPEPPPPPPPPPPPPPPWSSSSSSSSSSSSSSSSSSSSSSSSSS

WWWWWWWWWWWWPPRPPPPPPPPPPPPPSSSSSSSSSSSSSSSSSSSSSSSSSSSSSSS

WWWWWWWWWWWWWWWWPPPPPPPPPPPPWSSSSSSSSSSSSSSSSSSSSSSSSSSSSSSSSS

WWWWWWWWWPFP PPPPPPP P WWWWWWWWSSSSSSSSSSSSSSSSSSSSSSSSSSSSSSSSSSS

WWWWWWWWPPPPPPPPPPPPPPPPWWWWWSSSSSSSSSSSSSSSSSSSSSSSSSSSSSSSSSSSSS

WWWWWWWPPPPPPPPPPPPPPPPPPPWWWSSSSSSSSSSSSSSSSSSSSSSSSSSSSSSSSSSSSSS

WWWWWWPPPPPPPPEPPPEPPPPPPPPWWSSSSSSSSSSSSSSSSSSSSSSSSSSSSSSSSSSSSSS

WWWWWWWPFPPPPPPPPPPEPPPEPPRPPSSSSSSSSSSSSSS\$SSS\$SSSSSSSSSSSSSSSSSSSSS

WWWWWWWPPPPPPPPPPPF PPPPPPPPPSSSSSSSSSSSSSSSSSSSSSSSSSSSSSSSSSSSSSSSS

WWWWWWPPPPPPPPPPPPPRPPPPPPPPPSSSSSSSSSSSSSSSSSSSSSSSSSSSSSSSSSSSSSSS WWWWWWWPPPPPPPPPPPPPPPPPPPPPPSSSSSSSSSSSSSSSSSSSSSSSSSSSSSSSSSSSSSSSS

WWWWWWWPPPPPPPPPPPPPPPPPPPPPPWSSSSSSSSSSSSSSSSSSSSSSSSSSSSSSSSSSSSSSS

WWWWWWWPPPPPPPPPPPPPPPPPPPPWWSSSSS.3SSSSSSS\$SSSSSSSSSSSSSSSSSSSSSSSS WWWWWWWWPPEPPPPPPPPPPPPPPPWWWSSSSSSSSSSSSSSSSSSSSSSSSSSSSSSSSSSSSSS

WWWWWWWW PPPPPEP PPPEPPPPWWWWWWSSSSSSSSSSSSSSSSSSSSSSSSSSSSSSSSSSSS

WWWWWWWWWPPPEPPP PPPPERPPPWWWSSSSSSSSSSSSSSSSSSSSSSSSSSSSSSSSSSS

WWWWWWWWWWWWWWPPPPEPRPPPPRPSSSSSSSSSSSSSSSSSSSSSSSSSSSSSSSS

WWWWWWWWWWWWPPPPPPP PPPPPPPPPPSSSSSSSSSSS5S5SSSSSSSSSSSSSSS

WWWWWWWPPPPPPPPPPPPPPPPPPPPSSSSSSSSSSSSSSSSSSSSSSGSSS

WWWWWWPPPPPPRPPPPPPPPPRPPPPPWWSSSSSSSSSSSSSSSSSSSSS

WWWWWWWPRPPPPPPPPPPPPPEPPPPPPWWWWWSSSSSSSSSSSSSSS

WWWWWWWPPP PPPPPPQPPPPPPPPPPPPWWWWWWT

WWWWWWWPPPPPPPPPPEPPPPP PPPPPPWWWWWWW

WWWWWWWPPPPPPPPPPPPPPPEPPPPPPWWWWWWW

WWWWWW P PPPPPPPPPPPPPPP PPPPPPWWWWWW

WWWWWWWPPPEPPPPPPQPPPPPPPPPWWWWWWW

WWWWWWWPPPPPPPPPPPPPPPPPPWWWWWWW

WWWWWWWWPPPPPPEPPPPPPPWWWWWWWW

WWWWWWWWWWPPPPPPPPWWWWWWWWWW

WWWWWWWWWWWWWWWWWWWWWWWWWW

WWWWWWWWWWWKWWWWWWWWWW

WWWNWWWWWWWWWWWW

WWWWWWWW 


\section{Figure 2. Product Receiver Vessels Clustered Next to Solids in Feed Pump Tank (case next3)}

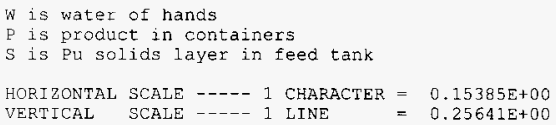

\subsubsection{Container Overbatch}

Case undert 3 , the base case for the calciner section of the glovebox as described in Section 4.2.1, includes two unit masses in the worst case positions in the glovebox, each unit mass consisting of three product receivers. As the maximum allowable unit mass size is $2 \ell$ (the equivalent of two product receivers), this represents two overbatch contingencies. Additionally, the product is $6.0 \mathrm{~g} \mathrm{Pu} / \mathrm{cm}^{3}$, representing another contingency of exceeding the product density limit. All the containers are surrounded by a $2.54 \mathrm{~cm}$ annulus of water, representing hands. The $k_{\text {eff }} 1 \sigma$ is $0.8929 \pm 0.0029$, which is below the 0.935 limit for a single contingency. 
HNF-SD-SQA-CSA-529, Rev. 0

\subsubsection{Stacking of Containers}

This contingency considers a worst case configuration of a unit mass by stacking containers. The worst case configuration for a unit mass including the contingency of stacking containers would be to create a stack of 1 pound slip lid cans. A stack of two slip lid cans is $15 \%$ taller than a single product receiver vessel.

Since there is not enough room beneath the feed pump tank to stack two slip lid cans, the second unit mass in this section is placed $25.4 \mathrm{~cm}$ (10 in.) from the first unit mass in the direction of the scrubber tank. Case stack was developed from case hand (section 4.6.3) to represent stacked containers by replacing each and every product receiver with a stack of two slip lid cans with $2.54 \mathrm{~cm}$ ( 1 in.) of close fitting water annuli around each the can. This case includes the contingencies of exceeding the product density limit of $5.5 \mathrm{~g} \mathrm{Pu} / \mathrm{l}$ by using $6.5 \mathrm{~g} \mathrm{Pu} / \mathrm{cm}^{3}$, multiple overbatching ( $3 \ell$ in each unit mass), and multiple stacking. Even under these extreme conditions, the calculated $\mathrm{k}_{\mathrm{eff}} \pm 1 \sigma$ is $0.9343 \pm 0.0029$, which is below the criticality safety limit. A second case was also run in which the calciner was filled with product. However, the $k_{\text {eff }} \pm 1 \sigma$ for this case is $0.9315 \pm 0.0029$, which is within one sigma of case stack, indicating that reactivity is mostly due to the containers on the floor, as would be expected.

\subsubsection{Placing a Container on the Lower Insulation}

Case onshelf considers a the contingency of a full product receiver vessel placed on top of the lower insulation. The upper insulation was removed from the model to maximize interaction between the misplaced can and the fissile material inside the calciner. However, a $2.54 \mathrm{~cm}$ (1 in.) spacing between the can and the calciner vessel was used to represent the space taken by the upper insulation. There is also a $2.54 \mathrm{~cm}$ ( $1 \mathrm{in}$.) thick annulus of water representing hands. This arrangement is shown in Figure 3.

This case is a modification of case nomist from Section 4.2.6. As with case nomist, the calciner is filled with dry product. There are two product receiver vessels beneath the calciner, and two beneath the feed tank. Off-gas filters are filled with feed solution. There is also a layer of feed solution up to the level of the criticality drain. Feed solution on the glovebox floor and filling the off-gas filters with feed solution is not part of this contingency, but represents an additional conservatism. Additionally, all containers are surrounded by a $2.54 \mathrm{~cm}$ (1 in.) annulus of water representing hands, but not directly between the container and the calciner. All product, which includes the $0.9525 \mathrm{~cm}(3 / 8 \mathrm{in}$.) layer on the floor, the product in the containers, and the product in the calciner, is $6.0 \mathrm{~g} \mathrm{Pu} / \mathrm{cm}^{3}$ and dry. With these contingencies and conservatisms, the $\mathrm{k}_{\mathrm{eff}} \pm 1 \sigma$ for onshelf is $0.9029 \pm 0.0029$, which is below the criticality safety limit. 


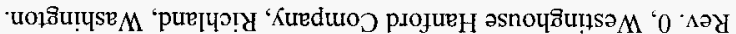

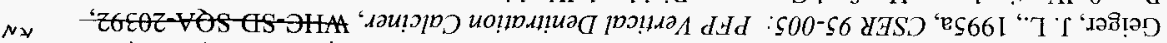
$Z, S O Z-\forall S T-\forall D S \cdot \square S-D H M$

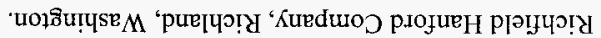

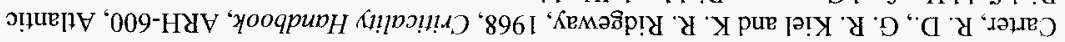

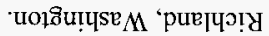

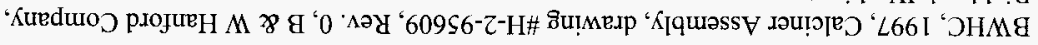

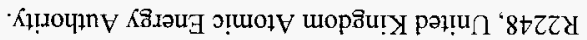

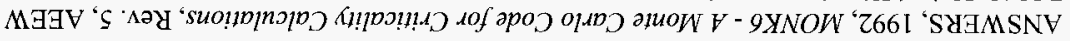

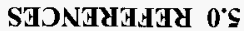

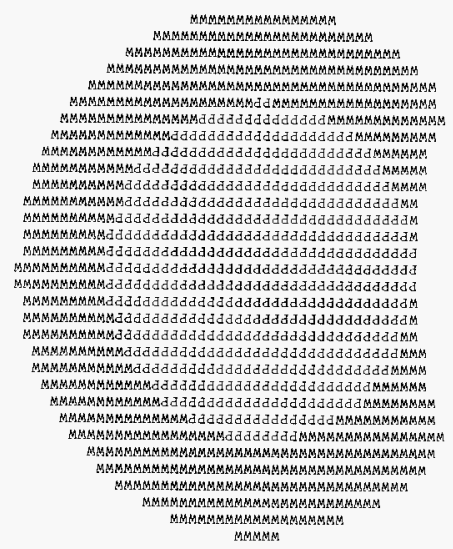

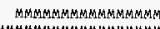

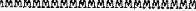

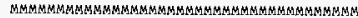

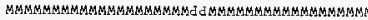
MMM

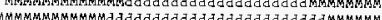
M⿻上丨mM

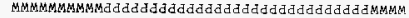
MHMMMMMMMMAd ddaddd

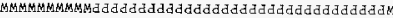

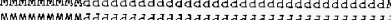

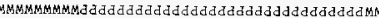

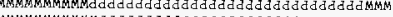
MMMM W M MMM MM MMMMM MMP МмМ М

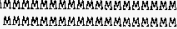
MMMMA

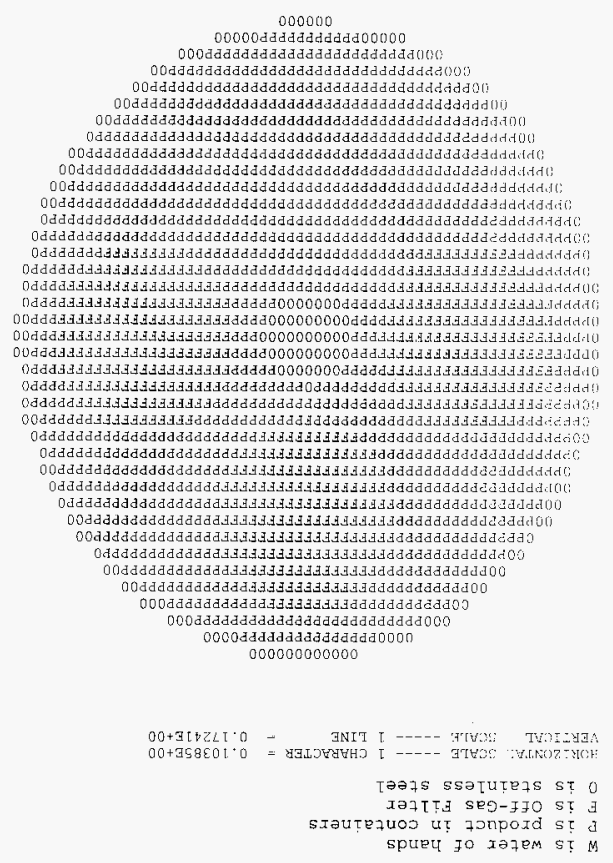

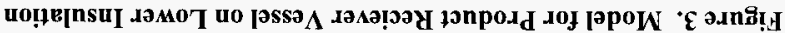


Geiger, J. L., 1995b, CSER 95-005 Addendum I Stainless Steel Insulation, WHC-SD-SQA-CSA20404, Rev. 0, Westinghouse Hanford Company, Richland, Washington.

Hammelman, J. E., 1974, Z Plant Sprinkler System Criticality Safety Analysis Report, ARH2406, Rev. 0, Atlantic Richfield Hanford Company, Richland, Washington.

Lehmkuhl, G. D., 1974, Criticality Drain Performance Study, RFP-2222, Dow Chemical U.S.A., Golden, Colorado.

LMI, 1996, Series 67 Metering Pumps: Instructions, Maintenance, Service, Liquid Metronics Division of Milton Leroy, Acton, Massachusetts.

Macklin, L. L., and E. M. Miller, 1992, CCVR 91-001; MONK6A Pu Validation, WHC-SDSQA-CSWD-20015, Rev. 0, Westinghouse Hanford Company, Richland, Washington.

Miller, E. M., 1994a, CCVR 94-001; MONK6B Pu Validation, WHC-SD-SQA-CSWD-20019, Westinghouse Hanford Company, Richland, Washington.

Miller, E. M., 1994b, CCVR 94-002; MONK6B - Software Quality Assurance Plan, WHC-SDSQA-CSWD-20017, Westinghouse Hanford Company, Richland, Washington.

Miller, E. M., 1997a, personal communication of E. M. Miller with G. S. Barney on May 2, 1997.

Miller, E. M., 1997b, personal communication of E. M. Miller with J. F. Durnil on June 5, 1997.

Stubbs, A.M., 1997, Calcination of Plutonium Nitrate Solution, Plutonium Finishing Plant Process Flow Document PFD-Z-300-001, Rev/Mod A-0, B \& W Company, Richland, Washington.

Wittekind, W. D., 1997, PFP Vertical Calciner Shield Wall Dose Rate Calculations Using $M C N P$, HNF-SD-CP-TI-218, Rev. 0, Fluor Daniel Northwest, Inc., Richland, Washington. 
HNF-SD-SQA-CSA-529, Rev. 0

APPENDIX A. INDEPENDENT REVIEW 
E. M. Miller of the Criticality and Shielding group carried out an independent, technical review of CSER 97-004, for which the following comments were provided.

The CSER 97-004 found that the production denitration calciner glovebox has a $\mathrm{k}_{\mathrm{eff}}$ of about 0.74 in a normal operating configuration with no hands in the glovebox. The $\mathrm{k}_{\mathrm{eff}}$ is this low because the plutonium oxide product is dry and the feed solution is in geometrically favorable tanks. Increasing reflection to the calciner, to product receiver containers, or to the 6inch tanks can substantially increase the reactivity of the glovebox. ARH-600 shows that for the plutonium density allowed in the tank solids, $2 \mathrm{~g} \mathrm{Pu} / \mathrm{l}$, mixed with water in the 6 -inch tanks, that the tanks are substantially subcritical with no reflection, but critical with full reflection even with $5 \% \mathrm{Pu}-240$. The nitrate, limited height of solids allowed, the difficulty of getting solids of $2 \mathrm{~g}$ $\mathrm{Pu} / \mathrm{l}$, and the difficulty in getting full water reflection make such an arrangement incredible, but the point is that operators should be aware that the addition of neutron reflecting materials, water of hands, polyethylene neutron shielding, or dense materials like lead or concrete should not be placed next to fissile material concentrations such as the feed tanks or product receiver containers.

The product receiver containers with dry product are safe even with the contingency of three product receiver containers adjacent with full water reflection. However, if water were to be added to wet the plutonium product in the product receiver containers, three containers with water or lead reflection may be critical per curves in ARH-600. Groupings of product receiver containers represent the largest possible concentration of fissile material in the calciner glovebox. Great care and thought needs to go into handling these containers.

This CSER has modelled the calciner conservatively. The calciner has a stirrer with a transition cone between stirring shaft and the top of the stirrer dome. The cone was not included in the calciner model in this CSER. So in cases of calcine and solution filling the calciner, a full diameter space above the stirring dome has fissile material where the actual calciner has a transition cone occupying the center of the space. This is the largest contiguous space for calcine inside the calciner model. Also, the absorbent lower insulation on the calciner is not as thick as modeled in the laboratory or production calciner. It is only about 4 inches thick. Because it is not as thick as modelled, it would not present as great a problem as was found for the thick models of the insulation when soaked with feed solution or as a reflector when modelled saturated with water.

The analysis of the calciner glovebox is conservative and shows that there are not any changes that raise reactivity rapidly. However, several limits need to be monitored and the results of actions understood. The density of the product needs to be monitored, spills of feed solution or product other than on the floor need to be cleaned up immediately, and the introduction of reflectors or moderators is to be prevented. Operators need to recognize that putting gloved hands around the product receiver containers increases its reactivity so that they will not circle more than one product container with hands and arms.

All $k_{\text {eff }}$ results were confirmed and three MONK runs were examined in detail and found to conservatively represent the system being analyzed. The input data for materials and dimensions were checked and found to be correct or conservative. The glass of the 6-inch tanks was not included in the glovebox model which is conservative as the boron in the glass is an 
effective neutron absorber. The lack of glass would increase interaction while the effect of reflection by the glass would not be significant in comparison. The formula worksheets were checked and the calculation of $\mathrm{H} / \mathrm{Pu}$ was corrected and revised $\mathrm{H} / \mathrm{Pu}$ results included in the CSER. The dimensions of the off-gas filters, lower insulation, criticality drain, and calciner were revised or had uncertainties, but they were treated conservatively. Although many calculations were done with incorrect off-gas filter inside diameters, the actual dimensions of the off-gas filters were used where it would be significant, when the filters were flooded by feed solution.

The review of the CSER found that it covered all credible contingencies and showed that the system was within allowable limits and that there was sufficient margin of safety to have contingencies without being easily brought above allowables or to approach criticality. An example is that the allowable product density is limited to $5.5 \mathrm{~g} \mathrm{Pu} / \ell$, but many of the analyses used higher densities and the results were within allowables. Although this variable needs to be monitored carefully, even with this parameter above its limit exceeding the allowable $k_{\text {eff }}$ requires flooding the calciner filled with calcine with feed solution and also saturating the surrounding lower insulation with water. This is an extreme condition that includes the contingencies of a calciner filled with calcine, flooding the inside of the calciner with feed solution, and saturating the lower insulation outside the calciner with water.

The technical arguments for qualifying the criticality safety of the calciner glovebox were found to be sound. The report incorporates suggested changes and expansions made by the reviewer. 


\title{
CHECKLIST FOR INDEPENDENT REVIEW
}

Document Reviewed: $\quad$ HNF-SD-SOA-CSA-529, Rev. 0. CSER 97-004: PFP

Author:

\section{Production Denitration Calciner System}

Karl E. Hillesland

\begin{abstract}
Yes No $\underline{N / A}$
$[X] \quad[] \quad[]$

$[X] \quad[] \quad[]$

$[x] \quad[] \quad[]$

Problem completely defined.

Necessary assumptions explicitly stated and supported.

Computer codes and data files documented.

$[x][] \quad[]$

Data checked for consistency with original source information as applicable.

[X] [ ] [ ] Mathematical derivations checked including dimensional consistency of results.

[X] [ ] [ ] Models appropriate and used within range of validity or use outside range of established validity justified.

$[X] \quad[] \quad[]$ Hand calculations checked for errors.

$[X][] \quad[]$ Code run streams correct and consistent with analysis documentation.

$[X][] \quad[] \quad$ Code output consistent with input and with results reported in analysis documentation.

[X] [ ] [ ] Acceptability limits on analytical results applicable and supported. Limits checked against sources.

[X] [ ] [ ] Safety margins consistent with good engineering practices.

[X] [ ] [ ] Conclusions consistent with analytical results and applicable limits.

[X] [ ] [ ] Results and conclusions address all points required in the problem statement.

[X] [ ] [ ] Have all reasonable accidents been considered?

$[X]$ [ ] [ ] Has low density water (steam) been evaluated as a moderator?

$[X][] \quad[]$ Is the fuel and other hardware composition correct?

[X] [ ] [ ] Are the cases considered conservative? Too conservative?

$[X][][] \quad$ Do the computer models adequately reflect the actual geometry? Have cross sectional cuts of the geometry been made and do they show the desired geometry?

[X] [ ] [ ] Has the analysis been reviewed by Safety? This may not be required in a preliminary design.

[X] [ ] [ ] Has the reviewer completed the Criticality Safety Course for Managers and Engineers?

Date completed $5 / 21 / 97$
\end{abstract}

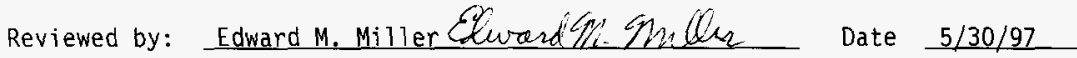

NOTE: Any hand calculations, notes, or summaries generated as part of this review should be signed, dated, and attached to this checklist. Materials should be labeled and recorded so that it is intelligible to a technically-qualified third party. 
HNF-SD-SQA-CSA-529, Rev, 0

APPENDIX B. MONK VALIDATION 


\section{Validation Procedure}

The validation of the method used in the analysis consists of testing the ability of the code and neutron cross-sections in calculation of known critical configurations, which are various benchmark experiments with the fissile material in question. Such analyses determine a calculational bias (the deviation of calculated $\mathrm{k}_{\text {eff }}$ from unity for the benchmark cases) and the uncertainties culminating from the experimental and calculational errors.

The safety criteria for future calculations on undetermined systems requires that the biasadjusted $\mathrm{k}_{\text {eff }}$ does not exceed 0.95 at the $95 \%$ confidence interval. This is expressed by the following formula;

$$
k_{\text {eff }}=k_{\text {calc }}-\text { bias }+\left(U_{b}^{2}+U_{c}^{2}\right)^{\frac{1}{2}} \leq 0.95
$$

where: $\quad \mathrm{k}_{\mathrm{calc}}=\mathrm{k}$ value given by the calculation of the system

bias $=$ mean difference $\left(\mathrm{k}_{\text {calc }}-1.0\right)$ for benchmark criticals

$\mathrm{U}_{\mathrm{b}}=95 \%$ confidence level uncertainty in bias determination

$\mathrm{U}_{\mathrm{c}}=95 \%$ confidence level uncertainty in new calculation.

Thus, the bias-adjusted $\mathrm{k}_{\text {eff }}$ includes the statistical uncertainties.

\section{Generic Validation of Plutonium Systems}

A report by L. L. Macklin and E. M. Miller (1992) presents the results of calculations to determine a generic bias for plutonium configurations, as encountered in the Plutonium Finishing Plant. Seventy benchmark experiments were calculated, ranging from simple metal spheres to highly diluted ( $9 \mathrm{~g}$ plutonium per liter) plutonium nitrate solution spheres, and compacts of $\mathrm{PuO}_{2}$ blended with polystyrene. A mean $\mathrm{k}_{\mathrm{eff}}$ value of 1.0047 was determined over the full experimental range, with an average standard deviation of 0.0097 .

The direct calculational bias is thus +0.0047 (average $\mathrm{k}_{\mathrm{eff}}$ greater than unity). Accounting for the uncertainties using tolerance limit analysis, the report then concludes that

At least $95 \%$ of all critical experiments of this type computed by the MONK6A code will produce calculated $\mathrm{k}_{\text {eff }}$ values greater than 0.9857 with $95 \%$ confidence.

For a standard deviation ( $\sigma$ ) of 0.01 or less for the convergence of a future calculation $\left(\mathrm{U}_{\mathrm{c}}\right)$, the 0.9857 value is lowered to 0.9855 . Rounded conservatively, a value of +0.015 can be used for [ -bias $+\left(\mathrm{U}^{2}{ }_{\mathrm{b}}-\mathrm{U}^{2}{ }_{\mathrm{c}}\right)^{1 / 2}$ ]. On this basis, it is determined that the true $\mathrm{k}_{\mathrm{eff}}$ of an analyzed configuration with plutonium will not exceed 0.95 with a $95 \%$ confidence level if the calculated value $\left(k_{\text {calc }}, \sigma \leq 0.01\right)$ is limited to a maximum of 0.935 .

The $95 \%$ confidence level on $99.9 \%$ of the data is 0.9699 . So a subcritical margin of $5 \%$ is $3.5 \%$ larger than the uncertainties between the $95.0 \%$ and the $99.9 \%$ coverage of the benchmark data. 


\section{Validation of MONK6B}

The validation of MONK6B code on the SUN microcomputer was documented in Miller (1994a). The essence of the validation was cross-correlation of calculational results obtained with this code version and computer with results for identical model input done on a CRAY machine with MONK6A. Also, the equivalence of MONK6A and MONK6B was well documented by the vendor in the verification package shipped with the software.

\section{$\underline{\text { References }}$}

Macklin, L. L., and E. M. Miller, 1992, CCVR 91-001; MONK6A Pu Validation, WHC-SDSQA-CSWD-20015, Rev. 0, Westinghouse Hanford Company, Richland, Washington.

Miller, E. M., 1994a, CCVR 94-001; MONK6B Pu Validation, WHC-SD-SQA-CSWD-20019, Westinghouse Hanford Company, Richland, Washington.

Miller, E. M., 1994b, CCVR 94-002; MONK6B - Software Quality Assurance Plan, WHC-SDSQA-CSWD-20017, Westinghouse Hanford Company, Richland, Washington. 
HNF-SD-SQA-CSA-529, Rev. 0

APPENDIX C. WORKBOOK FOR CALCULATION OF MATERIAL COMPOSITIONS 
HNF-SD-SQA-CSA-529, Rev. 0

\section{Plutonium Oxide Composition Worksheet}

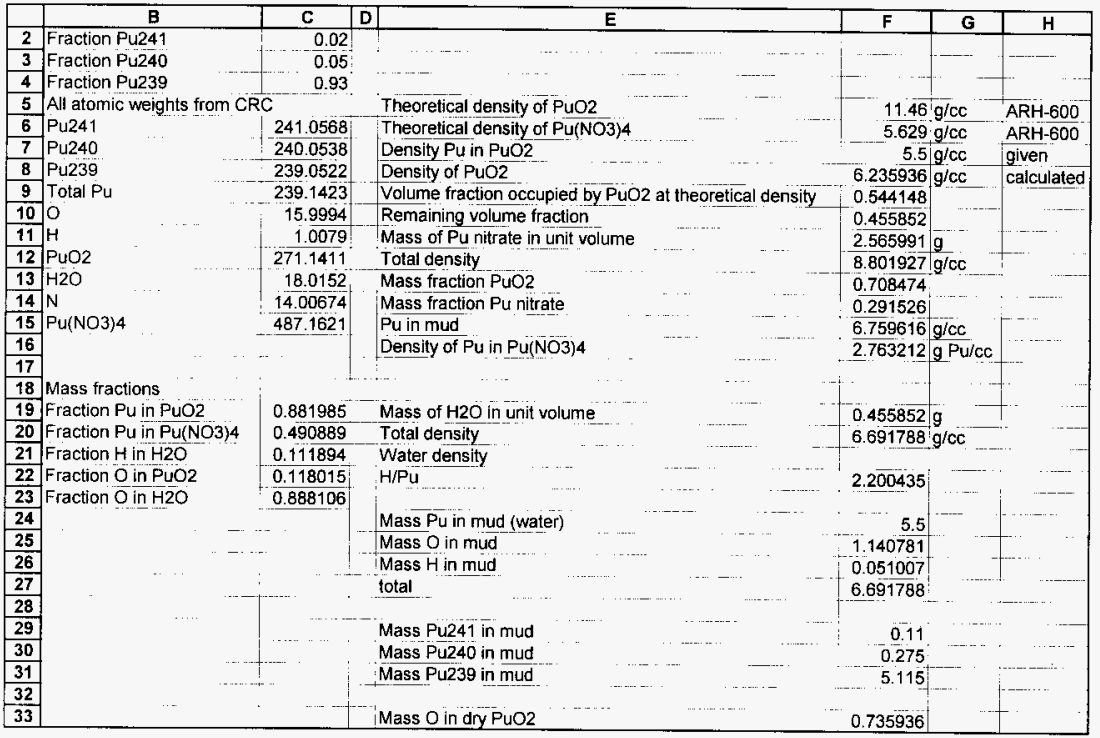

\begin{tabular}{|c|c|c|c|c|c|}
\hline & & 1 & $\mathrm{~J}$ & $\mathbf{K}$ & $L$ \\
\hline 7 & Density $\mathrm{Pu}$ in $\mathrm{PuO} 2$ & & 6 & & \\
\hline 8 & Density of PLO2 & & 6.802839 & 4.535226 & 2.267613 \\
\hline 9 & Volume fraction occupied & by PuO2 at theoretical density & $0 . \overline{593616}$ & 0.395744 & 0.197872 \\
\hline 10 & Remaining volume fraction & & 0.406384 & 0.604256 & 0.802128 \\
\hline 11 & 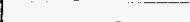 & & & & \\
\hline 12 & & $\ldots$ & & & \\
\hline$\frac{13}{14}$ & & $\cdots+\cdots$ & & & \\
\hline 15 & & & & & \\
\hline 16 & & . & & & \\
\hline 17 & & $\ldots$ & & & \\
\hline 18 & & …….... & $\cdots$ & & \\
\hline 19 & Mass of $\mathrm{H} 2 \mathrm{O}$ in unit volum & & 0.2 & 0.604256 & 0.802128 \\
\hline$\frac{20}{21}$ & Total density & & 7.002839 & 5.139482 & 3. 069741 \\
\hline 22 & HiPu & ......- & 0.884965 & 4.010591 & 10.64783 \\
\hline 23 & & & & & \\
\hline 24 & Mass Pu in mud (water) & & 6 & & \\
\hline 25 & Mass $O$ in mud & & 0.98046 & 1.071869 & $0 . \overline{979987}$ \\
\hline 26 & Mass $\mathrm{H}$ in mud & & 0.022379 & 0.067613 & 0.089754 \\
\hline 27 & & $\ldots \ldots$ & & -.......... & \\
\hline 28 & & & & & \\
\hline 29 & Mass Pu241 in mud & & 0.12 & 0.08 & 0.04 \\
\hline 30 & Mass Pu240 & & 0.3 & 0.2 & 0.1 \\
\hline 31 & Mass $\mathrm{P} 4239$ in mud & & 5.58 & 3.72 & 1.86 \\
\hline
\end{tabular}


HNF-SD-SQA-CSA-529, Rev. 0

Plutonium Oxide Composition Worksheet (Formulas)

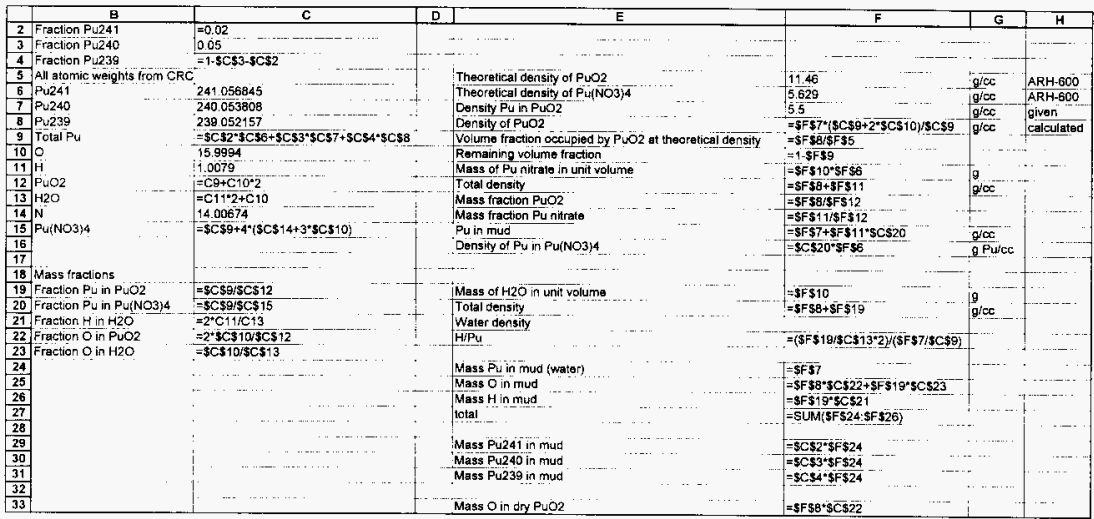

\begin{tabular}{|c|c|c|c|c|}
\hline & I & $J$ & $\mathbf{K}$ & $\mathbf{L}$ \\
\hline 7 & Density $\mathrm{Pu}$ in $\mathrm{PuO} 2$ & $6 \ldots$ & 4 & 2 \\
\hline B & Density of PuO2 & $=j \$ 7^{*}(\$ C \$ 9+2 * \$ C \$ 10) / \$ \operatorname{cs} \$$ & $=K \$ 7^{n}\left(\$ C \$ 9+2^{*} \$ C \$ 10\right) / \$ C \$ 9$ & $\Rightarrow L \$ 7^{*}(\$ C \$ 9+2 * \$ C \$ 10) / S C \$ 9$ \\
\hline 9 & Volume fraction occupied by PuO2 at theoretical density & $=J \$ 8 / \$ F \$ 5$ & $=K \$ 8 / \$ F \$ 5$ & $=$ L\$8I\$F\$5 \\
\hline$\frac{10}{11}$ & Remaining volume fraction & $=1-1 \$ 9$ & $=1-\mathrm{K} \$ 9$ & $=1-\operatorname{LS} 9$ \\
\hline 12 & 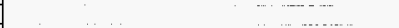 & - & 1. & 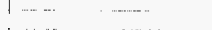 \\
\hline 13 & & $\ldots \ldots$ & .. .. & $\begin{array}{cc}\cdots & \cdots \\
1 & -\cdots\end{array}$ \\
\hline 15 & $-\cdots+\cdots$ & $\cdots$ & $-\ldots \ldots \ldots$ & $\ldots$. \\
\hline 16 & & & $\cdots \cdots$ & …... \\
\hline 17 & & & $\begin{array}{lll}\cdots & \cdots & \cdots\end{array}$ & 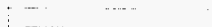 \\
\hline$\frac{18}{19}$ & Mass of $\mathrm{H} 2 \mathrm{O}$ in unit voiume & & $=K 10$ & $-\cdots$ \\
\hline 20 & Total density & $=J \$ B+J \$ 19$ & $=K \$ 8+K \$ 19$ & $\begin{array}{l}=L 10 \\
=L \$ 8+L \$ 19\end{array}$ \\
\hline 21 & & & & \\
\hline 22 & $\mathrm{H} / \mathrm{Fu}$ & $=\left(J \$ 19 / \$ \mathrm{C} \$ 13^{*} 2\right) /(\mathrm{J} \$ 7 / \$ \mathrm{C} \$ 9)$ & $=(K \$ 19 / \$ C \$ 13 * 2) /(K \$ 7 / \$ C \$ 9)$ & $=\left(\operatorname{L} \$ 19 / \$ \operatorname{Cs} 13^{*} 2\right) /(\operatorname{L} \$ 7 / \$ C \$ 9)$ \\
\hline 23 & 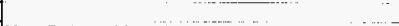 & & & \\
\hline 24 & Mass Pu in mud (water) & $=\mathrm{J} \$ 7$ & $=K \$ 7$ & $=$ L\$7 \\
\hline 25 & Mass $O$ in mud & $=J \$ 8 * \$ C \$ 22+J \$ 19^{*} \$ C \$ 23$ & $=K \$ 8^{*} \$ C \$ 22+K \$ 19^{*} \$ C \$ 23$ & $=L \$ 8 * \$ C \$ 22+\mathrm{L} \$ 19+\$ C \$ 23$ \\
\hline 26 & Mass $\mathrm{H}$ in mud & $=\sqrt{\$ 19^{*} \$ C \$ 21}$ & $=K \$ 19 * \$ C \$ 21$ & $=L \$ 19^{*} \$ C \$ 21$ \\
\hline $\begin{array}{l}27 \\
28\end{array}$ & (n)............... & - & ( . ...... & i \\
\hline 29 & Mass Pu241 in mud & $=\$ C \$ 2 * J \$ 24$ & $=\$ C \$ 2^{\circ} \mathrm{K} \$ 24$ & $=\$ \operatorname{Cs} \overline{2 *} L \$ 24$ \\
\hline 30 & Mass Pu240 in mud & $=\$ C \$ 3^{*} \mathrm{~J} \$ 24$ & $=\$ C \$ 3^{*} \mathrm{~K} \$ 24$ & $=\$ \operatorname{Co} \$ 3^{*} L \$ 24$ \\
\hline 31 & Mass Pu239 in mud & $=\$ C \$ 4^{*} J \$ 24$ & $=\$ C \$ 4^{*} \mathrm{~K} \$ 24$ & $=\$ C \$ 4^{*} \operatorname{L24}$ \\
\hline
\end{tabular}




\section{HNF-SD-SQA-CSA-529, Rev. 0}

\section{Nitrate Composition Worksheet}

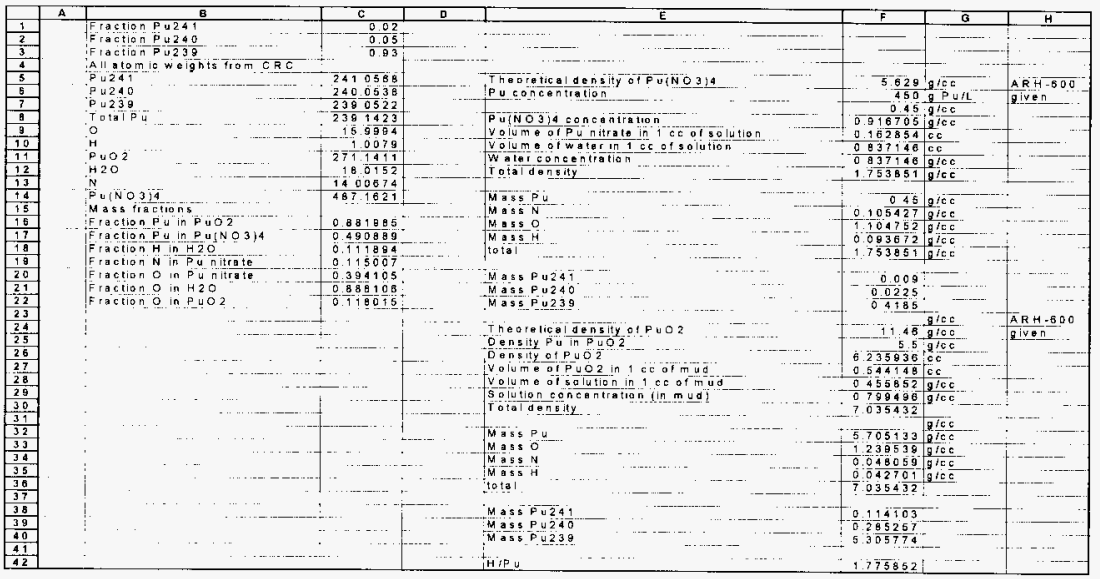

Nitrate Composition Worksheet (Formulas)

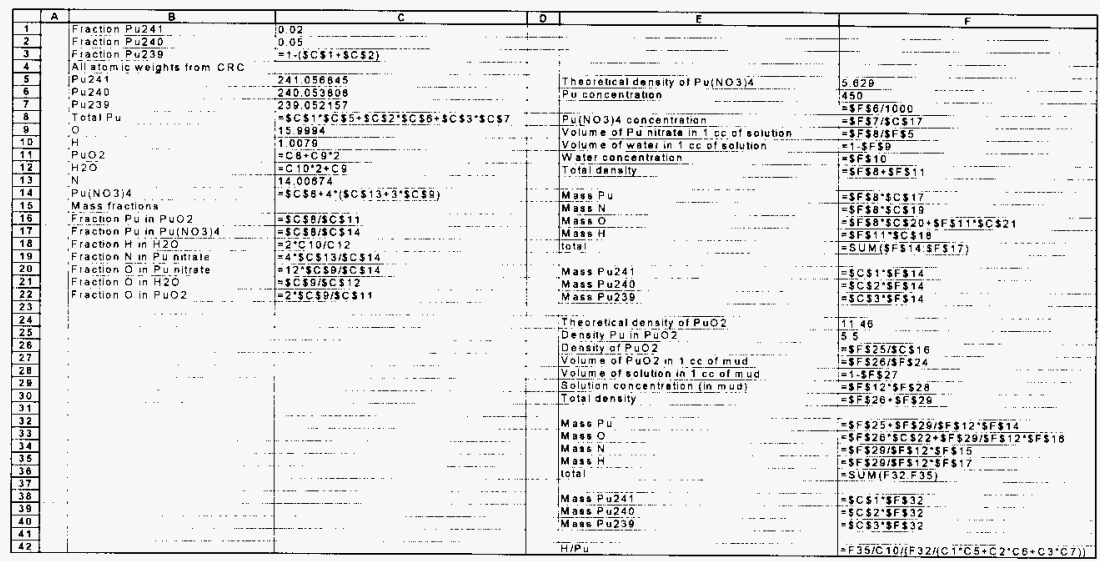


HNF-SD-SQA-CSA-529, Rev. 0

Plutonium Solution Composition Worksheet

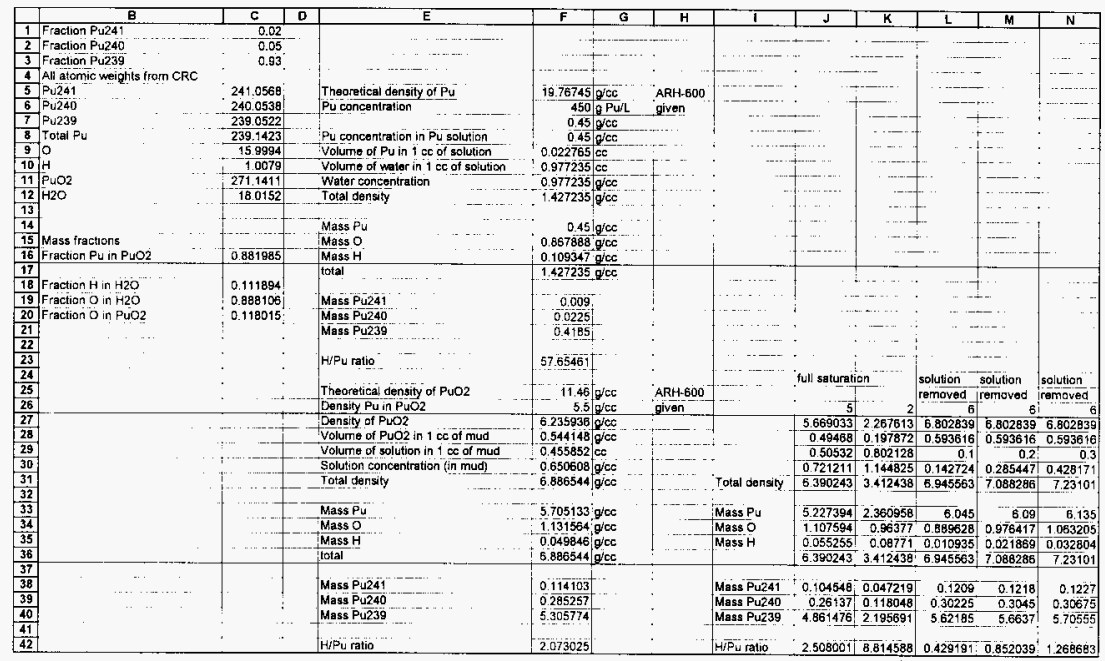


HNF-SD-SQA-CSA-529, Rev. 0

Plutonium Solution Composition Worksheet (Formulas)

\begin{tabular}{|c|c|c|c|c|}
\hline & B & $\mathbf{C}$ & E & $\mathbf{F}$ \\
\hline 1 & Fraction Pu241 & 0.02 & & \\
\hline 2 & Fraction Pu 240 & 005 & $x_{-}$ & (-) \\
\hline 3 & Fraction Pu239 & $=1-(\$ C \$ 1+\$ C \$ 2)$ & {$\left[\begin{array}{lll}-2 & -1\end{array}\right.$} & (n- \\
\hline 4 & All atomic weights from $C R C$. & & & \\
\hline 5 & Pu241 & 241.056845 & Theoretical density of $\mathrm{Pu}$ & $=19.76 / 5 \operatorname{cs} 7 * \$ \operatorname{cs} 8$ \\
\hline 6 & $\mathrm{Pu} 240$ & 240.053808 & Fu concentration & 450 \\
\hline 7 & Pu239 & 239.052157 & & $=\$ F \$ 6 / 1000^{\circ}$ \\
\hline 8 & TTotal Pu & $=\$ C \$ 1^{*} \$ C \$ 5+\$ C \$ 2 * \$ C \$ 6+\$ C \$ 3^{*} \$ C \$ 7$ & Pu concentration in Pu solution & $=\dot{F} \overline{7}$ \\
\hline 9 & & 15.9994 & Volume of Pu in $1 \mathrm{cc}$ of solution & $i=\$ F \$ 8 / \$ F \$ 5$ \\
\hline 10 & & 1.0079 & Volume of water in $1 \overline{c c}$ of solution & $=1 . \$ F \$ 9$ \\
\hline 11 & $\mathrm{PuO} 2$ & $=c 8+\cos ^{2}$ & Water concentration & $=\$ F \$ 10$ \\
\hline 12 & $\mathrm{H} 2 \mathrm{O}$ & $i=c 10^{*} 2+C 9$ & Total density & $=\$ F \$ B+\$ F \$ 11$ \\
\hline 13 & & & & \\
\hline 14 & & L. $-\mathrm{C}^{-}$ & Mass $P y$ & $=\$ F \$$ \\
\hline 15 & Mass fractions & & Mass 0 & $=\$ F \$ 11 \% \mathrm{CS} 19$ \\
\hline 16 & Fraction $\mathrm{Pu}$ in $\mathrm{PuO} 2$ & $=\$ C \$ B / \$ C \$ 11$ & Mass $H$ & $=\$ F \$ 11 . \$ C \$ 18$ \\
\hline 17 & & & total & $=\operatorname{SUM}(\$ F \$ 14: \$ F \$ 16)$ \\
\hline 18 & Fraction $\mathrm{H}$ in $\mathrm{H} 2 \mathrm{O}$ & $=2+\mathrm{C} 10 / \mathrm{C} 12$ & & \\
\hline 19 & Fraction $\mathrm{O}$ in $\mathrm{H} 2 \mathrm{O}$ & $=\$ \operatorname{c\$ } 9 / \$ C \$ 12$ & Mass P $\mathrm{P} 241$ & $=\$ C \$ 11^{\circ} \$ F \$ 14$ \\
\hline 20 & Fraction O in PuOz & $=2 \times \$ C \$ 9 / \$ C \$ 11$ & Mass Pu240 & $=\$ C \$ 2^{+} \$ F \$ 14$ \\
\hline 21 & & & Mass Pu239 & $=\$ C \$ 3 \times s F 14$ \\
\hline 22 & & {$[\ldots$} & & \\
\hline 23 &.$\quad \ldots \quad \cdots \cdots$ & & HIPu ratio & $=(\$ F \$ 16 / \$ C \$ 10)(0,46 / \$ C \$ 8)$ \\
\hline 24 & $\ldots$ & & & 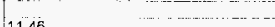 \\
\hline$\frac{25}{26}$ & $\cdots \cdots$ & & $\begin{array}{l}\text { Theoretical density of PuO2 } \\
\text { Density Pu in PuO2 }\end{array}$ & $-\quad-\quad$ \\
\hline 27 & & • & Density of PuO2 & $\begin{array}{l}5.5 \\
=\$ F \$ 26 / \$ C \$ 16\end{array}$ \\
\hline 28 & & ? & Volume of $\mathrm{PU} 02$ in $1 \mathrm{ce}$ of mud & $=\$ F \$ 27 / \$ F \$ 25$ \\
\hline 29 & & $\cdot$ & Volume of solution in 1 ce of mud & $=1-\$ F \$ 28$ \\
\hline 30 & & 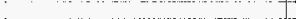 & Solution concentration (in mud) & $=\$ F \$ 12 * \$ F \$ 20$ \\
\hline 31 & & … & Total density. & $=\$ F \$ 27+\$ F \$ 30$ \\
\hline 32 & & . & & \\
\hline 33 & & $\ldots \ldots$ & Mass Pu & $=\$ F \$ 26+\$ F \$ 30 / \$ F \$ 12-\$ F \$ 14$ \\
\hline 34 & & (- & Mass o & $=\$ F \$ 27^{\prime} \$ C \$ 20+\$ F \$ 30 / \$ F \$ 12+\$ F \$ 15$ \\
\hline 35 & & & Mass H & $=\$ F \$ 30 / \$ F \$ 12 * \$ F \$ 16$ \\
\hline 36 & & $\ldots \ldots$ & total. & $=S \cup M(F 33: F 35)$ \\
\hline 37 & & & Mare & \\
\hline 38 & $\ldots$ & & Mass Pu241 & $=\$ C \$ 1+\$ F \$ 33$ \\
\hline 39 & & & Mass $P \cup 240$ & $=\$ C \$ 2 \times \$ F \$ 33$ \\
\hline 46 & & & Mass Pu239 & $=5 \mathrm{Cs} 3^{*} \mathrm{sFS} 33$ \\
\hline 41 & N..... & & & \\
\hline$\overline{42}$ & & & HiPu ratio & $=(\$ F \$ 35 / \$ C \$ 10) /(\$ F \$ 33 / \$ C \$ B)$ \\
\hline
\end{tabular}

\begin{tabular}{|c|c|c|c|c|c|c|}
\hline & I & $J$ & $\mathrm{~K}$ & L & M & $\mathbf{N}$ \\
\hline 24 & & full saturation & & solution & solution & solution \\
\hline$\frac{25}{26}$ & & & & 6 & removed & removed \\
\hline$\frac{20}{27}$ & & $-\mathrm{Js} 26 \operatorname{ses} 10^{-}$ & $=2 \pi 526 / 5 \operatorname{cs} 16^{\circ}$ & $=\frac{6}{=L 526 / 5 \operatorname{css} 15}$ & $\frac{6}{=M \$ 26 / \$ C \$ 16}$ & $\begin{array}{l}6 \\
=N \mathrm{~N} 526 / 5 \mathrm{C} \$ 16\end{array}$ \\
\hline$\frac{29}{29}$ & & $\begin{array}{l}=\mathrm{J} S 27 / 5 F \$ 25 \\
=1 . \mathrm{J} S 28\end{array}$ & $\begin{array}{l}=K \$ 27 / \$ \$ \$ 25 \\
=1-K \$ 28\end{array}$ & $=0.15$ & $=M \$ 27 / \$ F \$ 26$ & $\begin{array}{l}=N \$ 27 / S F \$ 25 \\
0.3\end{array}$ \\
\hline 30 & & $=5 F \$ 12-\sqrt{329^{-}}$ & $=8 F \$ 12^{2} \mathrm{~K} \$ 29$ & $\$ F \$ 12-L \$ 29$ & 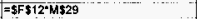 & $=\$ F \$ 12 N \$ 29$ \\
\hline 31 & Total densily. & $=4527+.1530$ & $=K \$ 27+K \$ 30$ & $=L \$ 27+L \$ 30$ & $=M-M 527+M \$ 30$ & $=\mathrm{N} \$ 27+\mathrm{N} \$ 30$ \\
\hline 33 & Mass Pu & $=J \$ 26+J 530^{\prime} \$ F 12 . \$ F \$ 14$ & $=\mathrm{k} \$ 2 \mathrm{z} \sigma \mathrm{K} \$ 30 / \$ \mathrm{~F} \$ 12^{*} \mathbf{5} \mathrm{F} \$ 14$ & $=\mathrm{L} \$ 26+\mathrm{L} \$ 30 / \$ \mathrm{SF} \$ 12^{*} \$ \mathrm{~F} \$ 14$ & $=M \$ 26+M \$ 30 / 5 F \$ 12 \$ \$ F 14$ & $=N \$ 26+N \$ 30, \$ F \$ 12 " \$ F \$$ \\
\hline 34 & Mass 0 & $=\sqrt{ } \$ 27+\$ C \$ 20+J \$ 30 / \$ F \$ 12 * \$ F \$ 15$ & $=K \$ 27-\$ C \$ 20+K \$ 30 / \$ F \$ 12 * \$ F \$ 15$ & $=L \$ 27 \times \$ C 520+L \$ 3015 F \$ 12^{2} \$ F \$ 15$ & $=M \$ 27 \$ C \$ 20+M \$ 30 / \$ F \$ 12-\$ F \$ 15$ & $1=N \$ 27$ 'SC $20+N \$ 30 / S F$ \\
\hline 35 & Mass H & $=J \$ 30 / \$ F \$ 12^{\circ} \mathbf{S F} \$ 16 \ldots \ldots$ & $\approx K \$ 30 / \$ F \$ 12+\$ F \$ 16$ & $=L \$ 30 / \$ F S 12+\$ F \$ 16$ & $=\dot{M} \$ 30 / \$ F \$ 12^{2} \$ F \$ 16$ & $=N \$ 30 / \$ F 512-\$ F \$ 16$ \\
\hline 36 & & :SSUM(J33:J36) & $=S U M(K 33: K 35)$ & $=$ SUM $(\mathbf{L 3} 3: \mathrm{L35})$ & $=5 \cup M(M 33: M 35)$ & $=S \operatorname{SOM}(\mathrm{N} 33: N(35)$ \\
\hline 37 & & & & & & \\
\hline 38 & Mass Pu241 & $=\$ C \$ 1 * 1533$ & $=\$ 0 \$ 1^{\circ} \mathrm{K} \$ 33$ & $=\$ C S 1-L \$ 3$ & & $=\$ C \$ 1+N \$ 33$ \\
\hline 39 & Mass Pu240 & $=\$ \operatorname{cs} 2^{\circ} \mathrm{J} s$ & $=\operatorname{scs} 2$ & $=\$ C$ & $=5 \operatorname{cs} 52 \mathrm{M} \$ 33$ & $=\$ \operatorname{cs} 2$ \\
\hline 40 & Mass Pu239 & $=\$ \operatorname{cs} 3.593$ & $=\$ \operatorname{Cs} \$ 3^{*} \mathrm{~K} \$ 33$ & $=5 \cos 3+2 \$ 33$ & $=5 \operatorname{css} 3^{\circ} 533$ & $=\operatorname{scs} 3^{*} \mathrm{~N} 533$ \\
\hline 41. & & & & & & \\
\hline $42 !$ & HJPu ratio & $\$ 10) /(\mathrm{J3} / \$ C \$ 8)$ & 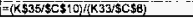 & 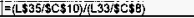 & $=(M-335 / s c=10)(M 33 / s c s a)$ & 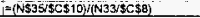 \\
\hline
\end{tabular}


HNF-SD-SQA-CSA-529, Rev. 0

\section{Soaked Lower Insulation Composition Worksheet}

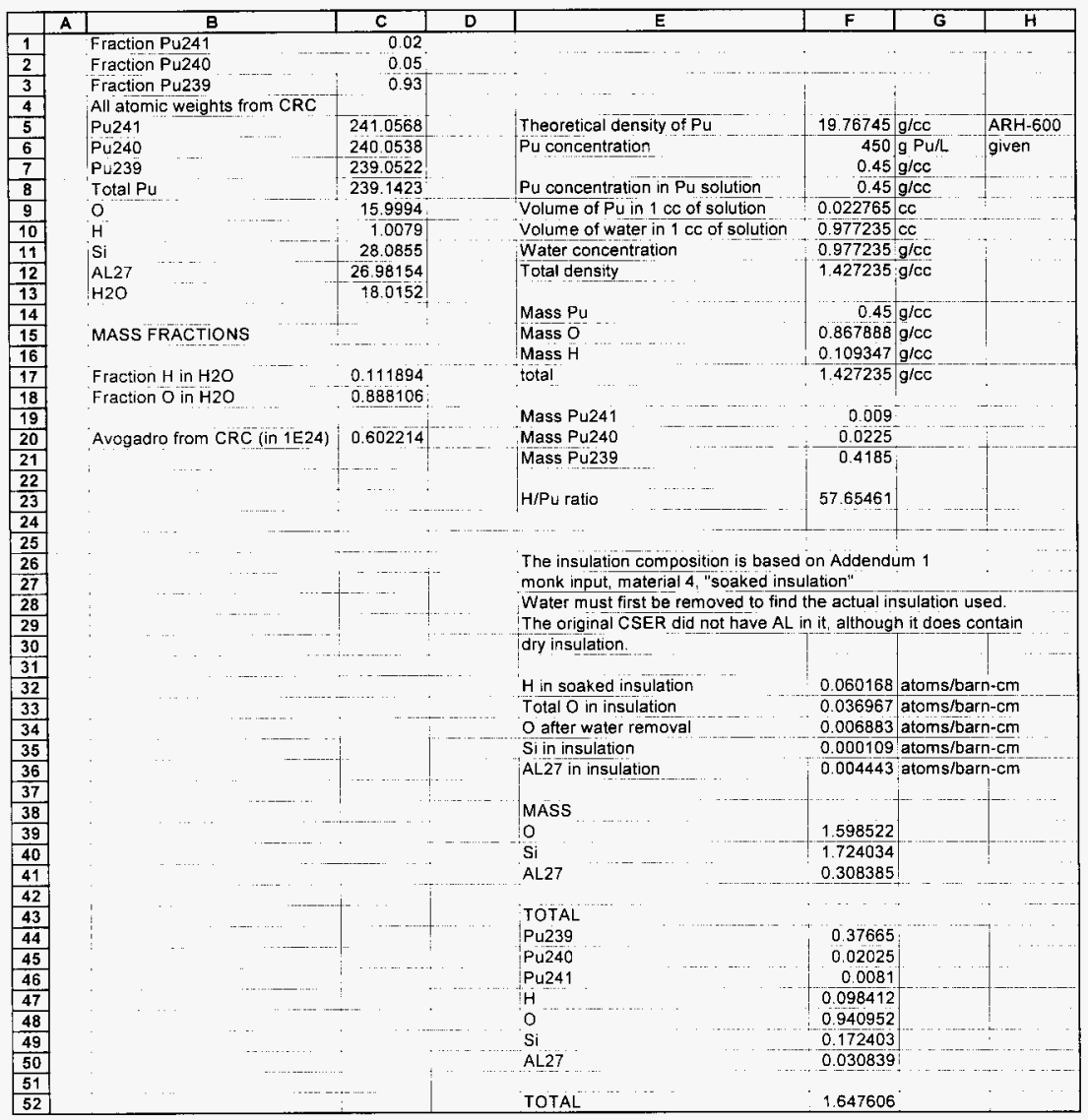


HNF-SD-SQA-CSA-529, Rev. 0

Soaked Lower Insulation Composition Worksheet (Formulas)

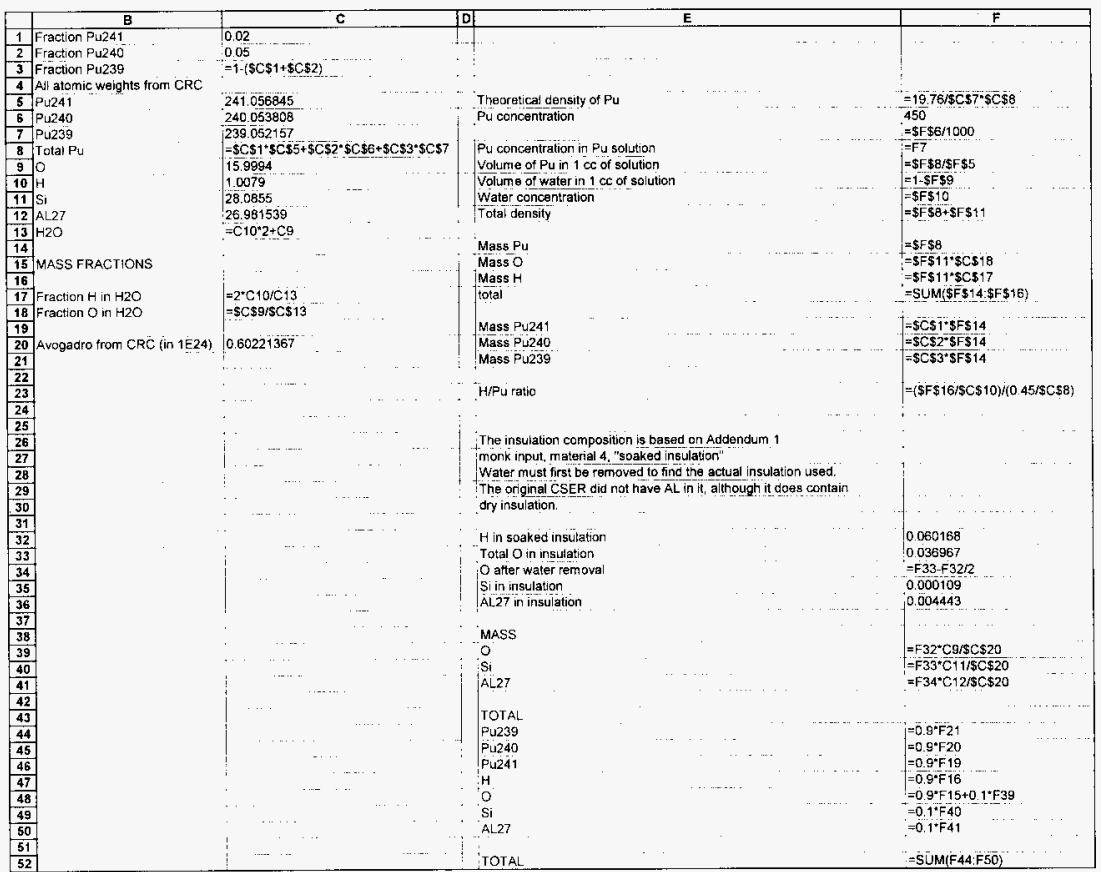


HNF-SD-SQA-CSA-529, Rev, 0

Upper Insulation Composition Worksheet

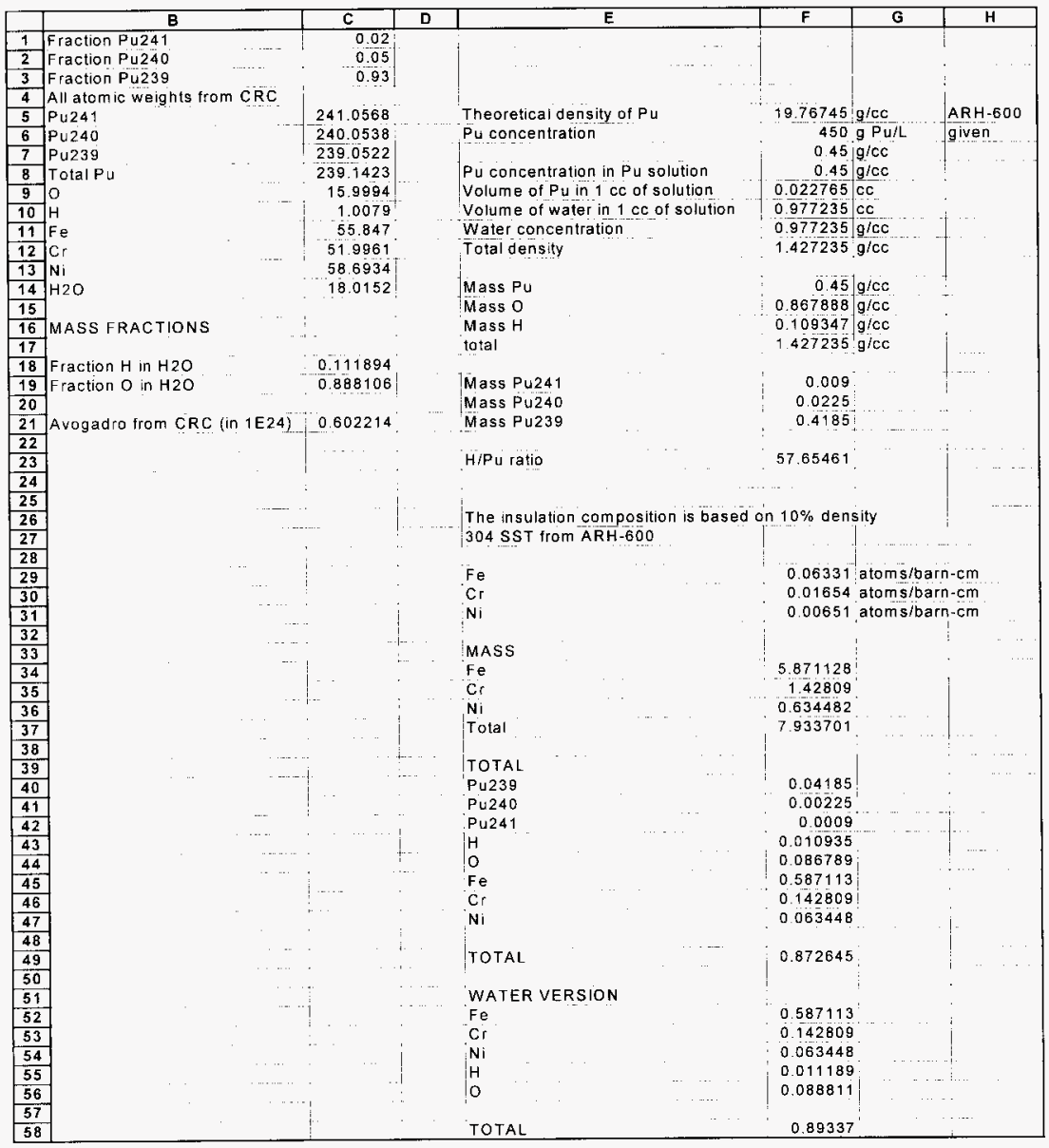


HNF-SD-SQA-CSA-529, Rev. 0

\section{Upper Insulation Composition Worksheet (Formulas)}

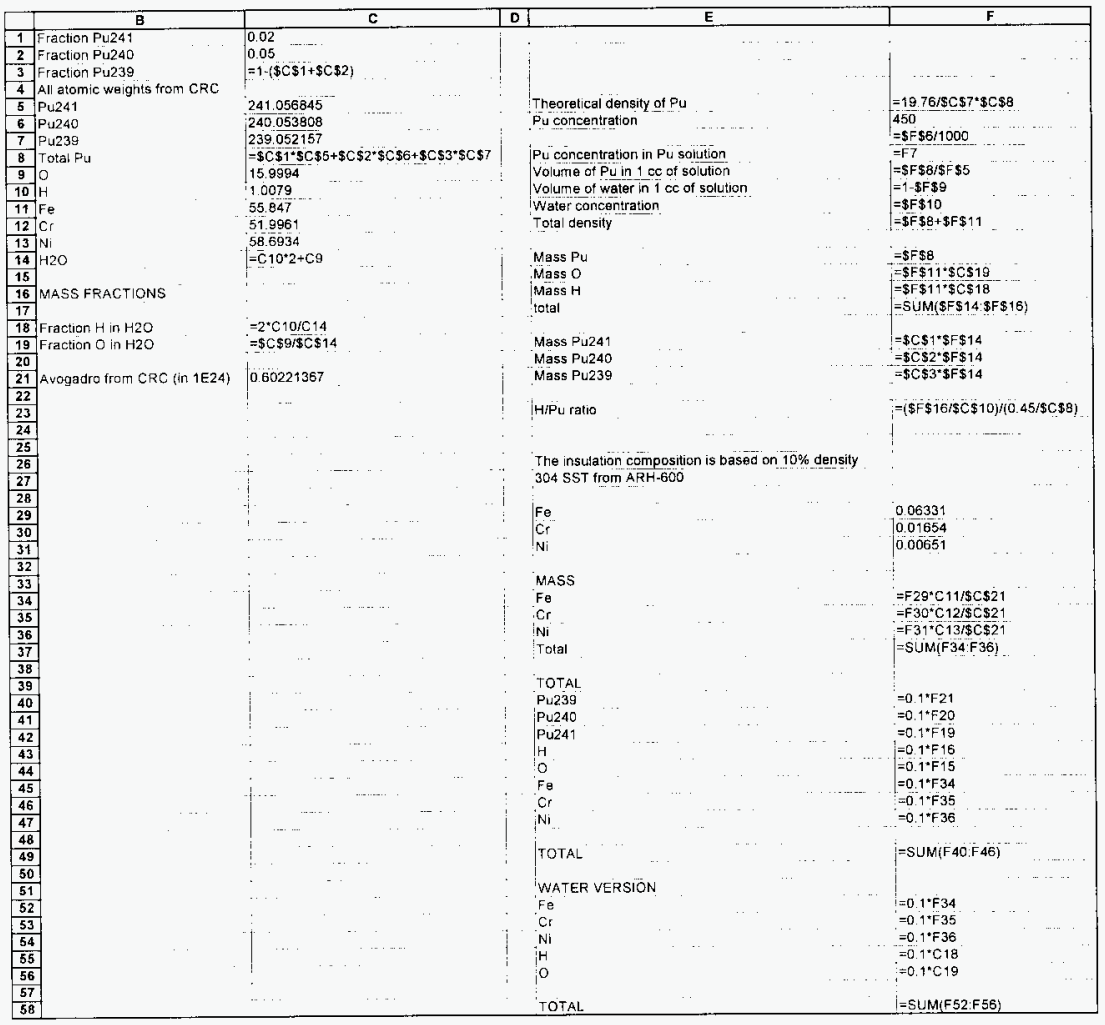


HNF-SD-SQA-CSA-529, Rev. 0

APPENDIX D. MONK INPUT FILES 


\section{HNF-SD-SQA-CSA-529, Rev. 0}

All monk input and output files are stored in CFS directory /w80395/crit in a UNIX*compressed and tarred format file called calciner.tar. An input filename is constructed from the case name followed by a "inp" extension. An output filename is constructed from a case name followed by a ".prt" extension. Included in this section are printouts of the more important input files (undert3, wmp2, int55dv5, waste).

*UNIX is a trademark licensed exclusively through Xopen Company Ltd. KN 


\section{HNF-SD-SQA-CSA-529, Rev. 0}

\section{undert3.inp}

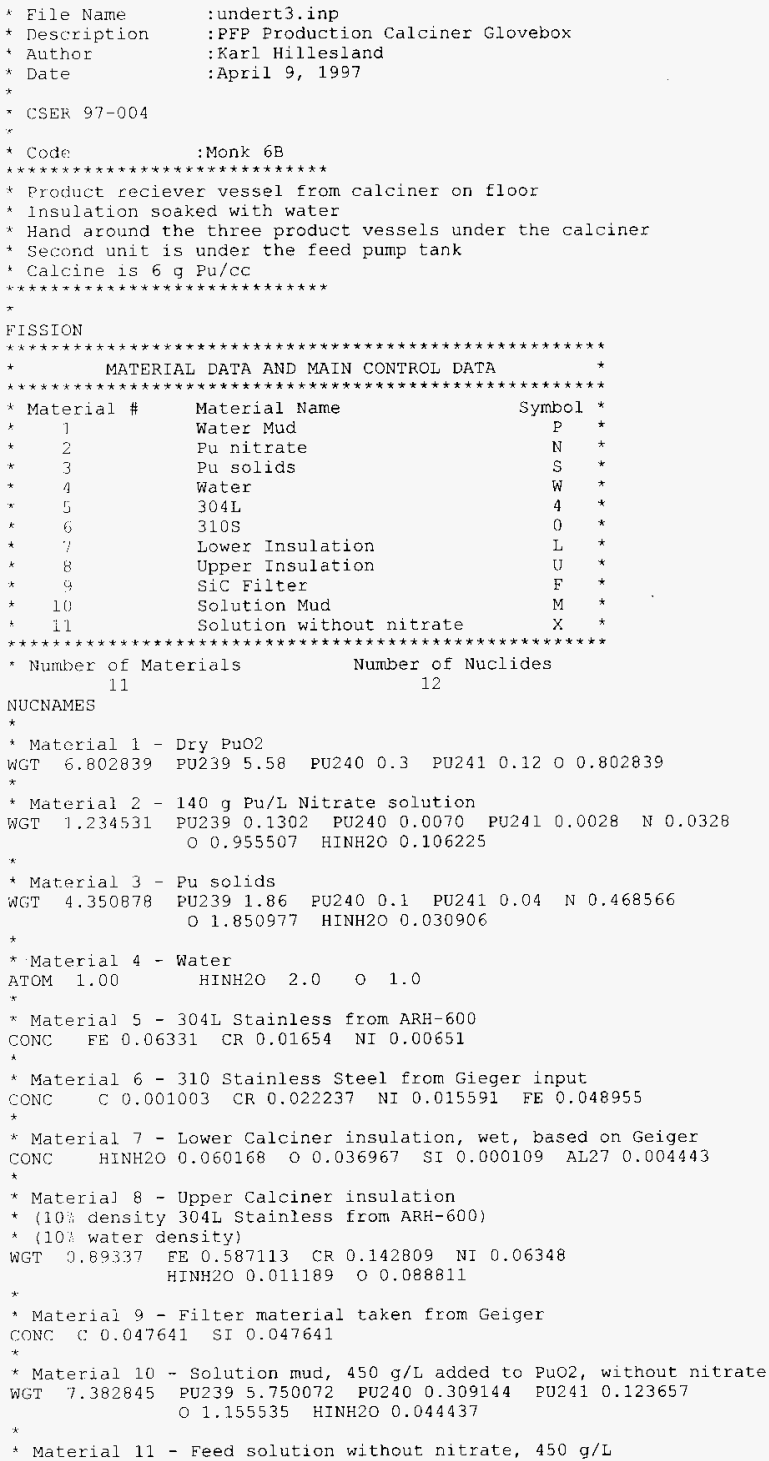


HNF-SD-SQA-CSA-529, Rev. 0

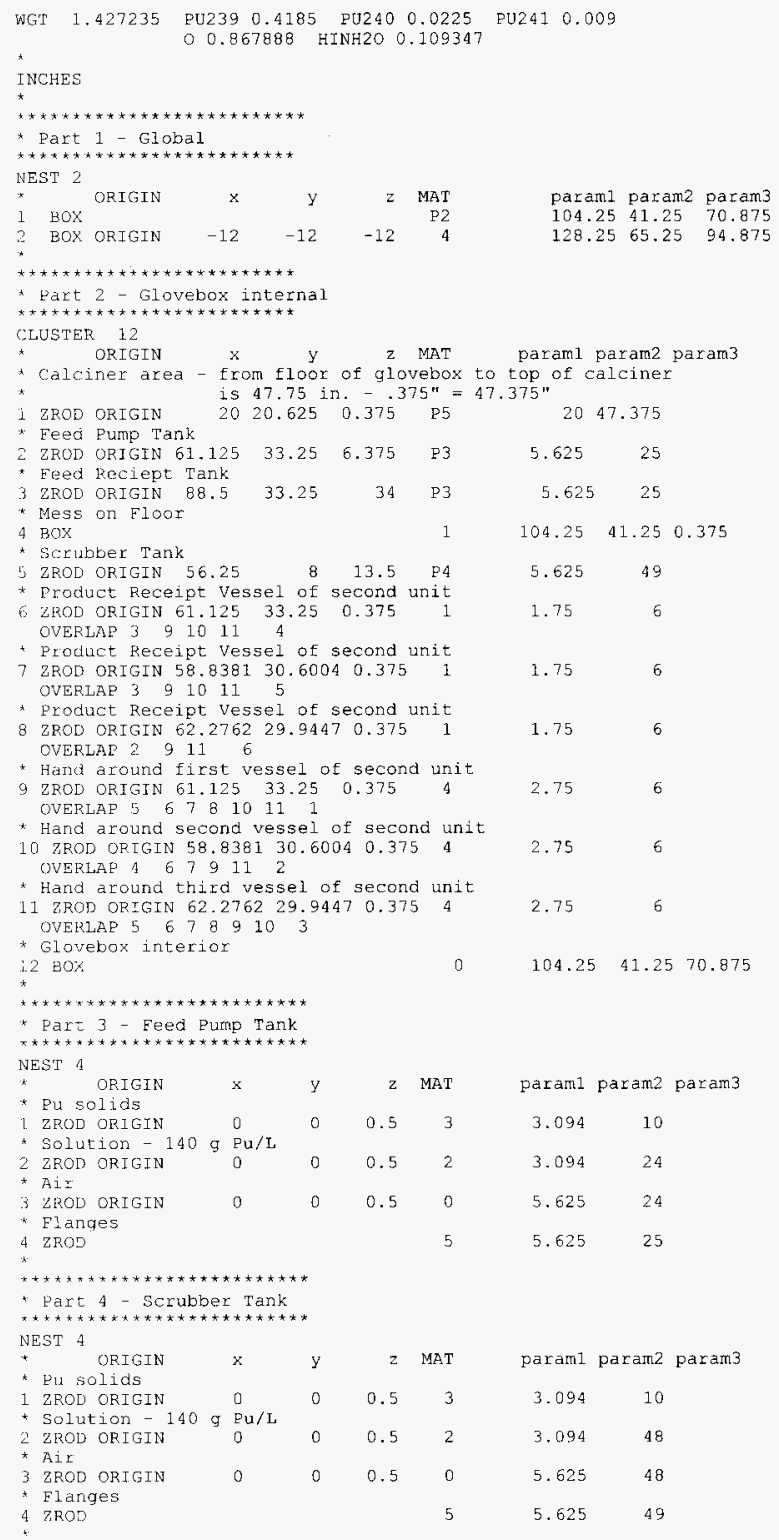




\section{HNF-SD-SQA-CSA-529, Rev. 0}

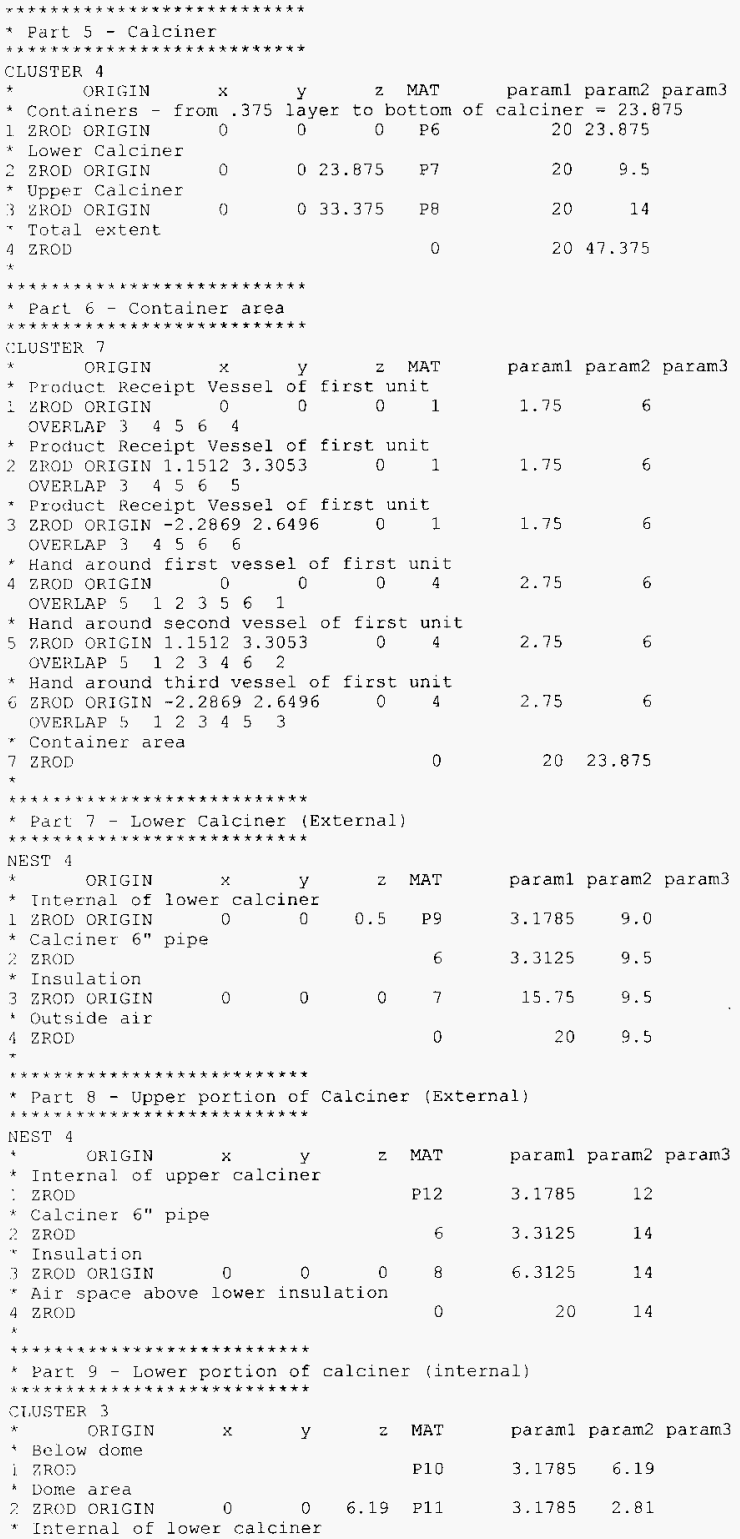




\section{HNF-SD-SQA-CSA-529, Rev. 0}

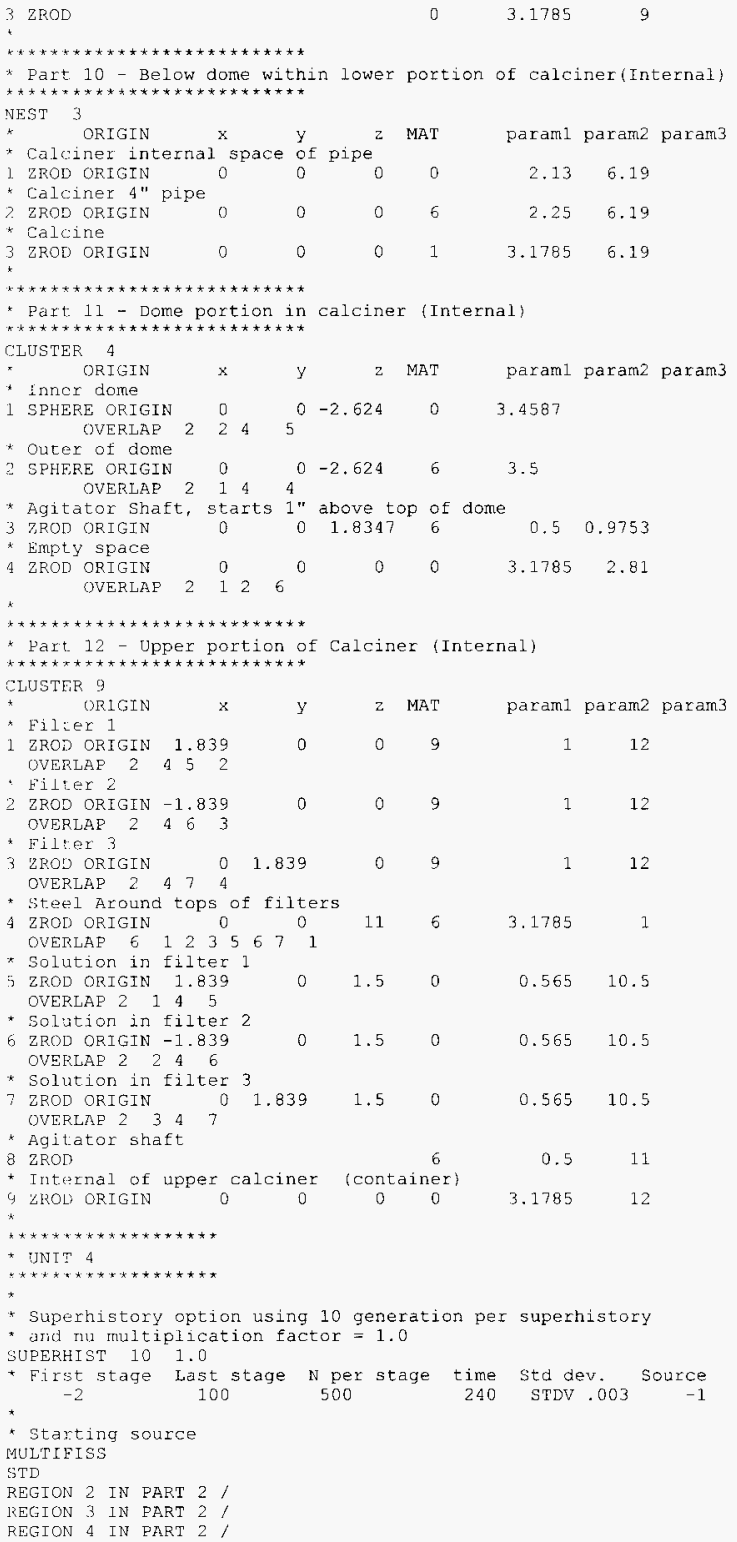




\section{HNF-SD-SQA-CSA-529, Rev. 0}

REGION 5 IN PART 2

REGION 6 IN PART 2 ,

REGION 7 IN PART 2 ;

REGION \& IN PART $2 /$

REGION 1 IN PART 6 /

REGION 2 IN PART $5 /$

REGION 3 IN PART E /

REGION 3 IN PART $10 \%$

END

CODE 11

PNSW 40 TUENM

- 'Iop left corner Top right corner Bottom left corner

$\begin{array}{lllllllll}* & y & y & z & x & y & z & x & y\end{array}$

* $z-z$ through feed tanks

$\begin{array}{lllllllll}-12 & 33.25 & 82.875 & 116.25 & 33.25 & 82.875 & -12 & 33.25 & -12\end{array}$

dowir center of calciner

$\begin{array}{lllllll}020.625 & 48 & 40 & 20.625 & 48 & 020.625 & 0\end{array}$

* close-up on dome

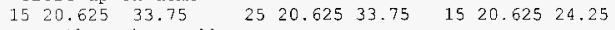

* $x-z$ through scrubber

$-12882.875116 .25$

$8 \quad 82.875-22$

$x-y$ for cans

0.25 cans
$x \rightarrow y$ for can

$+\quad x \rightarrow y$ for cans

1

$5 \quad 7041.25$

0.5

$-12$

$\begin{array}{lllllll}0.5 & 30 & 30 & 0.5 & 10 & 10 & 0.5\end{array}$




\section{HNF-SD-SQA-CSA-529, Rev. 0}

\section{wmp2.inp}

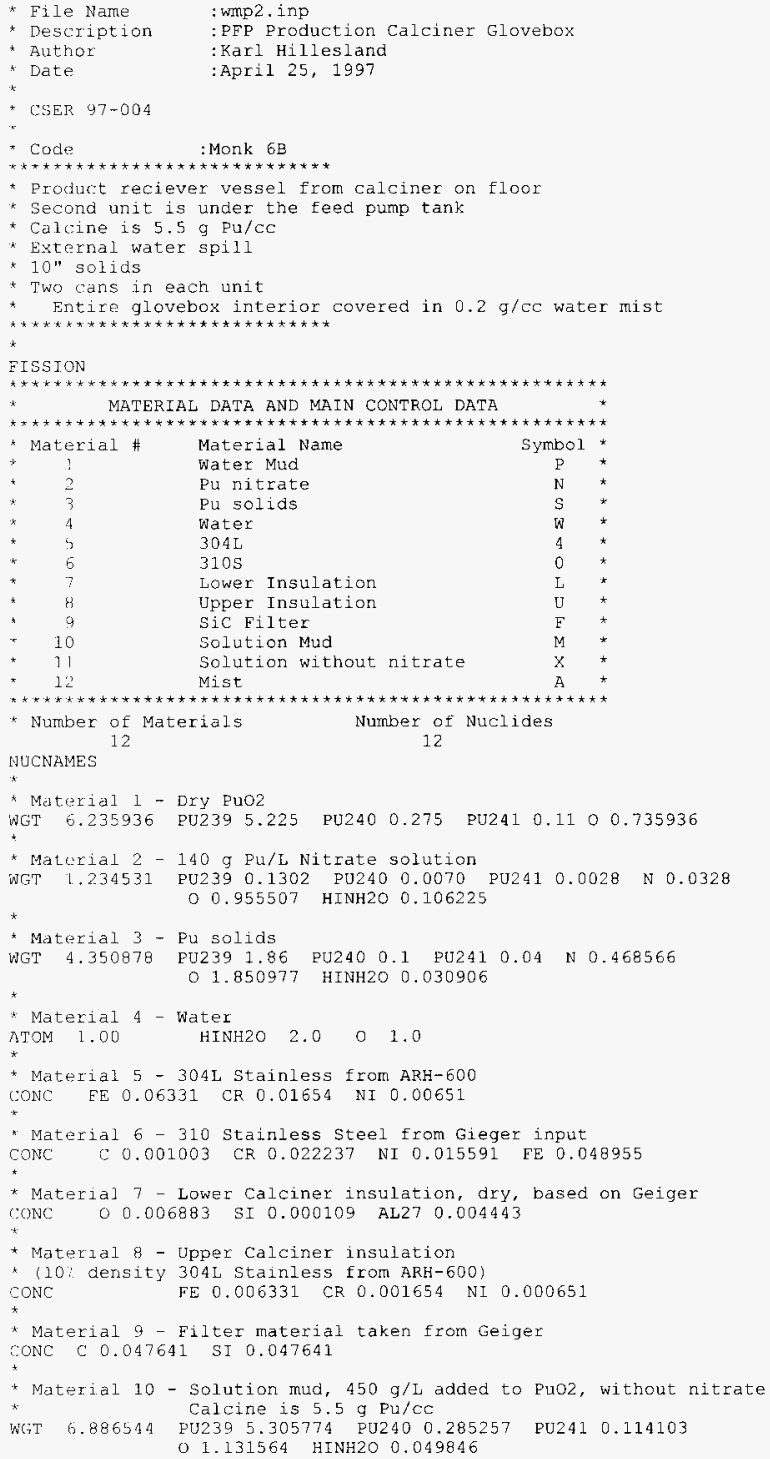


HNF-SD-SQA-CSA-529, Rev. 0

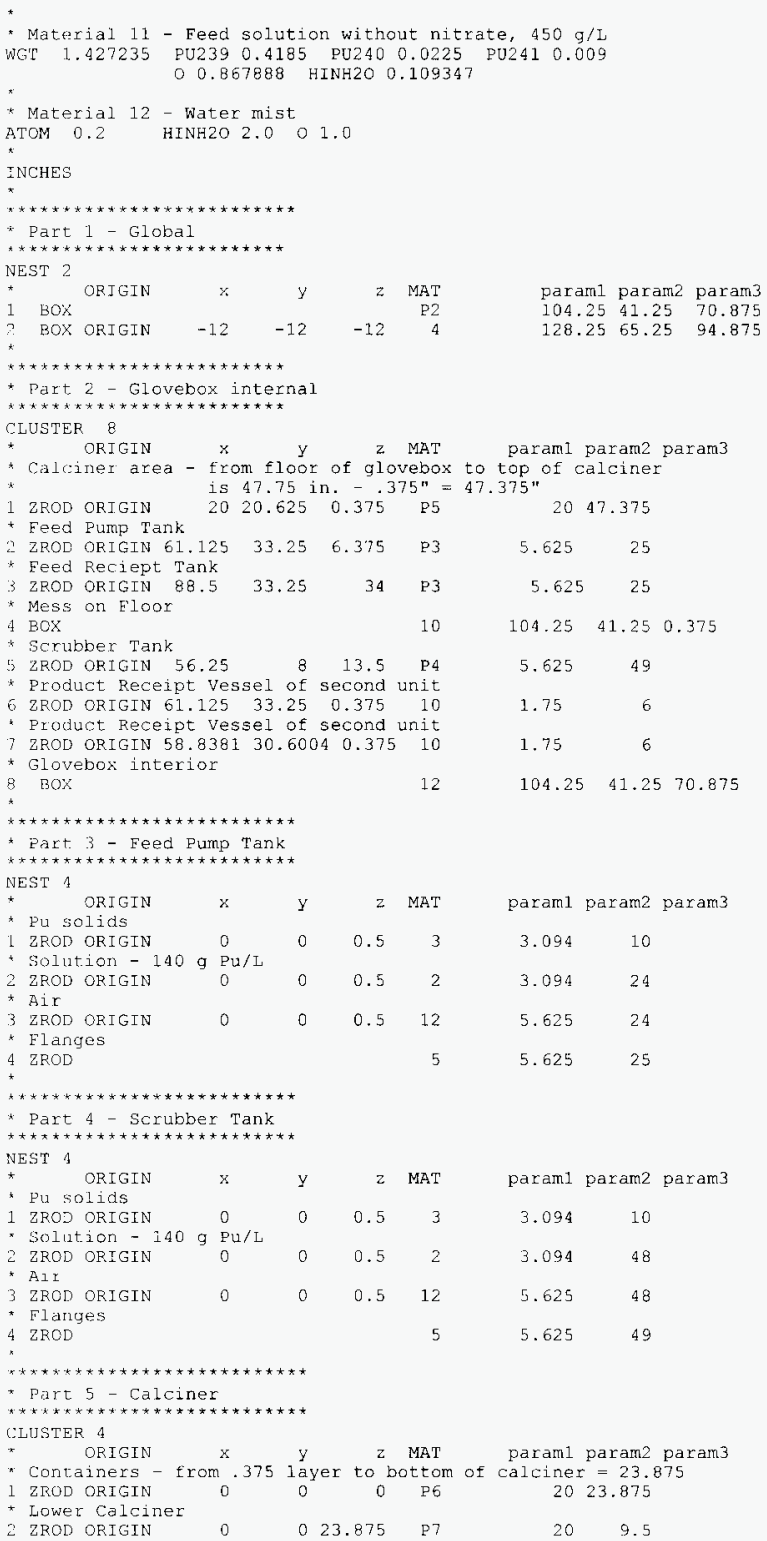


HNF-SD-SQA-CSA-529, Rev. 0

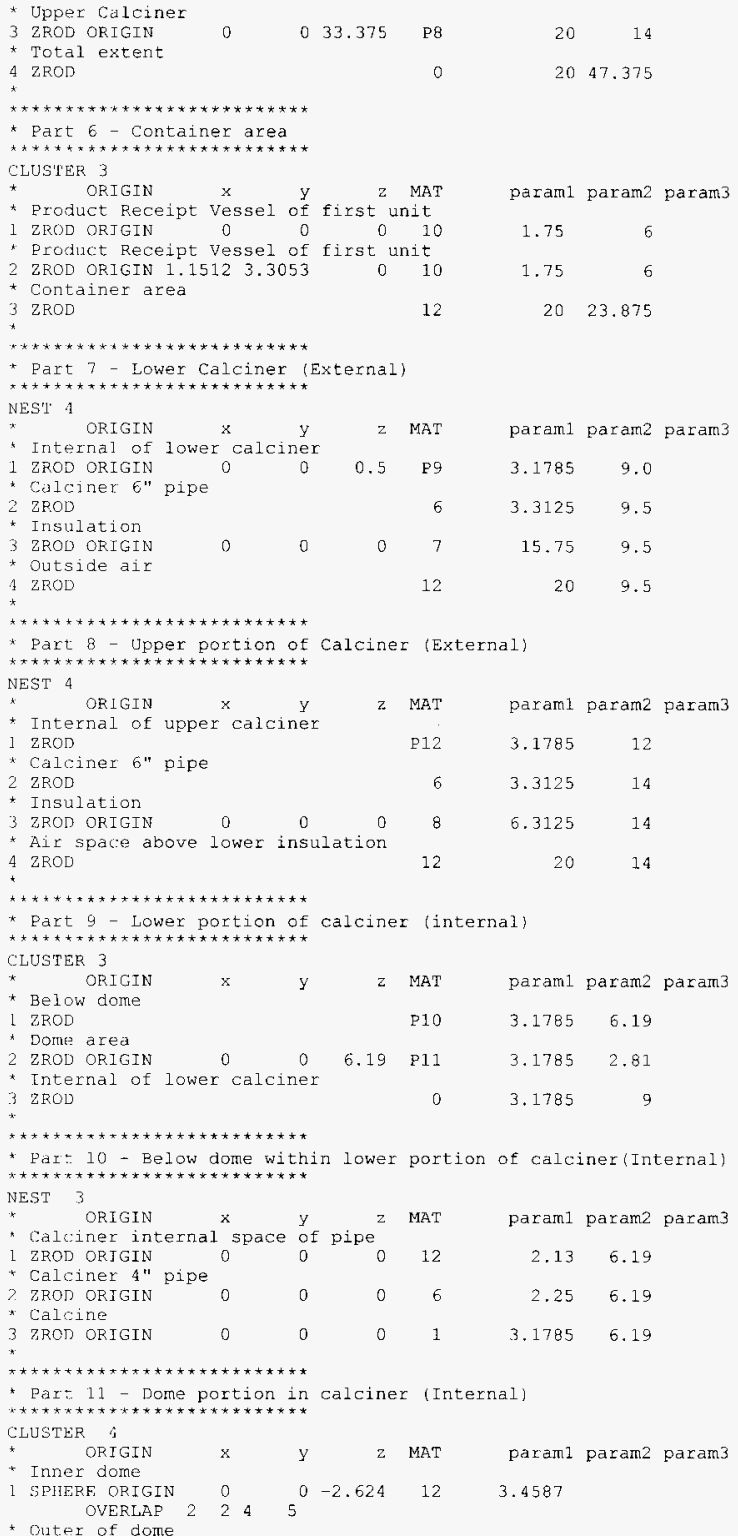


HNF-SD-SQA-CSA-529, Rev. 0

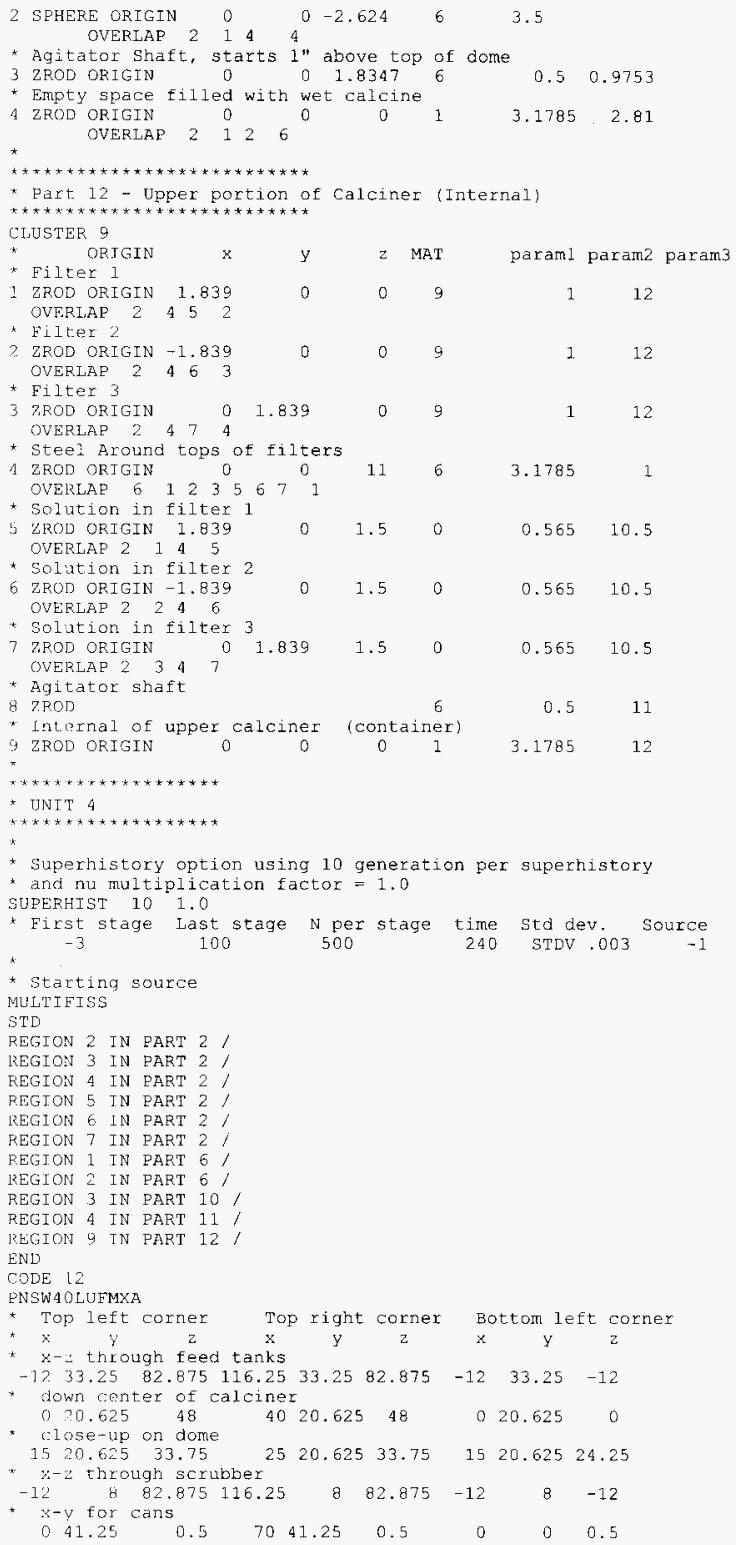


HNF-SD-SQA-CSA-529, Rev. 0

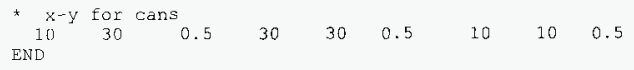




\section{HNF-SD-SQA-CSA-529, Rev. 0}

\section{int55dv5.inp}

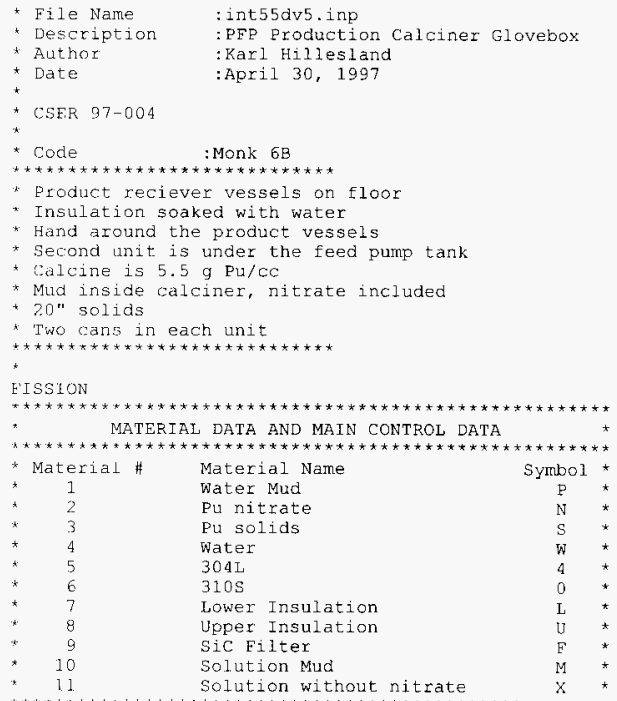


HNF-SD-SQA-CSA-529, Rev. 0

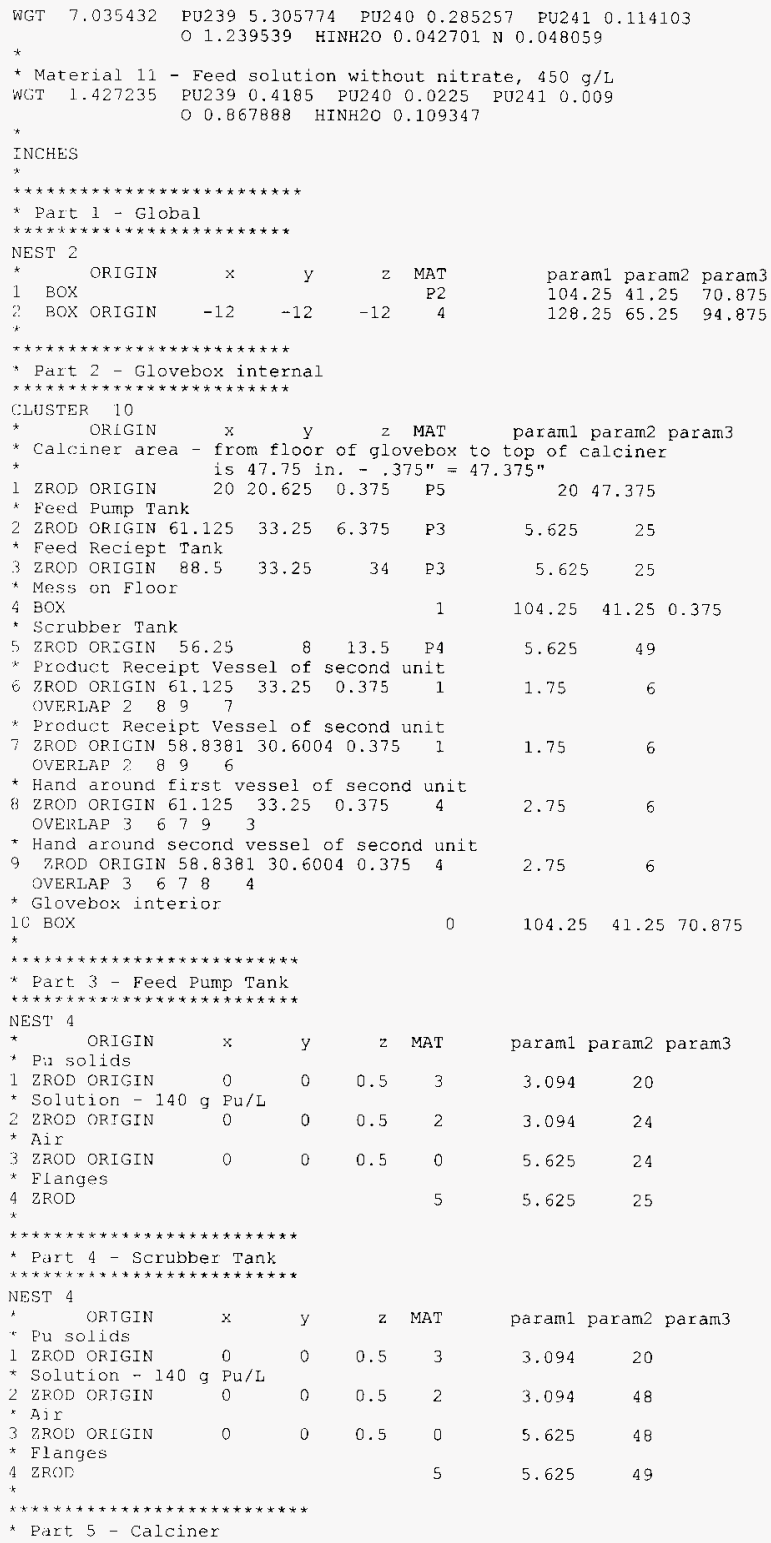

$\begin{array}{rrrr}z & \text { MAT } & \text { parami } & \text { param2 param3 } \\ 0.5 & 3 & 3.094 & 20 \\ 0.5 & 2 & 3.094 & 24 \\ 0.5 & 0 & 5.625 & 24 \\ & 5 & 5.625 & 25\end{array}$


HNF-SD-SQA-CSA-529, Rev. 0

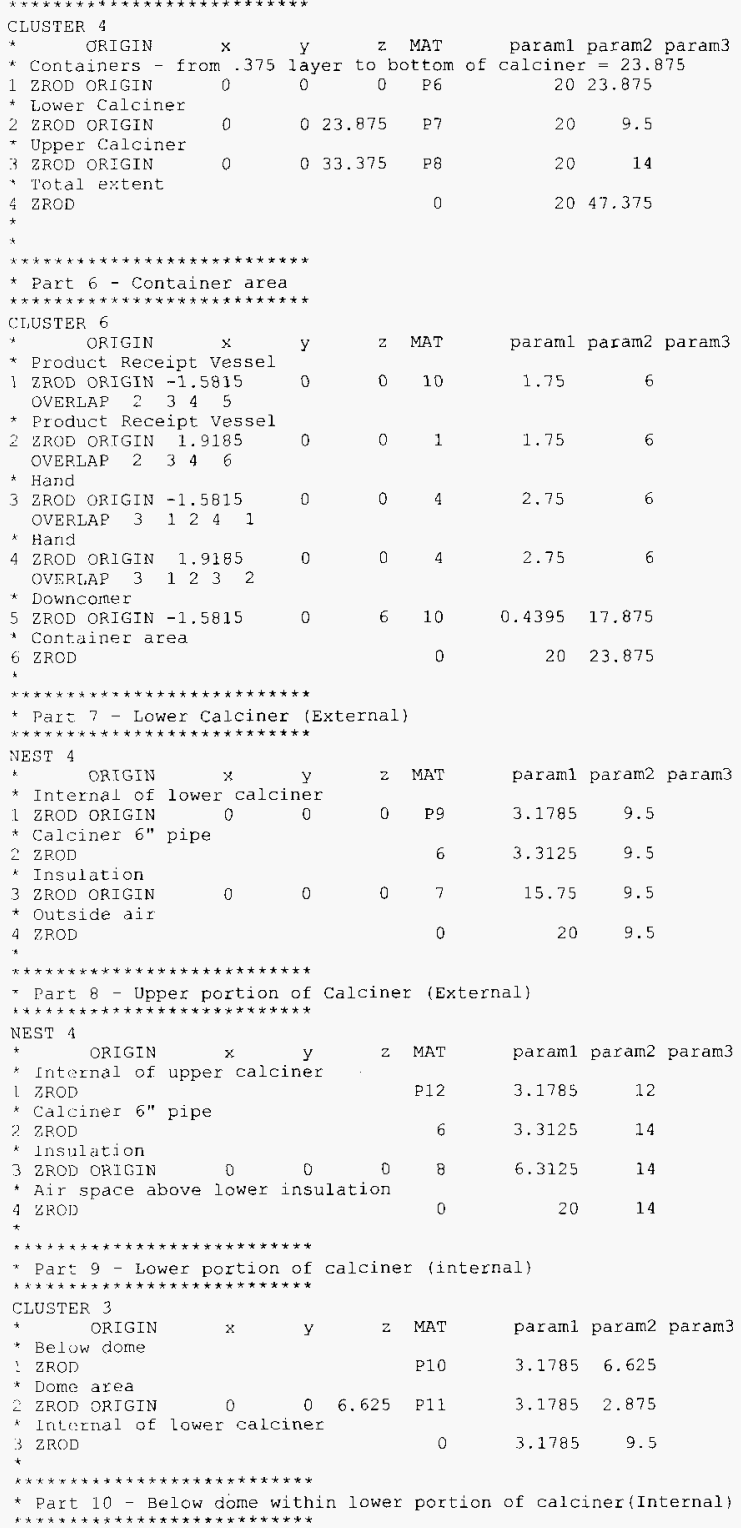




\section{HNF-SD-SQA-CSA-529, Rev. 0}

CLUSTER 7

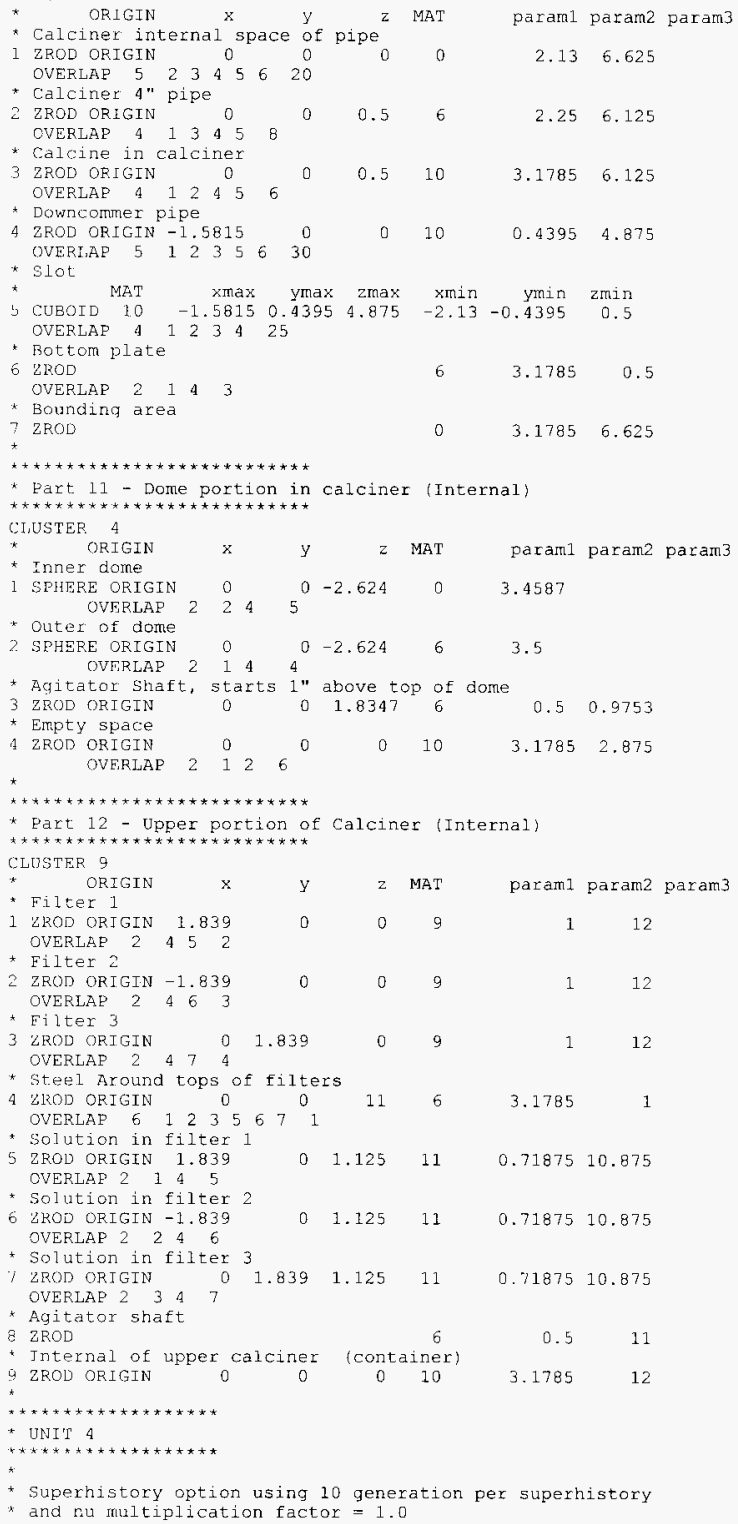


HNF-SD-SQA-CSA-529, Rev. 0

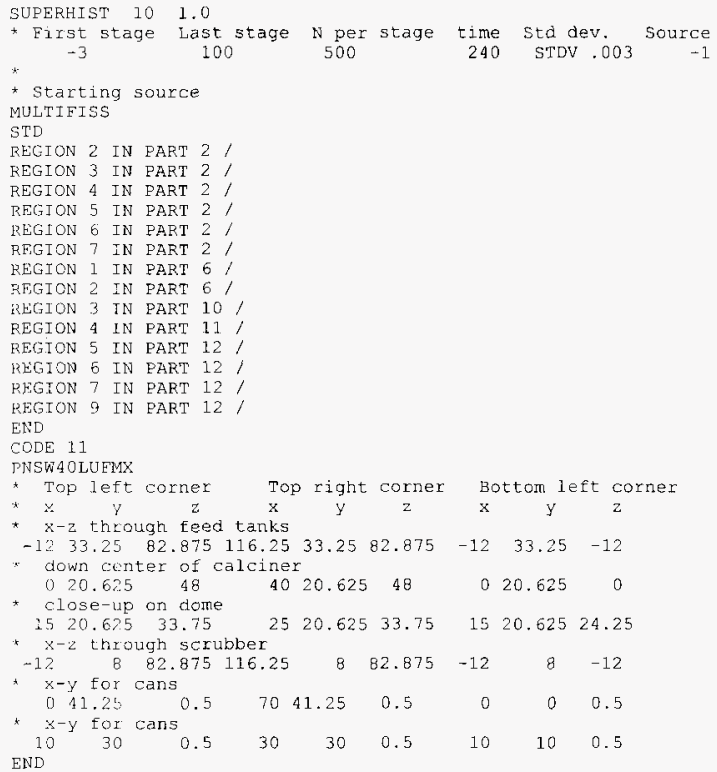


HNF-SD-SQA-CSA-529, Rev. 0

\section{waste.inp}

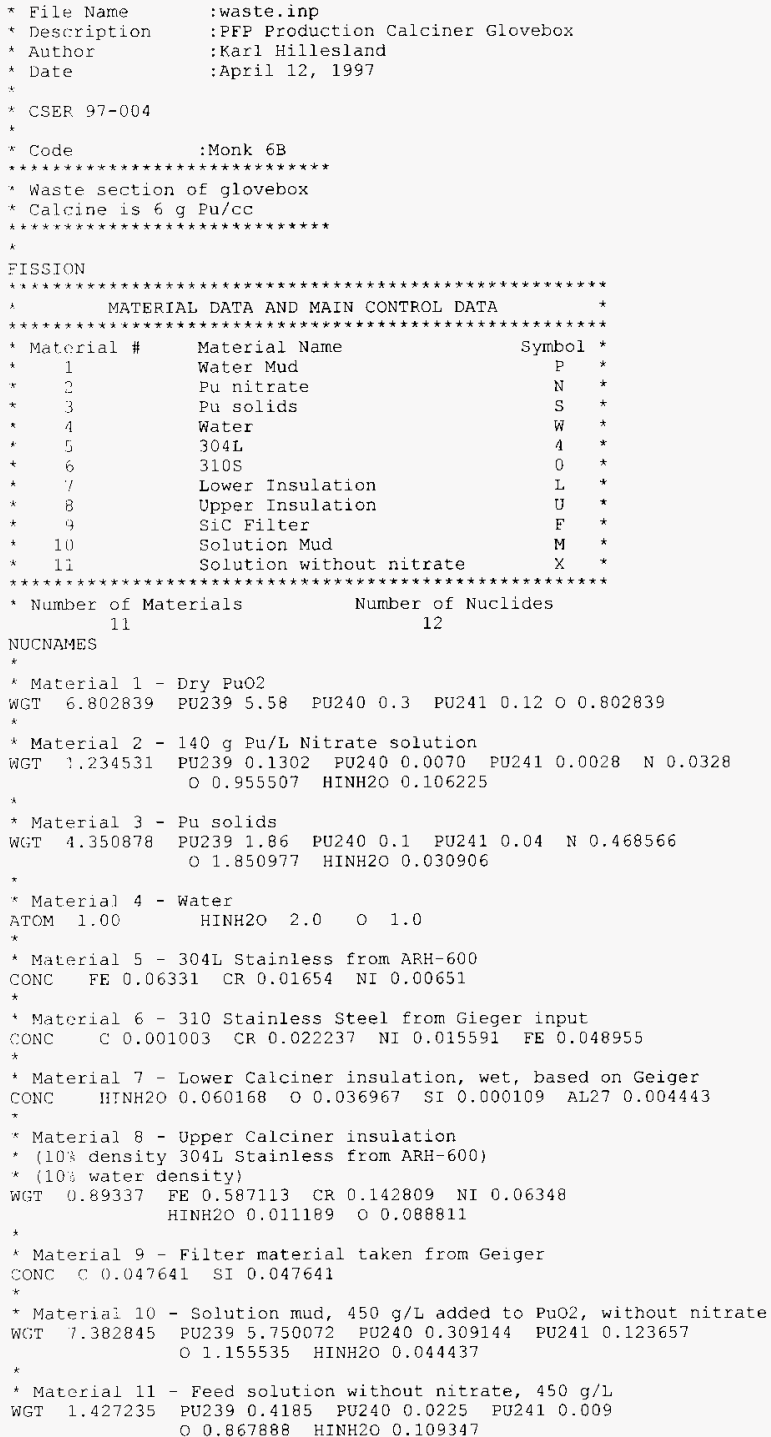




\section{HNF-SD-SQA-CSA-529, Rev. 0}

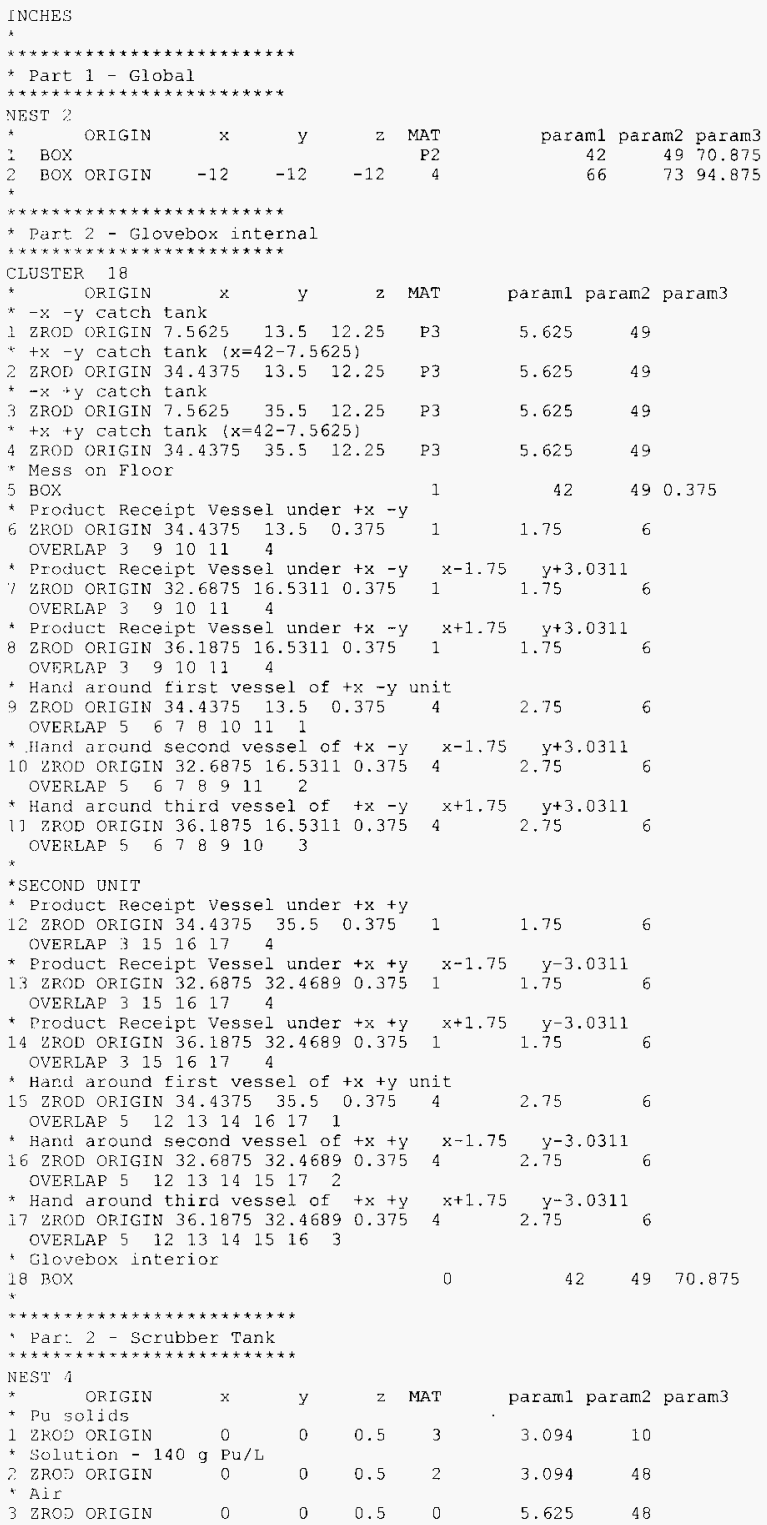


HNF-SD-SQA-CSA-529, Rev. 0

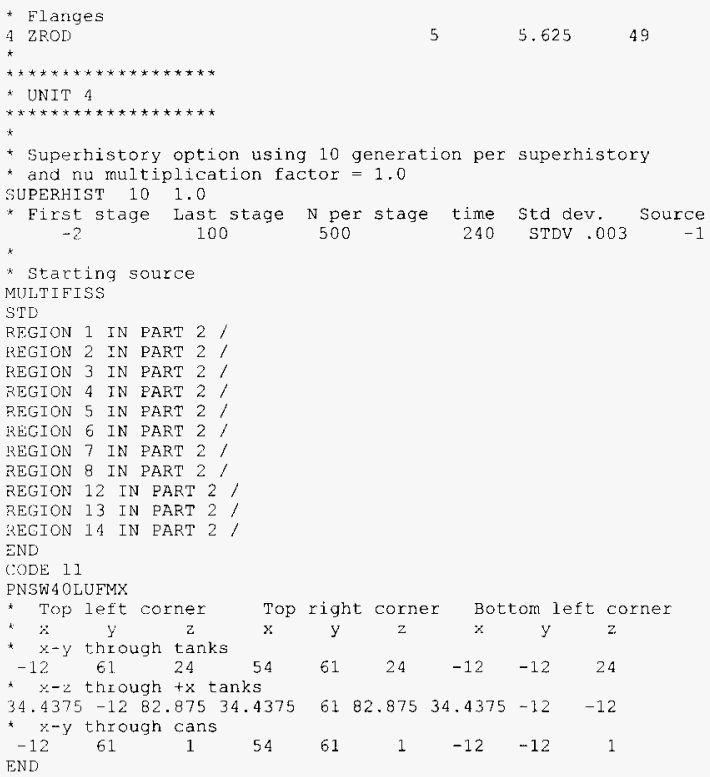


HNF-SD-SQA-CSA-529, Rev. 0

\section{ATTACHMENT 1. CORRESPONDENCE CONCERNING FEED SOLUTION CONCENTRATION}

This message is a reply to a previous message. The reply is given in italics in the body of the message. 
Author: Gregory G Bergquist at $\sim$ HANFORD03B

Date: 3/6/97 3:40 PM

Priority: Normal

CC: Edward M Miller at $\sim$ HANFORD02D

CC: Laurren $T$ (Tom) Nirider

TO: Karl E Hillesland at HANFORD07A

Subject: Re: Solution Pu concentration and drawings

\section{Greg,}

Message Contents

In the CSER for the lab calciner, the maximum Pu concentration was 450 $\mathrm{g} \mathrm{Pu} / \mathrm{L}$ of feed solution. Is this still the greatest credible concentration?

$Y$ Yes, The PUREX and PRF processes had crit limits that required nitrate solutions to be less than $450 \mathrm{~g} / \mathrm{l}$ (see CPS-Z-165-80701). If they were found higher, they were immediately diluted. The highest projected concentration of nitrate in PR Can storage is about $420 \mathrm{~g} / \mathrm{l} \mathrm{hased} \mathrm{on}$ one PR Can having a Pu value of 3365 grams in 8.0-8.5 liters of solution.

Additionally, glovebox $H C-227 S$ will have a limit of $450 \mathrm{~g} /$ for solution transferred from $P R$ cans into the glass batch tanks and will be verified by sample prior to sending to the new calciner glovebox. Each PR can unload is accompanied by a 2-3 liter flush with dilute nitric acid thus providing additional dilution.

... [Remainder of message not included] 
HNF-SD-SQA-CSA-529, Rev. 0

ATTACHMENT 2. CORRESPONDENCE CONCERNING PRODUCT DENSITY PRODUCED BY THE LAB CALCINER

The original was written by J.A. Compton, and forwarded by L.T. Nirider 
Author: Laurren T (Tom) Nirider at $\sim$ HANFORD03B

Date: $3 / 18 / 97$ 8:50 AM

Priority: Normal

TO: Karl E Hillesland at $\sim$ HANFORD07A

Subject: Vertical Calciner Product Tap Densities

Message Contents

I have reviewed the lab notebook and lab analysis results regarding our product samples from the vertical calciner for runs to date. It would be stretching things a bit to say we're definitely at an asymptote on the tap density of plutonium in the product. I am attaching the Lotus 1-2-3 files with my tables and graph to show the $\mathrm{Pu}$ tap densities over time. The last entry for $\mathrm{Pu}$ tap density is clearly higher than what had started to look a bit like an asymptote, so I can't really say we've peaked. Nonetheless, I still don't think we're going to exceed $5 \mathrm{gm} P u$ per cc by much, if at all. Our latest result of $4.75 \mathrm{gm} \mathrm{Pu} / \mathrm{cc}$ was, no doubt, assisted by having been reroasted powder from an earlier run whose product had a high loss on ignition. The highest $\mathrm{Pu}$ tap density without reroasting is only 4.26 .

One other point needs to be made and is not shown in the 1-2-3 table attached. We started with a pretty impure $\mathrm{PuO} 2$ bed and have increased the $\mathrm{Pu}$ fraction in the bed significantly. In other words, the $\mathrm{Pu}$ fraction and, therefore, the $\mathrm{Pu}$ density started low partly because the bed was fairly loaded with impurities. As we fed more and more reasonably pure PUREX and PRF solutions through the calciner, the Pu fraction in the bed increased. That fraction started around 0.75 and is now up to 0.855 as of the last sample results. The theoretical maximum $\mathrm{Pu}$ fraction is 0.882 , so we won't be getting much higher. As we reach our asymptote on the Pu fraction, that factor will stop assisting the increase in $\mathrm{Pu}$ tap density. Please remember that the production calciner will have occasional batches of impure feeds that will lower its product $\mathrm{Pu}$ fraction and $\mathrm{Pu}$ tap density.

We clearly need to continue running the calciner to see where the $\mathrm{Pu}$ tap density stops, among other reasons. We plan to do so as soon as the administrative hold on fissile material handling is lifted. I still don't believe we'll exceed $5.0 \mathrm{gm} \mathrm{Pu} / \mathrm{cc}$ consistently and I'm even more certain we won't reach $5.5 \mathrm{gm} \mathrm{Pu} / \mathrm{cc}$. 


\section{HNF-SD-SQA-CSA-529, Rev. 0}

\begin{tabular}{|c|c|c|}
\hline $\begin{array}{l}\text { Pu Tap De } \\
\text { gm Pu/cc }\end{array}$ & $\begin{array}{l}\text { sity Tracking } \\
\text { (not gm Pu } \\
\text { Cumulative }\end{array}$ & $\begin{array}{l}\text { O2/cc) } \\
\text { Pu Tap }\end{array}$ \\
\hline Run \# & Prod. (kg) & $\begin{array}{l}\text { Dens }(\mathrm{gm} / \mathrm{c} \\
\mathrm{c})\end{array}$ \\
\hline$=====$ & $=====$ & $=====$ \\
\hline $\mathrm{Pu}-7$ & 1.45 & 2.77 \\
\hline PP-01 & 2.48 & 2.97 \\
\hline PP-01 & 3.48 & 3.37 \\
\hline PP-02 & 3.5 & 3.27 \\
\hline PP-03 & 4.62 & 3.98 \\
\hline PP-05 & 6.8 & 4.04 \\
\hline PP-06 & $7.6 \mathrm{~S}$ & 4.04 \\
\hline PP-07 & 8.54 & 4.26 \\
\hline Post & 8.54 & 4.75 \\
\hline
\end{tabular}


HNF-SD-SQA-CSA-529, Rev. 0

Pu Tap Densities

Vertical Calciner

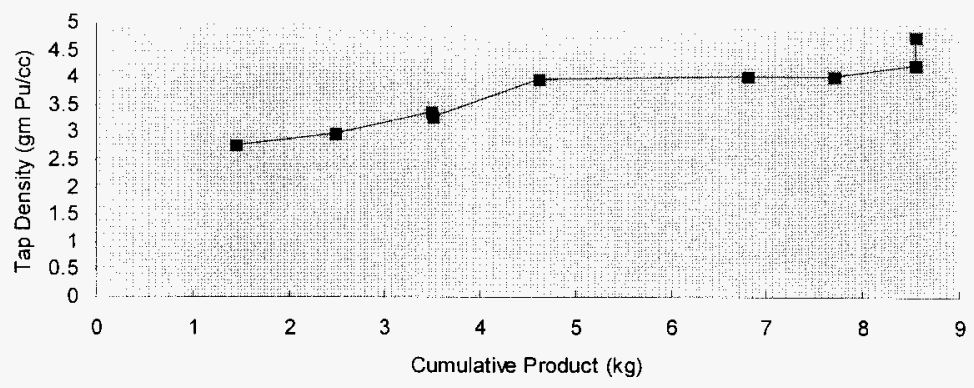

- Pu Tap Density 
HNF-SD-SQA-CSA-529, Rev. 0

ATTACHMENT 3. PR CANS CONTAINING URANIUM TO BE CALCINED 
$\rightarrow$ PR exn $\sim$ r.5 l.ters, $10 L \sim 10$ liter:

\begin{tabular}{|c|c|c|c|c|c|c|c|c|c|c|c|}
\hline \multicolumn{3}{|c|}{ Solutions Containing Uranium } & & & & & \multicolumn{3}{|c|}{ Fax } & \multicolumn{2}{|l|}{ Fand } \\
\hline Hem ID & $P u(g)$ & \%Pu240 & Type Can & Can & Material Ty & Est. Sep Da & ANSI & Cat Code & $U-g$ & Type & U235 \\
\hline $81-88-09-235$ & 1786 & 22.7 & PR & E519 & PU-DEP U & 1988 & F40 & 81 & 49 & Depleted & $0.70 \%$ \\
\hline $81-80-09-236$ & 1780 & 22.7 & PR & E349 & PU-DEP U & 1988 & $\mathbf{F} 40$ & 81 & 49 & Depleted & $0.70 \%$ \\
\hline $81-88-09-237$ & 1782 & 22.7 & PR & E364 & PU-DEP U & 1988 & $\mathbf{F 4 0}$ & 81 & 49 & Depleted & $0.70 \%$ \\
\hline $81-88-09-238$ & 1790 & 22.7 & PR & E439 & PU-DEP U & 1988 & $\mathbf{F 4 0}$ & 81 & 49 & Depleted & $0.70 \%$ \\
\hline $81-88-09-239$ & 1782 & 22.7 & PR & E307 & PU-DEP U & 1988 & F40 & 81 & 49 & Depleted & $0.70 \%$ \\
\hline $81-88-09-240$ & 1789 & 22.7 & PR & E306 & PU-DEP U & 1988 & F40 & 81 & 49 & Depleted & $0.70 \%$ \\
\hline $81-88-09-243$ & 1799 & 22.7 & PRR & E380 & PU-DEP U & 1988 & F40 & 81 & 49 & Depleted & $0.70 \%$ \\
\hline $81-88-09-244$ & 1796 & $22.7 !$ & IPR & E305 & PU-DEP U & 1988 & F40 & 81 & 49 & Depleted & $0.70 \%$ \\
\hline $81-88-09-245$ & 1793 & 22.7 & $P R$ & E491 & PU-DEP U & 1988 & F40 & 81 & 49 & Depleted & $0.70 \%$ \\
\hline $81-88-09-246$ & 1809 & 22.7 & PR & E535 & PU-DEP U & 1988 & F40 & 81 & 50 & Depleted & $0.70 \%$ \\
\hline $81-88-09-247$ & 1811 & 22.7 & PR & E503 & PU-DEP U & 1988 & $\mathbf{F 4 0}$ & 81 & 50 & Depleted & $0.70 \%$ \\
\hline $81-88-09-248$ & 361 & 22.7 & PR & E309 & PU-DEP U & 1988 & F40 & 81 & 10 & Depleted & $0.70 \%$ \\
\hline $\mathrm{H}-014$ & 679 & 6.14 & $10 \mathrm{~L}$ & H014 & PU-DEP U & 1976 & F40 & 88 & 1000 & Depleted & $0.66 \%$ \\
\hline H-018 & 679 & 6.14 & $10 \mathrm{~L}$ & H018 & PU-DEP U & 1976 & F40 & 88 & 2000 & Depleted & $0.66 \%$ \\
\hline$H-022$ & 678: & 6.14 & $10 \mathrm{~L}$ & $H 022$ & PU-DEP U & 1976 & F40 & 88 & 1000 & Depleted & $0.66 \%$ \\
\hline $\mathrm{H}-026$ & 680 & 6.14 & $10 \mathrm{~L}$ & H026 & PU-DEP U & 1976 & F40 & 88 & 2000 & Depleted & $0.66 \%$ \\
\hline $\mathrm{H}-037$ & 683 & 6.14 & $10 \mathrm{~L}$ & $\mathrm{H037}$ & PU-DEP U & 1976 & F40 & 88 & 1000 & Depleted & $0.66 \%$ \\
\hline $\mathrm{H}-047$ & $\overline{659}$ & 6.14 & $10 \mathrm{~L}$ & H047 & PU-DEP U & 1976 & $\overline{F 40}$ & 88 & 1000 & Depleted & $0.66 \%$ \\
\hline $\mathrm{H}-059$ & 679 & 6.14 & $10 \mathrm{~L}$ & H059 & PU-DEP U & 1976 & F40 & 88 & 2000 & Depleted & $0.66 \%$ \\
\hline $\mathrm{H}-063$ & 681 & 6.14: & $10 \mathrm{~L}$ & $\mathrm{H} 063$ & PU-DEPU & 1976 & F40 & 88 & 1000 & Depleted & $0.66 \%$ \\
\hline H-066 & 679 & 6.14 & $10 \mathrm{~L}$ & H066 & PU-DEP U & 1976 & $\mathrm{~F} 40$ & 88 & 2000 & Depleted & $0.66 \%$ \\
\hline $\mathrm{H}-070$ & 678 & 6.14 & $10 \mathrm{~L}$ & Ho70 & PU-DEP U & 1976 & $\mathbf{F 4 0}$ & 88 & 1000 & Depleted & $0.66 \%$ \\
\hline H-071 & 677 & 6.14 & $10 \mathrm{~L}$ & H071 & PU-DEPU & 1976 & F40 & 88 & 1000 & Depleted & $0.66 \%$ \\
\hline H-076 & 682 & 6.14 & $10 \mathrm{~L}$ & 1076 & PU-DEPU & 1976 & $F 40$ & 88 & 1000 & Depleted & $0.66 \%$ \\
\hline H-077 & 678 & 6.14 & $10 \mathrm{~L}$ & $\mathrm{Ho77}$ & PU-DEPU & 1976 & F40 & 88 & 2000 & Depleted & $0.66 \%$ \\
\hline $\mathrm{H}-082$ & 680 & 6.14 & $10 \mathrm{~L}$ & H082 & PUDEPU & 1976 & F40 & 88 & 1000 & Depleted & $0.66 \%$ \\
\hline $\mathrm{H}-085$ & 680 & 6.14 & $10 \mathrm{~L}$ & H085 & PU-DEPU & 1976 & $F 40$ & 88 & 2000 & Depleted & $0.66 \%$ \\
\hline$R-209$ & 657 & 6.14 & $10 \mathrm{~L}$ & R209 & PU-DEP U & 1976 & $F 40$ & 88 & 1000 & Depleted & $0.66 \%$ \\
\hline$R-228$ & 433 & 6.14 & $10 \mathrm{~L}$ & $R 226$ & PU-DEPU & 1976 & $\mathrm{~F} 40$ & 88 & 1000 & Depleted & $0.66 \%$ \\
\hline$R-232$ & 655 & 6.14 & $10 \mathrm{~L}$ & R232 & IPU-DEP U & 1976 & $\mathbf{F 4 0}$ & 88 & 2000 & Depleted & $0.66 \%$ \\
\hline$R-235$ & 649 & 6.14 & $10 \mathrm{~L}$ & $R 235$ & IPU-DEP U & 1976 & $F 40$ & 88 & 1000 & Depleted & $0.66 \%$ \\
\hline$R-243$ & 654 & 6.14 & $10 \mathrm{~L}$ & R243 & IPU-DEPU & 1976 & F40 & 88 & 1000 & Depleted & $0.66 \%$ \\
\hline
\end{tabular}




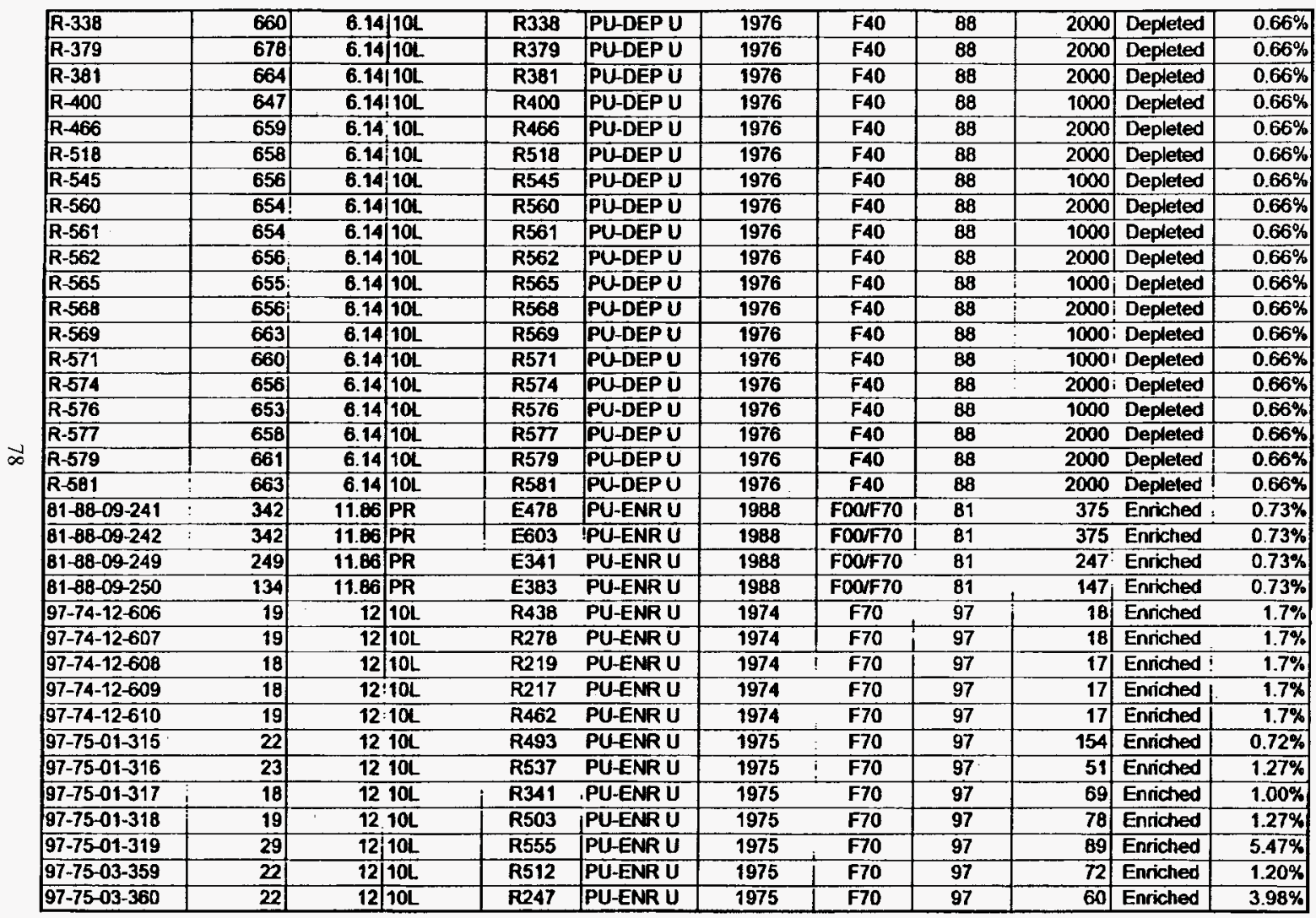




\begin{tabular}{|c|c|c|c|c|c|c|c|c|c|c|c|}
\hline $97-75-03-361$ & 21 & 12 & $10 \mathrm{~L}$ & R412 & PU-ENRU U & 1975 & F70 & 97 & 71 & Enriched & $3.30 \%$ \\
\hline $97-75-03-362$ & 23 & 12 & $10 \mathrm{~L}$ & R538 & PUENR U & 1975 & $F 70$ & 97 & 56 & Enriched & $2.20 \%$ \\
\hline $97-75-03-363$ & 21 & 12 & $10 \mathrm{~L}$ & $\mathbf{R 2 2 9}$ & PU-ENR U & 1975 & F70 & 97 & 65 & Enviched & $1 . \overline{08} \bar{x}$ \\
\hline $97-75-03-392$ & 20 & 12 & $10 \mathrm{~L}$ & R300 & PU-ENR U & 1975 & $F 70$ & 97 & 62 & Enriched & $1.08 \%$ \\
\hline $97-75-05-459$ & 23 & 12 & $10 \mathrm{~L}$ & $\mathbf{R 4 5 0}$ & FU-ENR U & $197 \overline{7}$ & F50/F 70 & 97 & 62 & Enriched & $0.72 \%$ \\
\hline $97-75-05-460$ & 21 & 12 & $10 \mathrm{~L}$ & R539 & PU-ENR U & 1975 & $\overline{F 70}$ & 97 & 69 & Enviched & $1.03 \%$ \\
\hline $97-75-05-461$ & 22 & 12 & $10 \mathrm{~L}$ & $R 234$ & PU-ENR U & 1975 & $\overline{F 70}$ & 87 & 80 & Enriched & $0.63 \%$ \\
\hline $97-75-05-463$ & 24 & 12 & $10 \mathrm{~L}$ & R567 & PU-ENR U & 1975 & $\overline{F 70}$ & 97 & 127 & Enriched & $0.83 \%$ \\
\hline $97-75-05-464$ & 46 & 12 & $10 \mathrm{~L}$ & $R 244$ & PU-ENRU & 1975 & $\overline{F 70}$ & $\overline{97}$ & 81 & Enriched & $\overline{0} . \overline{7} 2 \%$ \\
\hline $97-75-05-465$ & 121 & 12 & $10 \mathrm{~L}$ & $R 35 B$ & PUENRU & 1975 & F50/F70 & 97 & $\overline{\theta 2}$ & Enriched & $0.71 \%$ \\
\hline $97-75-05-466$ & 28 & 12 & $10 \mathrm{~L}$ & $R 269$ & PU-ENR U & 1975 & $F 70$ & 97 & 79 & Enriched & $0 . \overline{7} \overline{\%}$ \\
\hline $97-75-09-713$ & 17 & 12 & $10 \mathrm{~L}$ & $\mathrm{R} 272$ & Pu-EU & 1975 & F70 & 97 & 98 & Enriched & $1.03 \%$ \\
\hline $97-75-09-714$ & 29 & 12 & $10 \mathrm{~L}$ & $R 366$ & PU-EU & 1975 & $\overline{F 70}$ & $\overline{97}$ & 75 & Enriched & $1.28 \%$ \\
\hline $97-75-09-715$ & 20 & 12 & $10 \mathrm{~L}$ & R386 & Pu-EU & 1975 & $F 70$ & 97 & 139 & Enriched & $0.76 \%$ \\
\hline $97-75-09-716$ & 20 & 12 & $10 \mathrm{~L}$ & R548 & PU-EU & 1975 & $\overline{F 70}$ & 97 & 71 & Enriched & $0 . \overline{76 \%}$ \\
\hline $97-75-09-717$ & 19 & 12 & $10 \mathrm{~L}$ & R371 & PU-EU & 1975 & F70 & 97 & 77 & Enriched & $1.01 \%$ \\
\hline $97-75-09-718$ & $23:$ & 12 & $10 \mathrm{~L}$ & $R 295$ & PU-EU & 1975 & $F 70$ & 97 & 60 & Enriched & $\overline{0} . \overline{7} \overline{6} \%$ \\
\hline $97-75-12-880$ & 201 & 12 & $10 \mathrm{~L}$ & $\bar{R} 49 \overline{9}$ & PU-EU & 1975 & F70 & 97 & 76 & Entiched & $0 . \overline{79 \%}$ \\
\hline $97-75-12-881$ & 19 & 12 & $10 \mathrm{~L}$ & R230 & PU-EU & 1975 & F70 & 97 & $\overline{6} \overline{6}$ & Enriched & $0.72 \%$ \\
\hline $97-75-12-882$ & 22 & 12 & $10 \mathrm{t}$ & $\overline{R 336}$ & PU-EU & 1975 & F70 & 97 & 90 & Enriched & $\overline{0} . \overline{79 \%}$ \\
\hline $97-75-12-899$ & 22 & 12 & $10 \mathrm{~L}$ & R535 & PU-EU & 1975 & F70 & 97 & 71 & Enriched & $2 . \overline{82} \%$ \\
\hline $97-75-12-900$ & 20 & 12 & $10 t$ & $\mathbf{R 4 3 2}$ & PU-EU & 1975 & $F 70$ & 97 & $\overline{67}$ & Enviched & $\overline{7.46 \%}$ \\
\hline $97-75-12-901$ & 11 & 12 & $10 t$ & $\bar{R} \overline{415}$ & PU-EU & 1975 & $F 70$ & 97 & 42 & Enriched & $40.48 \%$ \\
\hline $97-75-12-902$ & 21 & 12 & $10 \mathrm{~L}$ & R570 & Pu-EU & 1975 & $F 70$ & 97 & 75 & Enriched & $0.79 \%$ \\
\hline $97-75-12-903$ & 19 & 12 & $10 \mathrm{~L}$ & $\mathbf{R 2 6 5}$ & Pu-EU & 1975 & F70 & 97 & 64 & Enriched & $9.45 \%$ \\
\hline $97-75-12-904$ & 15 & 12 & $10 \mathrm{~L}$ & R556 & Pu-EU & 1975 & F70 & 97 & 63 & Enriched & $9.45 \%$ \\
\hline $97-74-11-573$ & 18 & 12 & $10 \mathrm{~L}$ & $\mathrm{R} 202$ & PU-NAT U & 1974 & F50 & 97 & 49 & Natural & \\
\hline $97-74-11-574$ & 18 & 12 & $10 L$ & R218 & PU-NAT U & 1974 & F50 & 97 & 50 & Natural & \\
\hline $97-74-11-575$ & 19 & 12 & $10 \mathrm{~L}$ & $\mathrm{R} 540$ & PU-NAT U & 1974 & $F 50$ & 97 & $\overline{53}$ & Natural & \\
\hline $97-74-11-576$ & 17 & 12 & $10 \mathrm{~L}$ & R299 & PU-NAT U & 1974 & $\overline{F 50}$ & $\overline{9} \overline{7}$ & 47 & Natural & \\
\hline $97-74-11-577$ & 18 & 12 & $10 \mathrm{~L}$ & R558 & PU-NAT U U & 1974 & $F 50$ & 97 & 50 & Natural & \\
\hline $97-75-05-462$ & 22 & 12 & $10 \mathrm{~L}$ & R279 & PU-NAT U & 1975 & F701F50 & 97 & 70 & Natural & \\
\hline $97-75-12-879$ & 11 & 12 & $10 \mathrm{~L}$ & R505 & PिU-NAT U & 1975 & F70 750 & 97 & 68 & Natural & \\
\hline TOTALS = & 47805 & & & & & & \multicolumn{3}{|c|}{$\mathrm{i} \quad \overline{62710}$} & & \\
\hline ITEMS = & 100 & & & & & & \multicolumn{3}{|c|}{$i$} & & \\
\hline
\end{tabular}


HNF-SD-SQA-CSA-529, Rev. 0

ATTACHMENT 4. PRELIMINARY DRAWINGS 


\section{TRVT-SD-SQA-CSA-529, Rev. O}

Preliminary Drawing $A$

Top-Down View of Section of Glosebox Containing the Calcina:.

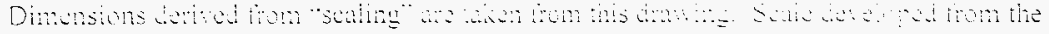

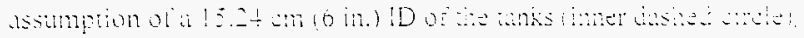

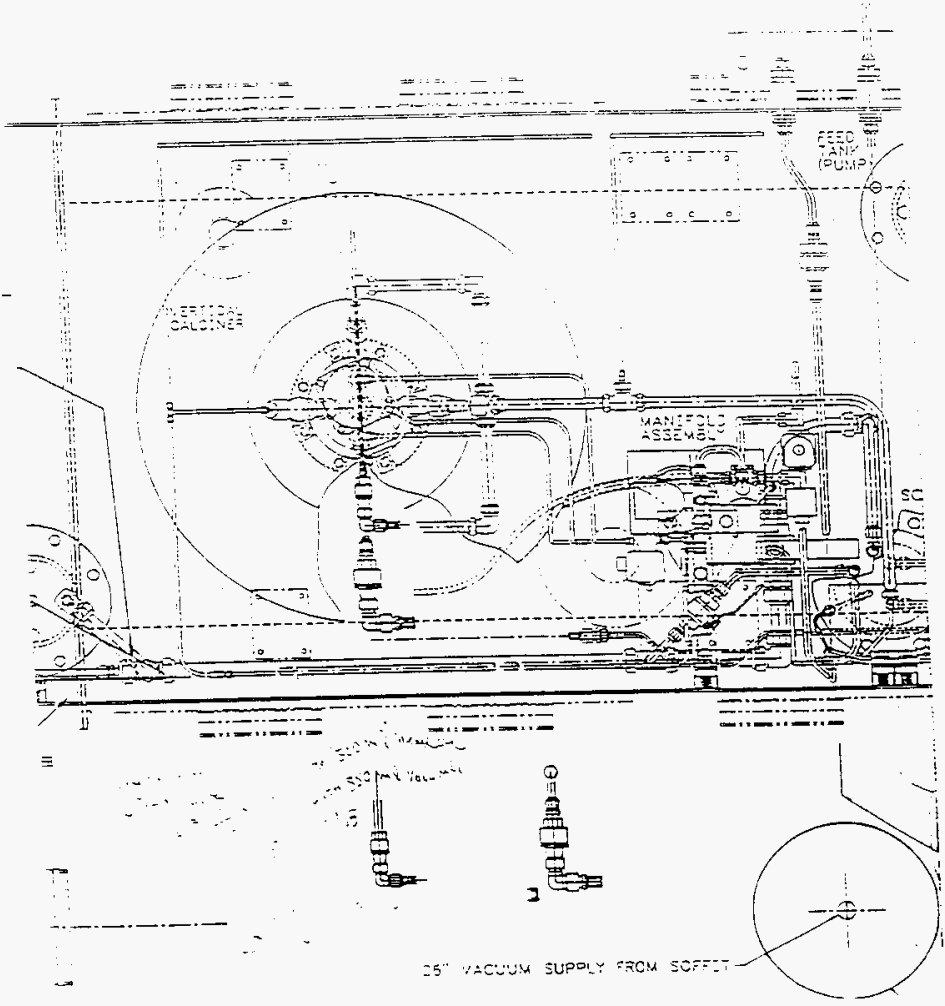




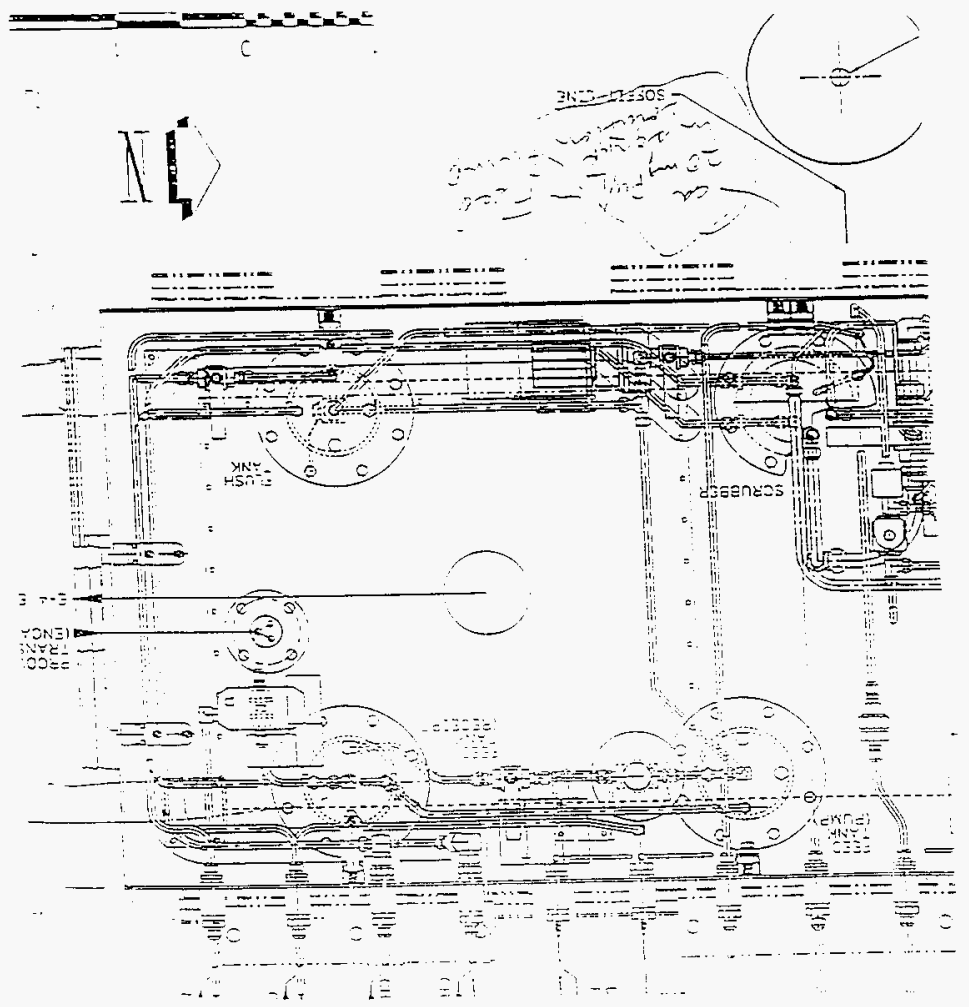

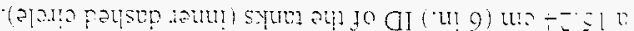

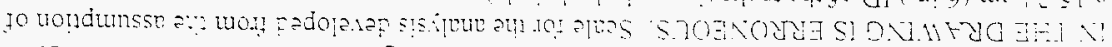

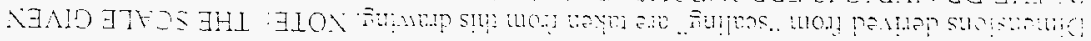

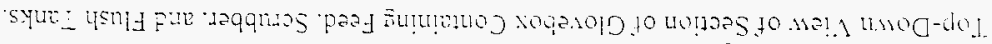

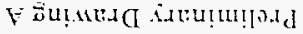




\section{Hi. F-SD-SQA-CSA-52\%, ReV.D}

Preliminary Drawing A

Sicle View of Section of Glovebox Containing Calciner.

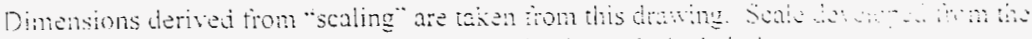

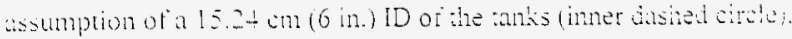

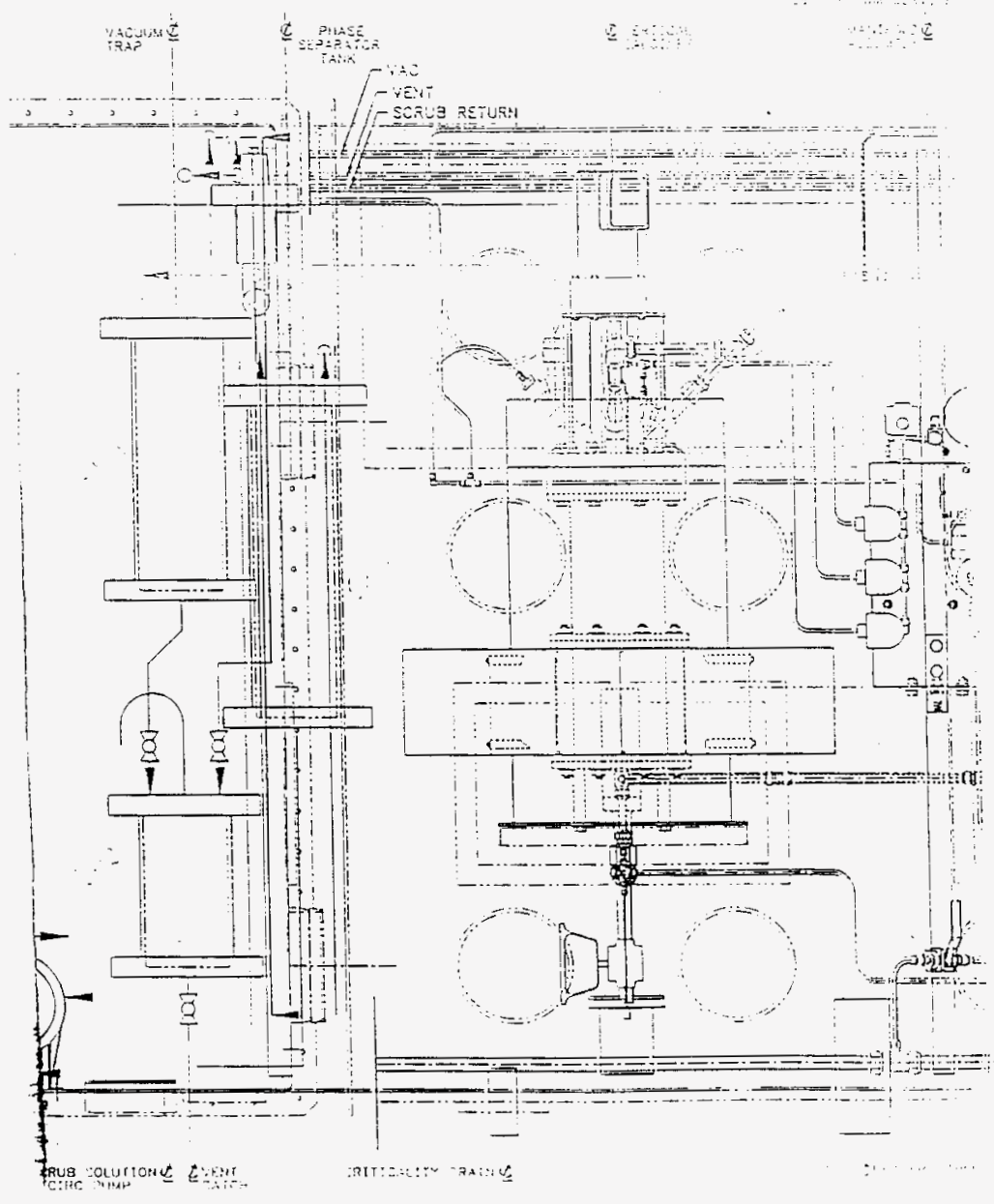




\section{HNF-SD-SQA-CSA-529, Rev, 0}

\section{Preliminary Drawing B}

Side View of the Section of the Glovebox Containing the Calciner

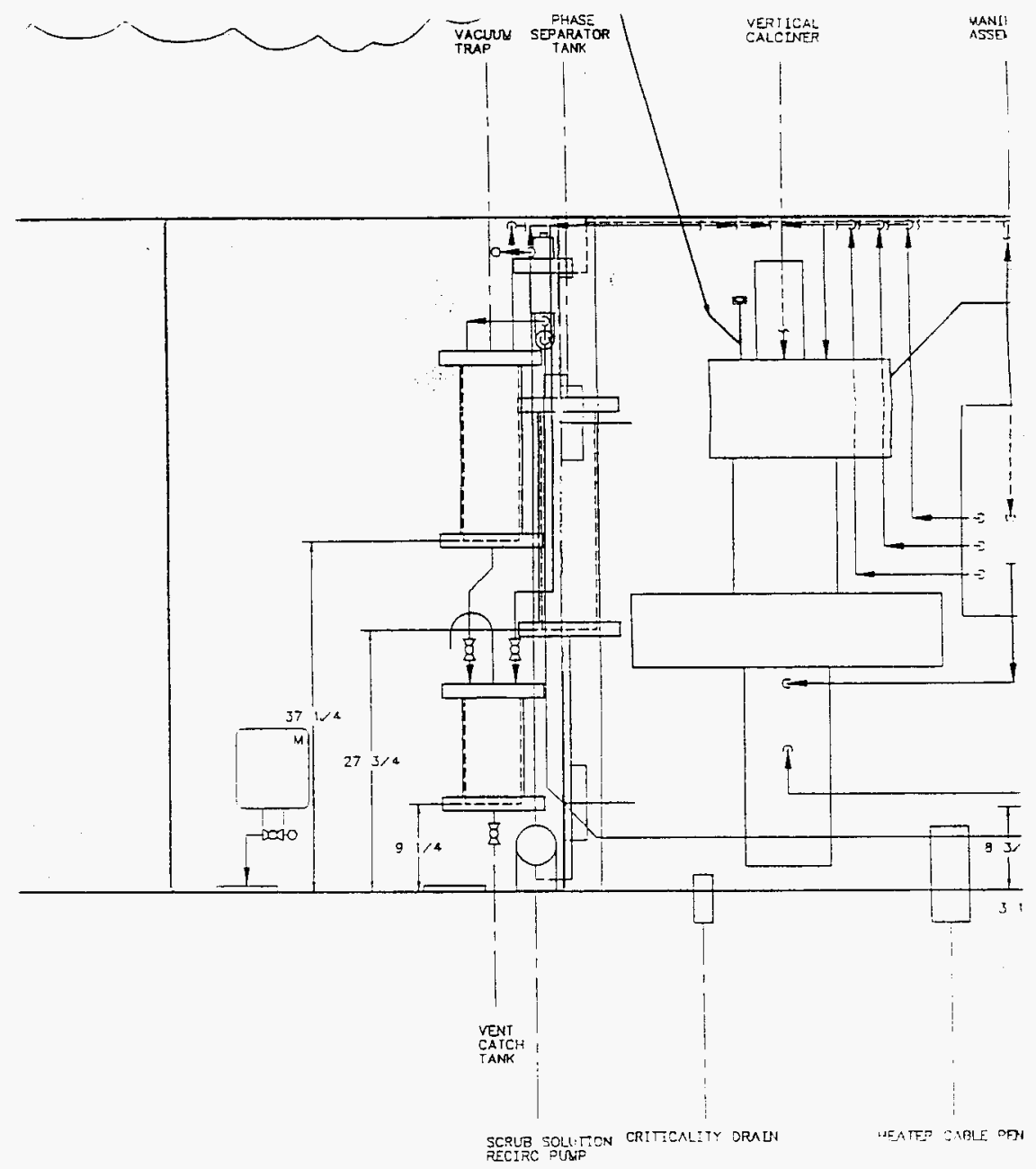


INE-SD-SQA-CSA-529, Rev. O

Prelminary Drawing $\mathrm{B}$

Top-Dimn Ver athe Waste Section of the Glovebox

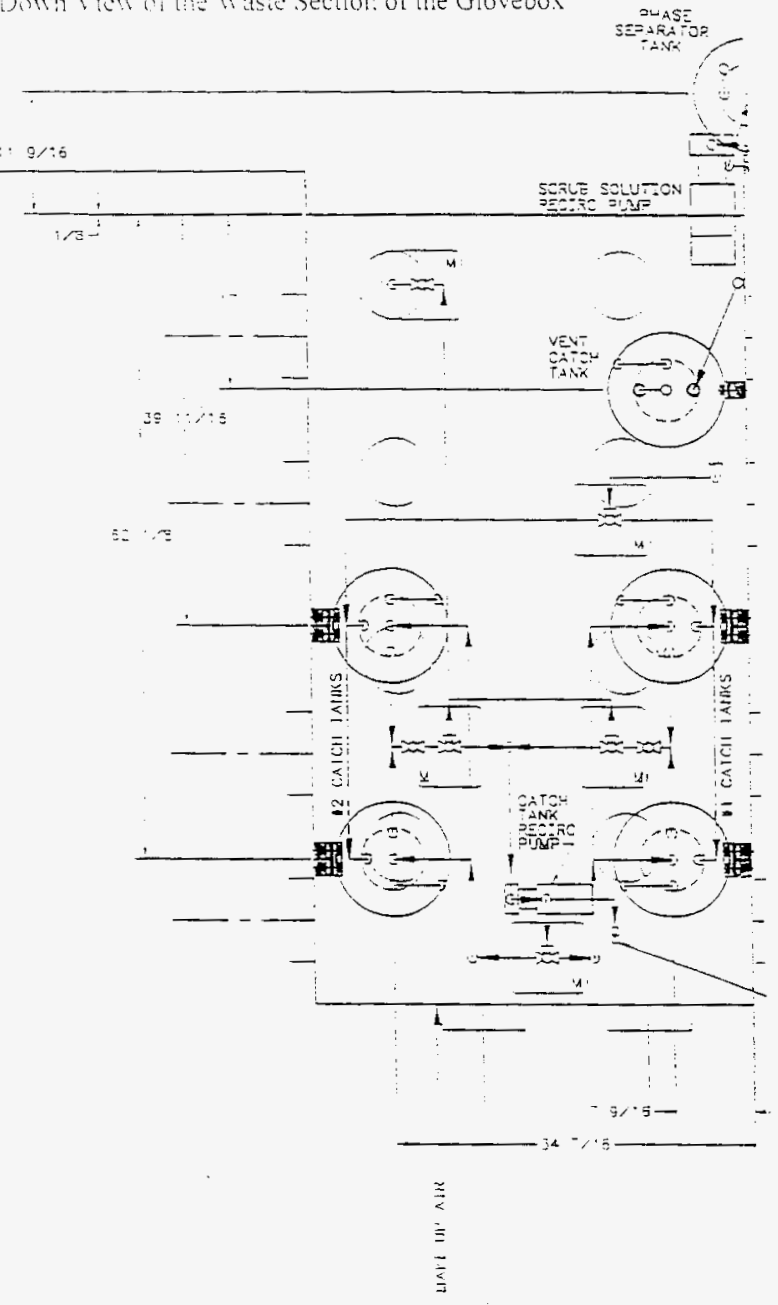




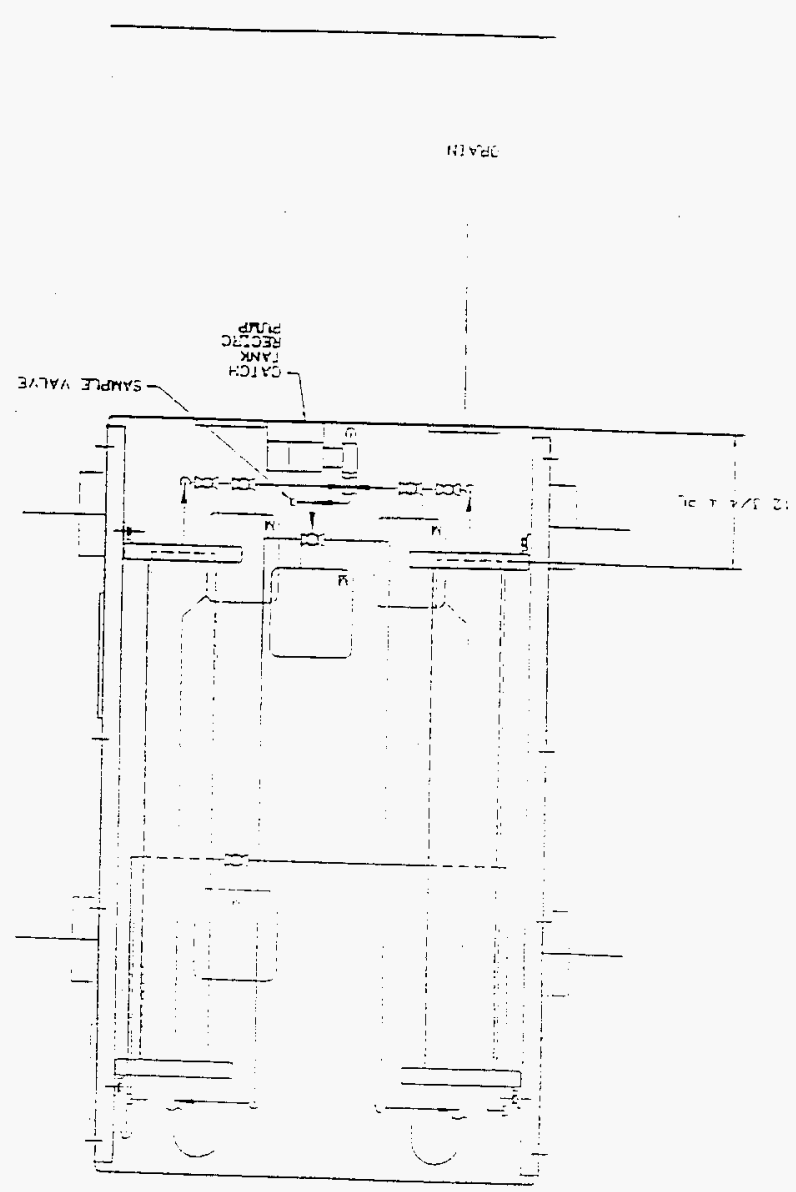

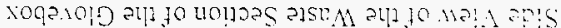

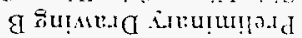


HNF-SD-SQA-CSA-529, Rev. 0

ATTACHMENT 5. HAND MEASUREMENTS TAKEN BY K.E. HILLESLAND AND RECEIVED FROM J.F. DURNIL BY PHONE, 3/12/97 
HNF-SD-SQA-CSA-529, Rev. 0

$3 / 12 / 97$

Found the following information:

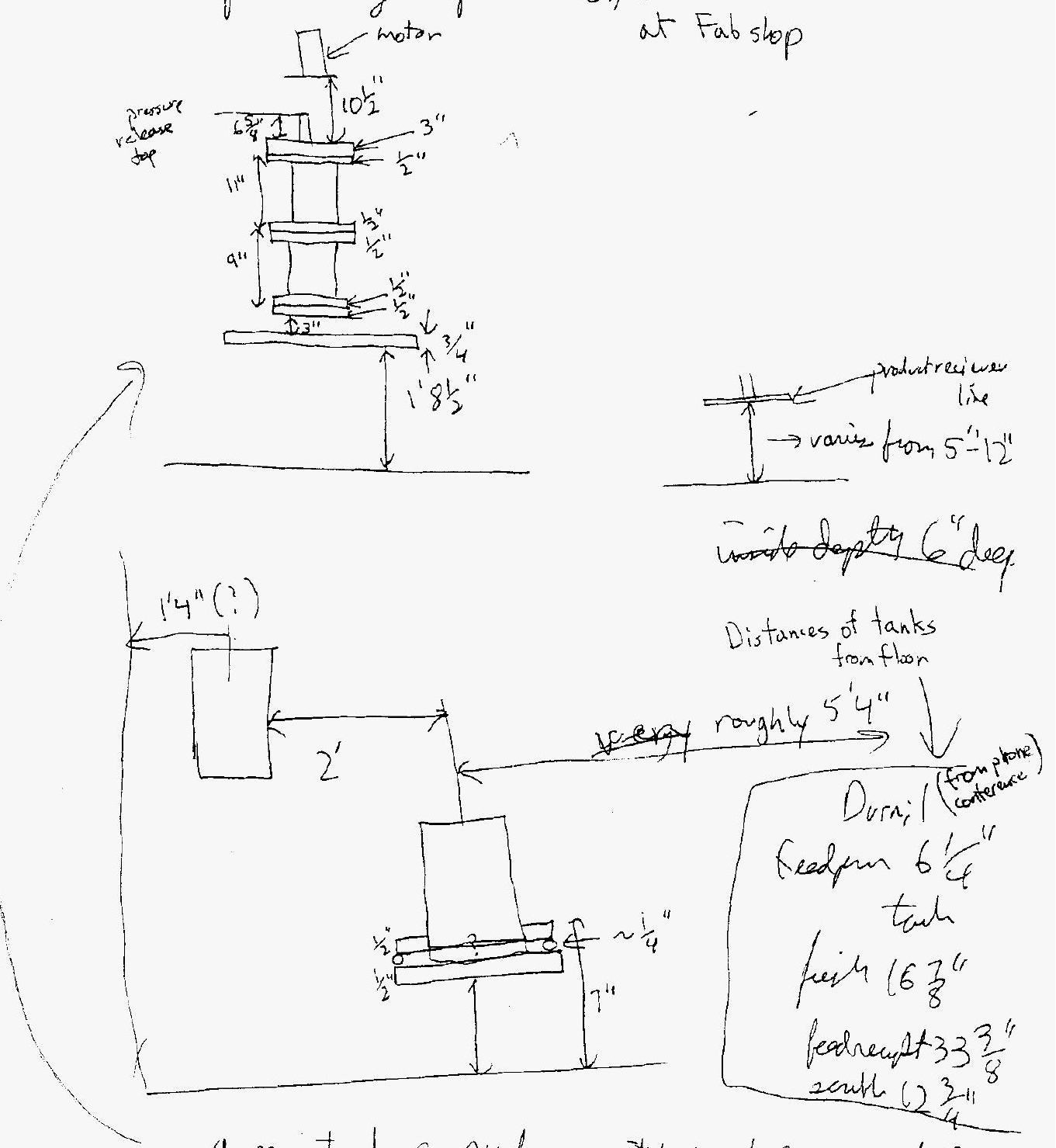

Appears te le so surfers with much room on salem. 89 fretting $\rightarrow$ although must investigate insulation. Feed tamis art id have wo om. 
HNF-SD-SQA-CSA-529, Rev. 0

Measurements received from telephone conversation with J.F. Durnil

Distances of bottom of tanks from floor

Feed Pump Tank $61 / 4^{\prime \prime}$

Flush Tank 167/8"

Feed Receipt Tank 33 3/8"

Scrubber Tank 123/4"

Distances of tanks from south, inner wall of glovebox

Feed Pump Tank 43 3/8"

Flush Tank $\quad 153 / 4^{\prime \prime}$

Feed Receipt Tank 15 5/8"

Scrubber Tank $471 / 2 "$

Overall internal glovebox dimensions for calciner section (above rounded part on floor)

length: $1035 / 8^{\prime \prime}$

width: $411 / 4^{\prime \prime}$ 
HNF-SD-SQA-CSA-529, Rev. 0

ATTACHMENT 6. CORRESPONDENCE CONCERNING MAXIMUM CREDIBLE FEED SOLUTION SPILL 
HNF-SD-SQA-CSA-529, Rev. 0

Author: Gregory G Bergquist at $\sim$ HANFORD03B

Date: 3/3/97 10:55 AM

Priority: Normal

TO: Karl E Hillesland at HANFORD07A

Subject: Pu Liquid on VC Glovebox Floor

Message Contents

Karl,

I searched for answer or explanation to your question regarding the release of concentrated Pu solution onto the glovebox floor from transfer operations. The flowsheet document covers most of the information.

The Feed Receipt Tank (FRT) will have a 10 liter working volume. The tank is equipped with a conductivity probe (LEH-230-J) which will shut off the transfer route by electrically (EV-230-J) closing the air supply to an air operated (Air-to-Open) ball valve (BV-230-J). The liquid from $\mathrm{HC}-227 \mathrm{~S}$ will be pumped to $\mathrm{HC}-230 \mathrm{C}-2$. Estimated line holdup after the pump is turned off and BV-230-J is closed will be about 9 liters (high point in transfer line to $\mathrm{HC}-230 \mathrm{C}-2$ ) and about 9 liters (high point in transfer line to $\mathrm{HC}-227 \mathrm{~S}$ ).

Once the FRT is filled it will be gravity drained through a diaphram operated valve (DOV-230-F) to the Feed Pump Tank (FPT) which will also have a 10 liter working volume. The FPT is equipped with a high liquid level interlock which will close the air supply to the DOV by electrically shutting solenoid valve (EV-230-F) thus stopping the flow from the FRT.

The Process Engineering group is planning for operations to load-in up to 4 PR Cans ( 8.5 liters) into a single batch tank ( 45 liters) in glovebox HC-227S. An existing CSER for HC-227S supports this activity. Loading in the $4 \mathrm{PR}$ cans and associated dilute acid flush to grossly clean the PR can would give us about a 40-45 liter feed source in HC-227S for transfer to the FRT in glovebox HC-230C-2.

If the $1 / 2$ " transfer line leaks the 3 " encasement piped is sloped to either drain back into HC-227S or HC-230C-2 depending on where the leak would occur. The leak would go directly to floor of either glovebox. So under unusual conditions we could possibly have 45 liters in a $\mathrm{HC}-227 \mathrm{~S}$ batch tank and about 9 liters held up in the transfer line that could be pumped to the floor of $\mathrm{HC}-230 \mathrm{C}-2$. There will always be about 9 liters of solution that will remain on the $\mathrm{HC}-227 \mathrm{~S}$ side of the transfer line. 
Additionally, glovebox HC-230C-2 will be equipped with a sump probe located underneath the FRT and FPT which will detect a leak if the solution depth on the floor reaches about $1 / 2^{\prime \prime}$.

We also have the human side of this entire evolution. The operations staff will be intimately involved with all plutonium solution transfers. They will watch it like a hawk. I can't overemphasize this point. We will also perform a material balance after each transfer to assure that the solution is accounted for.

Greg B. 
HNF-SD-SQA-CSA-529, Rev. 0

ATTACHMENT 7. HAND SKETCH OF LOWER INSULATION ON CALCINER 

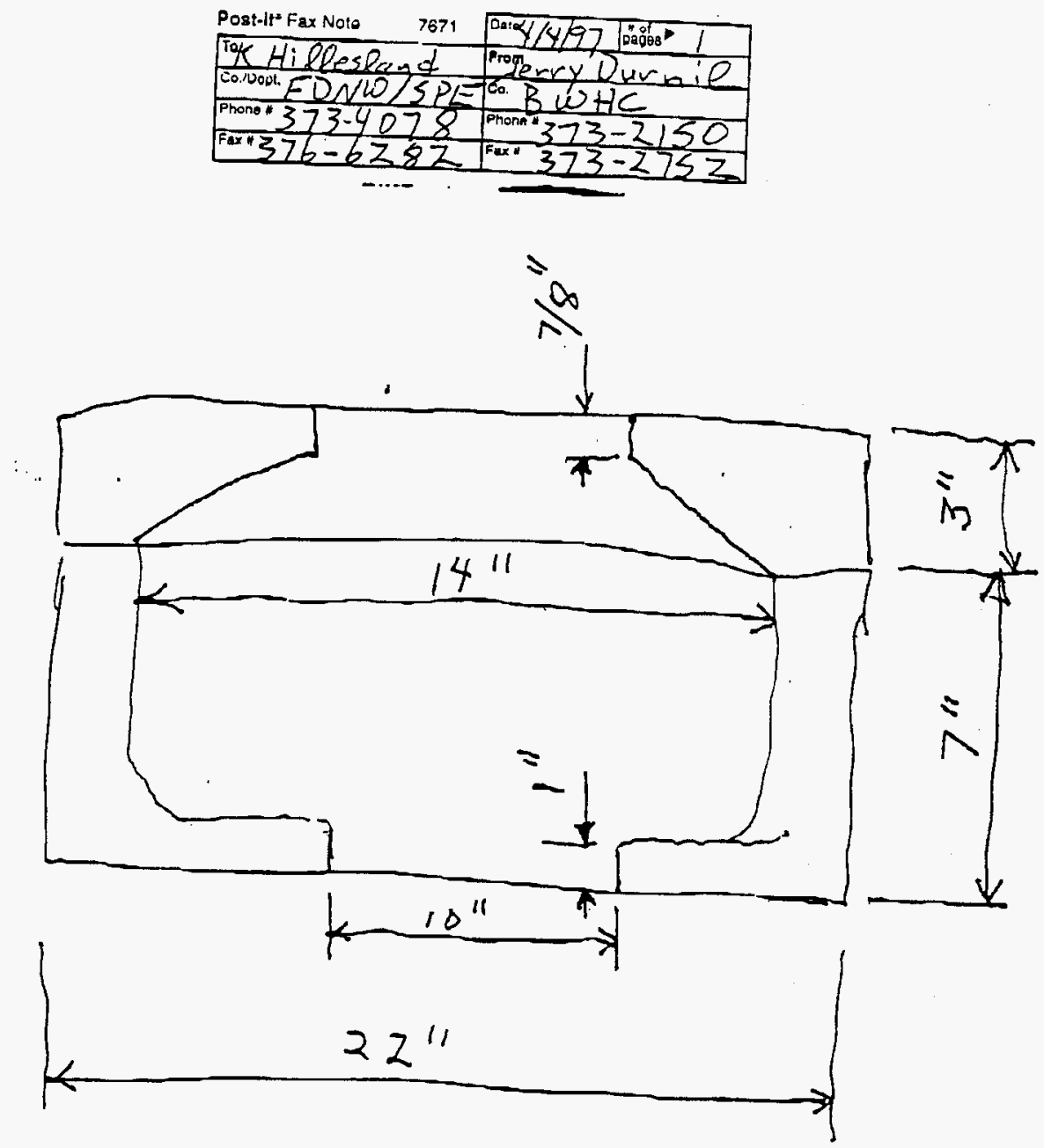
HNF-SD-SQA-CSA-529, Rev. 0

ATTACHMENT 8. DIMENSIONS OF FILTERS AS MEASURED BY J.F. DURNIL (Responses by J.F. Durnil to inquiries concerning dimensions given in italics) 
HNF-SD-SQA-CSA-529, Rev. 0

Author: Jerome F (Jerry) Durnil at $\sim$ HANFORD03B

Date: 4/21/97 3:39 PM

Priority: Normal

TO: Karl E Hillesland at $\sim$ HANFORD07A

CC: Jerome F (Jerry) Durnil

Subject: Re[3]: Dimensions I still need Message Contents

Do you have the thickness of the bottom of the filter? (Model uses

$1.5 \mathrm{in.)}$

Karl

Measured thickness is about $11 / 8^{\prime \prime}\left(1.125^{\prime \prime}\right)$

Subject: Re: Dimensions I still need Reply Separator

Author: Jerome F (Jerry) Durnil at $\sim$ HANFORD03B

Date: 4/21/97 9:15 AM

I've been using some dimensions from the lab calciner criticality calculational models, but I don't know where they came from. Do you have the following?

Dimensions for the filter elements (inner and outer)

Filter Element dimensions, measured filter element with tape measure:

Outer Diam: 2 "

Inner Diam: I 7/16" (1.4375")

Total Length: $12.25^{\prime \prime}$

Estimated insertion length: 11.25" filter length below their mounting flange.

Height of the "inner dome" in the calciner. I have drawing H-2-95609, which specifies a height for the cylindrical section ( $4.875 \mathrm{in}$.), and then specifies the domed portion as "cap, 4 in. sched 10S BTWLD", but I don't know what that means in terms of the height I want.

4-inch diameter buttweld pipe cap has a listed height of 2.5", Ref. Chem Engineer handbook, 5th Ed., Perry \& Chilton, Table 6.26

Karl Hillesland

373-4078 


\section{DISTRIBUTION SHEET}

\begin{tabular}{|c|c|c|c|c|c|}
\hline \multirow{2}{*}{$\begin{array}{l}\text { To } \\
\text { Distribution }\end{array}$} & \multirow{2}{*}{\multicolumn{2}{|c|}{$\begin{array}{l}\text { From } \\
\text { Criticality and Shielding }\end{array}$}} & \multirow{2}{*}{\multicolumn{3}{|c|}{$\frac{\text { Page } 1 \text { of } \not 09, K \sum \forall q / 4 / q}{\text { Date } 8 / 28 / 97}$}} \\
\hline & & & & & \\
\hline \multicolumn{3}{|c|}{ Project Title/Work Order } & \multicolumn{3}{|c|}{ EDT No. 621299} \\
\hline \multicolumn{3}{|c|}{ CSER 97-004: PFP Production Denitration Calciner System } & \multicolumn{3}{|c|}{ ECN No. N/A } \\
\hline \multicolumn{2}{|c|}{ Name } & $\begin{array}{l}\text { Text } \\
\text { With All } \\
\text { Attach. }\end{array}$ & $\begin{array}{l}\text { Text } \\
\text { Only }\end{array}$ & $\begin{array}{l}\text { Attach./ } \\
\text { Appendix } \\
\text { Only }\end{array}$ & $\begin{array}{l}\text { EDT/ECN } \\
\text { Only }\end{array}$ \\
\hline
\end{tabular}

B \& W Hanford

G.G. Bergquist

J.F. Durnil

M.W. Gibson

C.M. Kronval1

J.L. Mejia

L.T. Nirider

S.E. Nunn

A.L. Ramble

$\begin{array}{ll}\text { T5-55 } & X \\ T 5-55 & X \\ T 5-55 & X \\ T 5-15 & X \\ T 5-08 & X \\ T 5-53 & X \\ T 5-11 & X \\ T 5-54 & X\end{array}$

Fluor Daniel Hanford

S. Tsai

E.J. Krejci

Fluor Daniel Northwest

K.D. Dobbin

D.G. Erickson

S.R. Gedeon

H.J. Goldberg

J. Greenborg

K.E. Hillesland

J.S. Lan

E.M. Milier

L.L. Pedersen (3)

R.H. Ruben

W.D. Wittekind

W.T. Watson

Central Files (Original +2)
B1-19

B1-19

HO-35

HO-35

HO-35

$\mathrm{HO}-35$

HO- 35

HO-35

$\mathrm{HO}-35$

HO-35

HO-35

HO-35

HO-35

HO-31

A3-88 $x$

$X$

$x$
$x$
$x$
$x$
$x$
$x$
$x$
$x$
$x$
$x$
$x$
$x$

$X$ 